\title{
Pump Jet Mixing and Pipeline Transfer Assessment for High-Activity Radioactive Wastes in Hanford Tank 241-AZ-102
}

\author{
Y. Onishi \\ K. P. Recknagle \\ B. E. Wells
}

July 2000

Prepared for the U.S. Department of Energy under Contract DE-AC06-76RLO 1830

Pacific Northwest National Laboratory Richland, Washington 99352 



\section{DISCLAIMER}

This report was prepared as an account of work sponsored by an agency of the United States Government. Neither the United States Government nor any agency thereof, nor any of their employees, make any warranty, express or implied, or assumes any legal liability or responsibility for the accuracy, completeness, or usefulness of any information, apparatus, product, or process disclosed, or represents that its use would not infringe privately owned rights. Reference herein to any specific commercial product, process, or service by trade name, trademark, manufacturer, or otherwise does not necessarily constitute or imply its endorsement, recommendation, or favoring by the United States Government or any agency thereof. The views and opinions of authors expressed herein do not necessarily state or reflect those of the United States Government or any agency thereof. 


\section{DISCLAIMER}

Portions of this document may be illegible in electronic image products. Images are produced from the best available original document. 


\section{Summary}

We evaluated how well two 300-hp mixer pumps would mix solid and liquid radioactive wastes stored in Hanford double-shell Tank 241-AZ-102 (AZ-102) and confirmed the adequacy of a three-inch $(7.6-\mathrm{cm})$ pipeline system to transfer the resulting mixed waste slurry to the AP Tank Farm and a planned waste treatment (vitrification) plant on the Hanford Site. Tank AZ-102 contains 854,000 gallons $\left(3,230 \mathrm{~m}^{3}\right)$ of supernatant liquid and 95,000 gallons $\left(360 \mathrm{~m}^{3}\right)$ of sludge made up of aging waste (or neutralized current acid waste).

The study comprises three assessments: waste chemistry, pump jet mixing, and pipeline transfer. Our waste chemical modeling assessment indicates that the sludge, consisting of the solids and interstitial solution, and the supernatant liquid are basically in an equilibrium condition. Thus, pump jet mixing would not cause much solids precipitation and dissolution, only $1.5 \%$ or less of the total AZ-102 sludge.

Our pump jet mixing modeling indicates that two 300 -hp mixer pumps would mobilize up to about $23 \mathrm{ft}(7.0 \mathrm{~m})$ of the sludge nearest the pump but would not erode the waste within seven inches $(0.18 \mathrm{~m})$ of the tank bottom. This results in about half of the sludge being uniformly mixed in the tank and the other half being unmixed (not eroded) at the tank bottom.

We evaluated sludge mobilization and mixing for cases where a diluent (a mixture of water, ferric nitrate, sodium nitrite, and sodium hydroxide) was added to the tank at a volume ratio of 6:1 (diluent to sludge). We assumed that half of the AZ-102 sludge was dissolved and that the yield strength of the washed AZ-102 sludge was reduced from $1,540 \mathrm{~Pa}$ to $1.2 \mathrm{~Pa}$ for this assessment. These pump jet mixing simulations indicated that, under these assumptions, the two 300-hp mixer pumps would totally mobilize and uniformly mix the sludge in Tank AZ-102 within two hours.

The waste pipeline transfer assessments indicate that the critical velocity for the AZ-102 slurry is $1.5 \mathrm{ft} / \mathrm{sec}(0.46 \mathrm{~m} / \mathrm{s})$ or less, which is much less than the expected $6-\mathrm{ft} / \mathrm{sec}(1.8-\mathrm{m} / \mathrm{s})$ operating pipeline velocity. At the $1.2-\mathrm{ft} / \mathrm{sec}(0.37 \mathrm{~m} / \mathrm{s})$ critical velocity predicted by the Wasp method, the associated pressure drops from the AZ Farm to the AP Farm and to the treatment plant are expected to be $7.3 \mathrm{ft}(2.2 \mathrm{~m})$ and $14 \mathrm{ft}(4.2 \mathrm{~m})$, respectively, corresponding to only $1.6 \%$ and $3.0 \%$ of the available $450-\mathrm{ft}(137-\mathrm{m})$ pump head. At $6-\mathrm{ft} / \mathrm{sec}(1.8 \mathrm{~m} / \mathrm{s})$ operating velocity, the expected pressure drops between AZ-102 and the AP Tank Farm and treatment plant are $153 \mathrm{ft}(47 \mathrm{~m})$ and $285 \mathrm{ft}(87 \mathrm{~m})$, respectively, $34 \%$ and $63 \%$ of the available pump head. If the solids concentration were $36 \mathrm{vol} \%$, the pressure drop from the AZ Tank Farm to the treatment plant would be $450 \mathrm{ft}(137 \mathrm{~m})$ at $6-\mathrm{ft} / \mathrm{sec}(1.8-\mathrm{m} / \mathrm{s})$ velocity, which is more than $2.1-\mathrm{ft} / \mathrm{sec}$ $(0.64 \mathrm{~m} / \mathrm{s})$ critical velocity at this solids concentration. Even if the mixer pumps were to mobilize the entire inventory of $\mathrm{AZ}-102$ solids, the average suspended solids concentration would be 3.1 vol\%, which is less than $10 \%$ of the 36 vol\%. Thus, the pipeline transfer pump has enough capacity to transfer the AZ-102 slurry under expected conditions to the AP Tank Farm and treatment plant without depositing solids in the pipelines. 



\section{Contents}

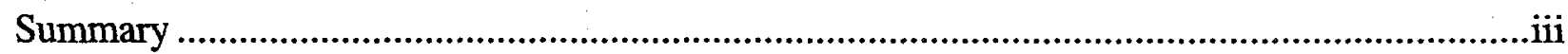

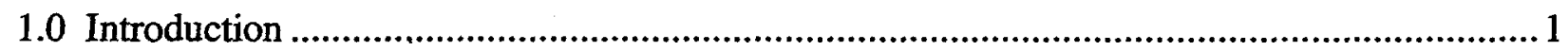

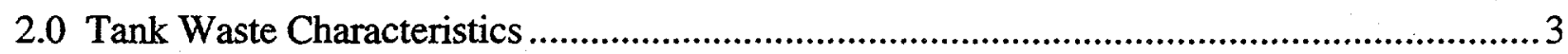

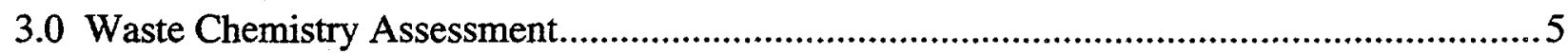

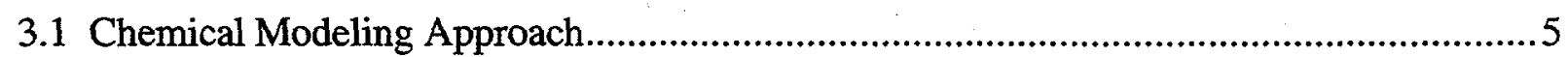

3.2 Step 1: Selection of Aqueous Species of Interstitial Solution ............................................ 6

3.3 Step 2: Determination of Dissolvable Solids in AZ-102 Sludge ........................................6

3.3.1 Step 2.1: Identification of Dissolvable Solids..........................................................

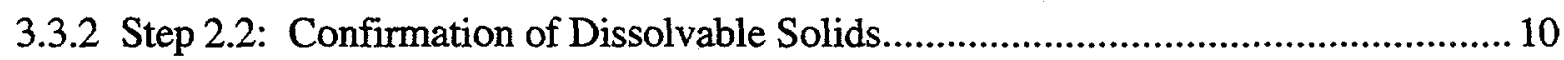

3.4 Step 3: Mixture of AZ-102 Sludge and Supernatant Liquid ........................................... 11

3.5 Step 4: Determination of Changes on Waste Properties and Solid Amount

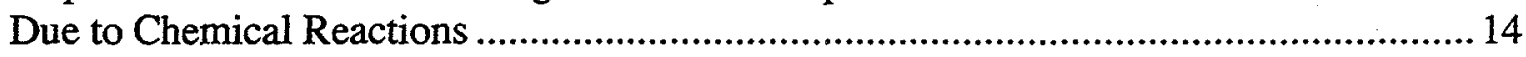

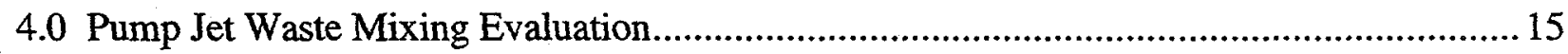

4.1 Pump Jet Mixing in Current AZ-102 Tank Conditions ............................................... 15

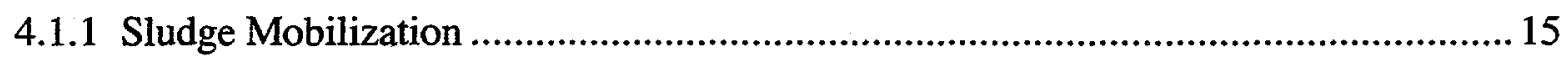

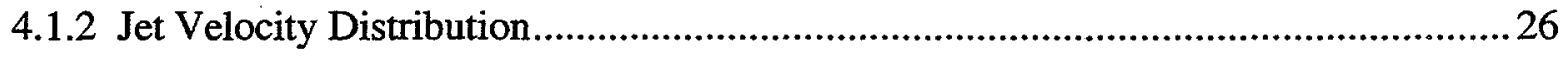

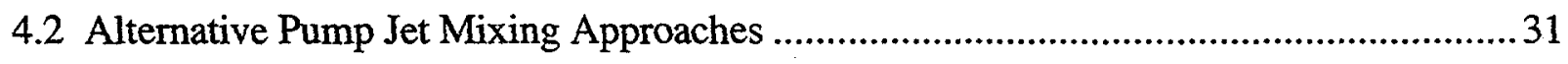

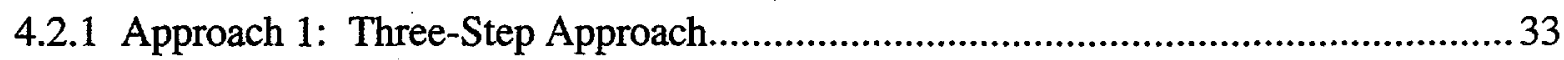

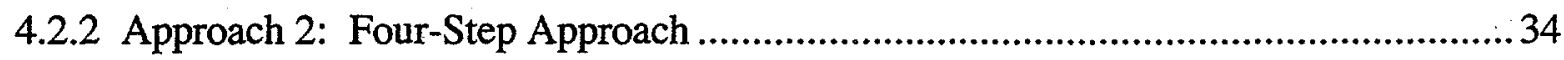

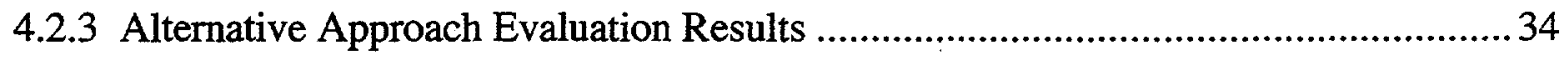

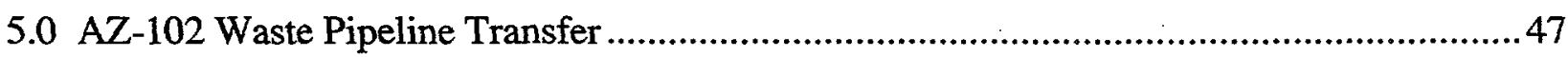

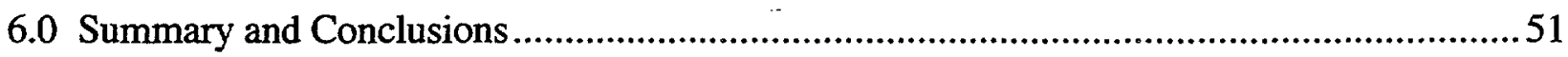

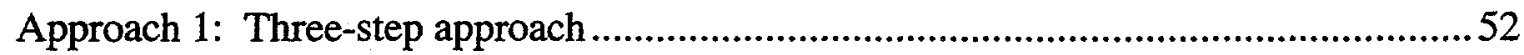

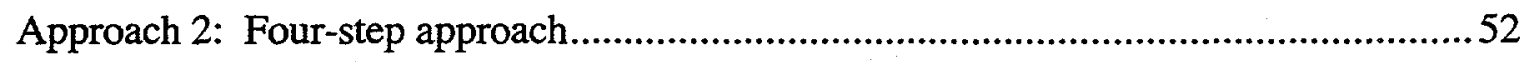

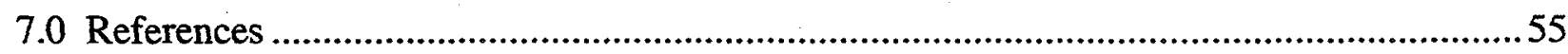




\section{Figures}

2.1 AZ-102 Tank Waste Volume-Based Particle Size Distribution ........................................4

3.1 Predicted Aqueous Species Concentrations of the AZ-102

Interstitial Solution with Measured Data

3.2 Predicted AZ-102 Solid Concentrations with Measured Data ......................................... 11

3.3 Predicted Aqueous Species Concentrations Resulting from Mixing

Tank AZ-102 Sludge and Supernatant Liquid, and Measured Values of the

Original Supernatant Liquid Prior to Mixing

3.4 Predicted Solids Concentrations Resulting from Mixing AZ-102 Sludge

and Supernatant Liquid and Expected Solid Concentrations .

4.1 Initial Conditions of Sludge and Supernatant Liquid on Vertical Plane 2

4.2 Predicted Distributions of Velocity and Solids Concentration on Vertical Plane 2 at Two Simulation Hours

4.3 Predicted Distributions of Velocity and Solids Concentration on Vertical Plane 7 at Two Simulation Hours.

4.4 Predicted Distributions of Velocity and Solids Concentration on Vertical Plane 10 at Two Simulation Hours

4.5 Predicted Distributions of Velocity and Solids Concentration on Vertical Plane 13 at Two Simulation Hours

4.6 Predicted Distributions of Velocity and Solids Concentration on Vertical Plane 14 at Two Simulation Hours

4.7 Predicted Distributions of Velocity and Solids Concentration on Vertical Plane 15 at Two Simulation Hours

4.8 Predicted Distributions of Velocity and Solids Concentration on Vertical Plane 21 at Two Simulation Hours

4.9 Predicted Distributions of Velocity and Solids Concentration on Vertical Plane 17 at Two Simulation Hours

4.10 Jet Centerline Velocity and TEMPEST Prediction Compared with

Measured Values for Three-Dimensional Homogeneous Jet

4.11 Predicted Nondimensional Jet Centerline Velocity of the AZ-102 Pump Jet with the Homogeneous Jet Velocity Distribution.

4.12 Predicted Jet Centerline Velocity with Centerline Distance of the AZ-102

Pump Jet with Homogeneous Jet Velocity Distribution

4.13 Predicted Lateral Distribution of Nondimensional Longitudinal Velocity

for AZ-102 Pump Jet with Homogeneous Jet Velocity Distribution.

4.14 Predicted Lateral Distribution of Longitudinal Velocity with Lateral

Distance for AZ-102 Pump Jet with Homogeneous Jet Velocity Distribution

4.15 Predicted Distributions of Velocity and Solids Concentration on

Vertical Plane 14 at Two Simulation Hours for Case 1

4.16 Predicted Distributions of Velocity and Solids Concentration on Vertical Plane 15 at Two Simulation Hours for Case 1 
4.17 Predicted Distributions of Velocity and Solids Concentration on Vertical Plane 17 at Two Simulation Hours for Case 1

4.18 Predicted Distributions of Velocity and Solids Concentration on Vertical Plane 14 at Two Simulation Hours for Case 2

4.19 Predicted Distributions of Velocity and Solids Concentration on Vertical Plane 15 at Two Simulation Hours for Case 2.

4.20 Predicted Distributions of Velocity and Solids Concentration on Vertical Plane 17 at Two Simulation Hours for Case 2

4.21 Predicted Distributions of Velocity and Solids Concentration on Vertical Plane 14 at Two Simulation Hours for Case 3

4.22 Predicted Distributions of Velocity and Solids Concentration on Vertical Plane 15 at Two Simulation Hours for Case 3

4.23 Predicted Distributions of Velocity and Solids Concentration on

Vertical Plane 17 at Two 3Simulation Hours for Case 3

4.24 Predicted Distributions of Velocity and Solids Concentration on

Vertical Plane 14 at Two Simulation Hours for Case 4

4.25 Predicted Distributions of Velocity and Solids Concentration on

Vertical Plane 15 at Two Simulation Hours for Case 4

4.26 Predicted Distributions of Velocity and Solids Concentration on

Vertical Plane 17 at Two Simulation Hours for Case 4.

5.1 Calculated Pipeline Pressure Drop Versus Pipeline Velocity for the

AZ-102 Slurry with 1.6 vol\% Solids.

5.2 Calculated Pipeline Pressure Drop Versus Solids Concentration for the

AZ-102 Slurry at $6 \mathrm{ft} / \mathrm{sec}(1.8 \mathrm{~m} / \mathrm{s})$

\section{Tables}

3.1 Chemical Compositions and Their Measured or Estimated Concentrations

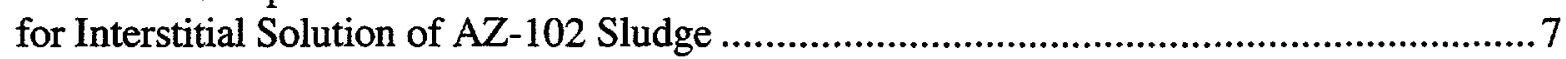

3.2 Solids and Their Measured or Estimated Concentrations in AZ-102 Sludge ........................ 7

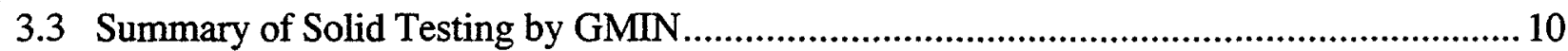

3.4 Chemical Compositions and Measured or Estimated Concentrations of the AZ-102 Supernatant Liquid ..................................................................................... 12

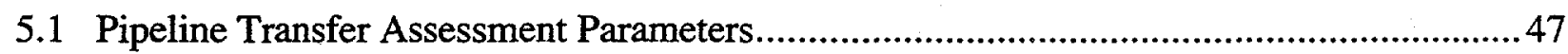

5.2 AZ-102 Slurry Transfer Conditions at Critical Velocity of $1.2 \mathrm{ft} / \mathrm{sec}(0.37 \mathrm{~m} / \mathrm{s}) \ldots \ldots \ldots \ldots \ldots . . .48$

5.3 AZ-102 Slurry Transfer Conditions at Pipeline Velocity of $6 \mathrm{ft} / \mathrm{sec}(1.8 \mathrm{~m} / \mathrm{s}) \ldots \ldots \ldots \ldots \ldots \ldots \ldots . . .48$ 


\subsection{Introduction}

The purposes of this study were 1) to examine how well two 300 -hp mixer pumps would mix solid and liquid radioactive wastes stored in Hanford double-shell Tank (DST) 241-AZ-102 and 2) to confirm the adequacy of a three-inch $(7.6-\mathrm{cm})$ pipeline system to transfer the resulting mixed waste slurry to the AP Tank Farm and a planned waste treatment (vitrification) plant in the 200 East Area of the U.S. Department of Energy's Hanford Site in Washington State.

Tank AZ-102, with its diameter of $75 \mathrm{ft}(23 \mathrm{~m})$ and operating depth of $35 \mathrm{ft}(10.7 \mathrm{~m})$, received aging waste (or neutralized current acid waste). It currently contains 854,000 gallons $\left(3,230 \mathrm{~m}^{3}\right)$ of supernatant liquid and 95,000 gallons $\left(360 \mathrm{~m}^{3}\right)$ of sludge (Ryan 1995).

Two 300-hp mixer pumps will be installed, one on each side of the tank $22 \mathrm{ft}(6.7 \mathrm{~m})$ from the tank center. The pumps have 17 -inch $(43-\mathrm{cm})$-diameter inlet openings and 6-inch $(15-\mathrm{cm})$ diameter exit openings that will be located $7(18 \mathrm{~cm})$ and 17 inches $(43 \mathrm{~m})$ above the tank bottom, respectively. These pumps will rotate at $0.2 \mathrm{rpm}$ and have two 6 inch $(15-\mathrm{cm})$ nozzles that will inject $60-\mathrm{ft} / \mathrm{sec}(18.3 \mathrm{~m} / \mathrm{s})$ jets to mix the stored wastes.

We used the chemistry simulation code, GMIN (Felmy 1995), reactive computational fluid dynamics code, TEMPEST (Onishi et al. 1996a), and pipeline formulas developed by Wasp (1963, 1977). The GMIN computer code (Felmy 1995) was used to evaluate potential chemical reactions during the pump jet mixing operation. GMIN is an equilibrium chemical simulation code that simulates aqueous chemical reactions, solid dissolution/precipitation, and adsorption/desorption by minimizing Gibbs free energy and using Pitzer's equations. As such, it is applicable to high ionic-strength conditions such as AZ-102 tank waste. This chemical evaluation was to confirm that the AZ-102 supernatant liquid and solids are chemically in an equilibrium condition. If so, no solids dissolution or precipitation would occur during waste mixing.

The three-dimensional TEMPEST computer code (Trent and Eyler 1994) was applied to Tank AZ-102 to simulate waste mixing generated by the $60-\mathrm{ft} / \mathrm{sec}$ rotating jets and to determine the effectiveness of these two rotating pumps to mix the waste. TEMPEST can simulate coupled flow, mass/heat transport, and chemical reactions (equilibrium and kinetic reactions) (Onishi et al. 1996a). We used the fluid mechanics portion of TEMPEST to solve three-dimensional, timedependent equations of flow, turbulence, heat, and mass transport, based on conservation of:

- fluid mass (the equation of continuity)

- momentum (the Navier-Stokes equations)

- turbulent kinetic energy and its dissipation

- mass of dissolved constituents

- mass of solid constituents.

TEMPEST uses integral forms of the fundamental conservation laws applied in the finite volume formulation. It uses the $\mathrm{k}-\varepsilon$ turbulence model (Rodi 1984) to solve the turbulence of 
kinetic energy and its dissipation. TEMPEST can accommodate non-Newtonian fluids as well as fluids whose rheology depends upon solid concentrations (Mahoney and Trent 1995; Onishi and Trent 1998).

We used the empirical Wasp formulas (Wasp 1963, 1977) to estimate the pipe flow's critical velocity, below which solids could deposit in the pipe, and the pipeline pressure drop to evaluate transfer of the mixed AZ-102 slurry to the AP Tank Farm and to the treatment plant through the 3-inch (7.6-cm) pipeline. We also used the Oroskar-Turian (1980) and Zandi-Govatos (1967) methods to evaluate the critical velocity.

Section 2 describes the AZ-102 waste conditions. Section 3 describes chemical modeling by GMIN, and Section 4 reports pump jet mixing modeling results with TEMPEST. AZ-102 waste pipeline transfer assessments using the WASP, Oroskar-Turian, and Zandi-Govatos methods are presented in Section 5. The summary and conclusions are presented in Section 6, and cited references are listed in Section 7. 


\subsection{Tank Waste Characteristics}

Tank AZ-102 has a diameter and an operating depth of $75 \mathrm{ft}(23 \mathrm{~m})$ and $35 \mathrm{ft}(10.7 \mathrm{~m})$, respectively; its operational storage capacity is $1,160,000$ gallons $\left(4,390 \mathrm{~m}^{3}\right)$. The tank contains twenty 30-inch- (76-cm-) diameter airlift circulators and 33-inch- $(84-\mathrm{cm}$-)-diameter steam heating coils, which are no longer used. It currently contains 854,000 gallons $\left(3,230 \mathrm{~m}^{3}\right)$ of supernatant liquid and 95,000 gallons $\left(360 \mathrm{~m}^{3}\right)$ of sludge-type radioactive waste (Ryan 1995).

Tank AZ-102 received high-level aging waste from the PUREX Plant, high strontium waste from B Plant, and complex concentrated waste from 242-A evaporator beginning in 1976 . In 1986, most of this waste was removed. After 1986, it received aging waste (or neutralized current acid waste) from the PUREX Plant and waste water. Although it still remains in active service, the tank last received an aging waste in 1990 (Ryan 1995).

Current waste make-up is 90 vol\% supernatant liquid and 10 vol\% sludge. The supernatant liquid and sludge occupy 310 inches $(7.87 \mathrm{~m})$ and 35 inches $(0.89 \mathrm{~m})$, respectively, of the total tank waste level of 345 inches $(8.76 \mathrm{~m})$. The average temperature of the supernatant liquid is $131^{\circ} \mathrm{F}\left(55^{\circ} \mathrm{C}\right)$, and the maximum sludge temperature is $182^{\circ} \mathrm{F}\left(83^{\circ} \mathrm{C}\right)$.

The density and viscosity of the supernatant liquid are $1,100 \mathrm{~kg} / \mathrm{m}^{3}$ and $1 \mathrm{cP}$, respectively (Ryan 1995). The dissolved solids constitute $15.9 \mathrm{wt} \%$ of the supernatant liquid, and $84.1 \mathrm{wt} \%$ is water. The bulk sludge density is $1,490 \mathrm{~kg} / \mathrm{m}^{3}$ (Ryan 1995). The sludge has a yield strength of $1,540 \mathrm{~Pa}$; within a few centimeters of the bottom the yield strength is $2,650 \mathrm{~Pa}$. Once the sludge is disturbed, the yield strength may be reduced to about $60 \mathrm{~Pa}$, ${ }^{\text {(a) }}$ roughly a 25 - to 44 -fold reduction. When the sludge was mixed with 1.5 times its volume of supernatant liquid, the yield strength of the mixture was reduced to $2 \mathrm{~Pa}^{(\text {(b) }}$ a 770 - to 1,300 -fold reduction from the undiluted condition. When the sludge was diluted by 10 times its volume of supernatant liquid, the mixed slurry totally lost its yield strength. Thus, diluting the sludge with liquid significantly reduces its ability to resist mobilization.

The sludge contains $51 \mathrm{wt} \%$ water. The solids density was estimated to be $2,360 \mathrm{~kg} / \mathrm{m}^{3}$. Solid particle sizes based on volume vary from 0.5 to $13 \mu \mathrm{m}$, with a median size of $3.4 \mu \mathrm{m}$, as shown in Figure 2.1 (Ryan 1995).

(a) Gray WJ, ME Peterson, RD Scheele, and JM Tingey. 1993. "Characterization of the First Core Sample of Neutralized Current Acid Waste from Double-Shell Tank AZ-102." Unpublished report, Pacific Northwest Laboratory, Richland, Washington.

(b) Morrey EV and JM Tingey. 1995. "Comparison of Simulants to Actual Neutralized Current Acid Waste: Process and Product Testing of Three NCAW Core Samples from Tank 101-AZ and 102-AZ." C95-02.03E, unpublished report, Pacific Northwest Laboratory, Richland, Washington. 


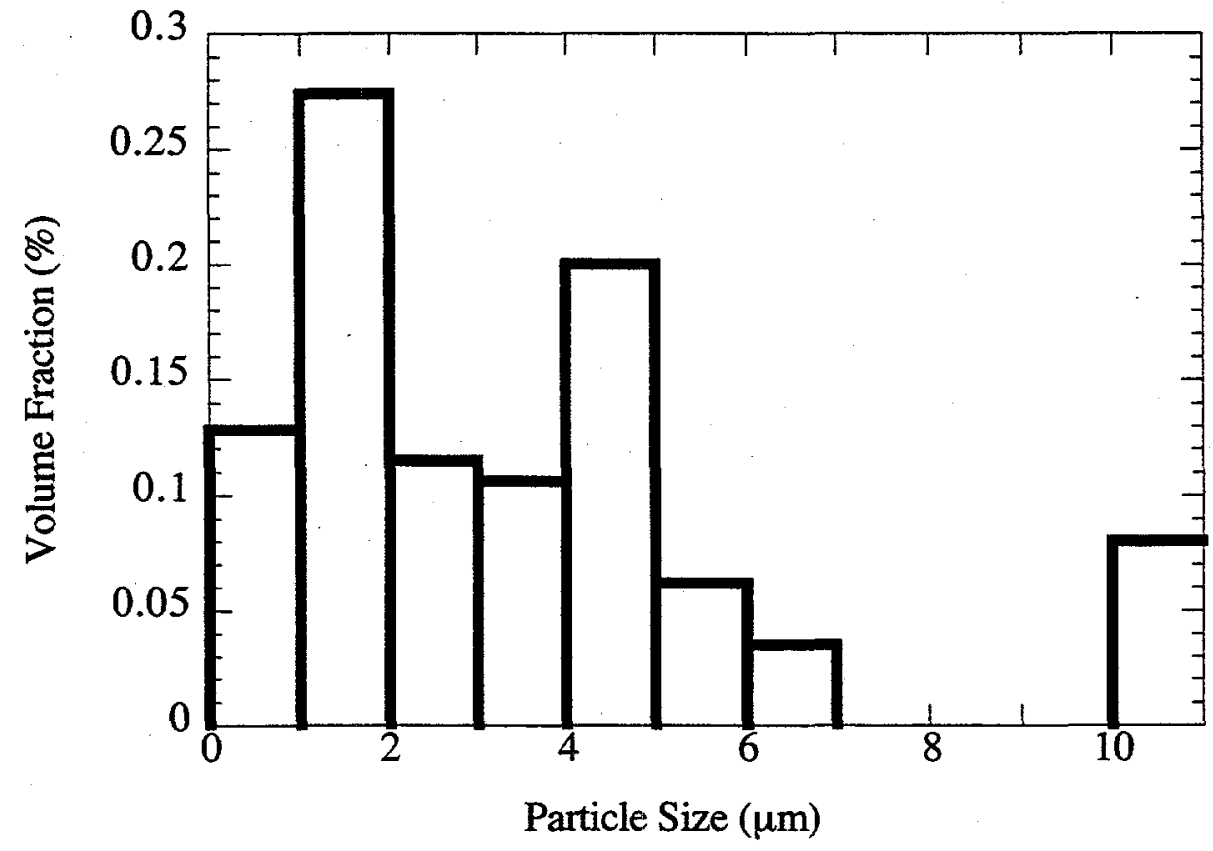

Figure 2.1. AZ-102 Tank Waste Vollume-Based Particle Size Distribution 


\subsection{Waste Chemistry Assessment}

\subsection{Chemical Modeling Approach}

As stated in Sections 1 and 2, the waste in Tank AZ-102 is high-activity level aging waste (or neutralized current acid waste). There are 854,000 gallons $\left(3,230 \mathrm{~m}^{3}\right)$ of supernatant liquid and 95,000 gallons $\left(360 \mathrm{~m}^{3}\right)$ of sludge (Ryan 1995). The average temperature of the supernatant liquid is $131^{\circ} \mathrm{F}\left(55^{\circ} \mathrm{C}\right)$; the maximum sludge temperature is reported to be $182^{\circ} \mathrm{F}\left(83^{\circ} \mathrm{C}\right.$ ) (Ryan 1995).

We investigated whether the AZ-102 supernatant liquid and solids are in an equilibrium condition. Because the present waste has been in AZ-102 since 1986 and the sludge thickness is only 35 inches $(0.88 \mathrm{~m})$, the sludge and supernatant liquid are expected to be in equilibrium condition. If they are not in equilibrium, AZ-102 waste properties (e.g., density and viscosity of supernatant liquid and sludge, and sludge yield strength) and the amount of solids in the sludge may change due to solids dissolution and precipitation induced by the pump jet mixing. These possible changes, in turn, would affect how and how much AZ-102 sludge would be mobilized by the two 300 -hp mixer pumps. Thus we performed a chemical evaluation of the waste before assessing the effectiveness of the mixer pumps.

We used the chemical code GMIN to simulate chemical reactions and phase equilibrium to determine whether

- AZ-102 solids are in equilibrium condition with the interstitial solution within the AZ-102 sludge

- AZ-102 sludge (consisting of the solids and the interstitial solution) would be in an equilibrium condition with AZ-102 supernatant liquid if the mixer pumps fully mix the sludge and supernatant liquid.

The following steps were taken to conduct this assessment:

STEP 1. Assign cations, anions, and neutral aqueous species with the correct charge balance for the interstitial solution of the sludge by using the measured analytical chemistry data.

STEP 2. Determine dissolvable solids in the sludge that are saturated with the interstitial solution

Substep 2.1. Simulate chemical reactions between the interstitial solution and one solid at a time to determine whether the solid is saturated with the measured interstitial solution without much change in solution chemistry. 
Substep 2.2. Simulate chemical reactions of the interstitial solution aqueous species and all dissolvable solids selected under Substep 2.1 together to confirm that these solids are saturated with the interstitial solution without much change in solution conditions.

STEP 3. Simulate chemical reactions of the full mixture of sludge (both interstitial solution and solids as selected under Step 2) and the supernatant liquid to determine whether solids precipitation and dissolution will occur due to pump jet mixing.

STEP 4. Determine possible changes in waste properties and solid amounts due to chemical reactions identified under Step 3.

We chose $131^{\circ} \mathrm{F}\left(55^{\circ} \mathrm{C}\right)$ as the waste temperature for all the $\mathrm{AZ}-102$ chemistry assessments.

\subsection{Step 1: Selection of Aqueous Species of Interstitial Solution}

Tank AZ-102 sludge (solid and interstitial solution) mostly contains $\mathrm{Al}, \mathrm{Cd}, \mathrm{Cr}, \mathrm{Fe}, \mathrm{Na}, \mathrm{Ni}$, $\mathrm{Si}, \mathrm{U}, \mathrm{Zr}$, inorganic carbon, and organic carbon (likely acetate), with the main anions of $\mathrm{F}, \mathrm{OH}^{-}$, $\mathrm{NO}_{3}^{-}, \mathrm{NO}_{2}^{-}$, and $\mathrm{SO}_{4}{ }^{2-}($ Ryan 1995$){ }^{(a, b)}$ Water accounts for $51 \%$ of the sludge. Based on the characterization report by Ryan (1995), we selected the following species for the interstitial solution to perform the chemical reaction modeling: $\mathrm{Na}^{+}, \mathrm{Al}(\mathrm{OH})_{4}^{-}, \mathrm{Cr}(\mathrm{OH})_{4}^{-}, \mathrm{CO}_{3}{ }^{2-}, \mathrm{H}_{2} \mathrm{SiO}_{4}^{2-}$, $\mathrm{NO}_{3}^{-}, \mathrm{NO}_{2}^{-}, \mathrm{SO}_{4}^{2-}, \mathrm{F}^{-} \mathrm{OH}, \mathrm{NaNO}_{3}(\mathrm{aq})$, and $\mathrm{NaNO}_{2}(\mathrm{aq})$. For interstitial solution in the AZ-102 sludge layer, aqueous species selected in this study and their measured or estimated molalities are presented in Table 3.1. These molality values were input into GMIN for the sludge chemistry assessment. Note that $\mathrm{NO}_{3}{ }^{-}$and $\mathrm{NO}_{2}{ }^{-}$in this table include their anion forms as well as a part of neutral aqueous species of $\mathrm{NaNO}_{3}(\mathrm{aq})$ and $\mathrm{NaNO}_{2}$ (aq), respectively.

\subsection{Step 2: Determination of Dissolvable Solids in AZ-102 Sludge}

Based on the characterization report by Ryan (1995) and chemical analysis performed by Gray et al. ${ }^{(a)}$ we selected the following as possible dissolvable solids in the AZ-102 sludge: $\mathrm{Al}(\mathrm{OH})_{3}(\mathrm{~s})$, amorphous $\mathrm{Cr}(\mathrm{OH})_{3}, \mathrm{NaNO}_{3}(\mathrm{~s}), \mathrm{NaNO}_{2}(\mathrm{~s})$, thermonatrite $\left(\mathrm{Na}_{2} \mathrm{CO}_{3} \cdot \mathrm{H}_{2} \mathrm{O}(\mathrm{s})\right)$, thenardite $\left(\mathrm{Na}_{2} \mathrm{SO}_{4}(\mathrm{~s})\right), \mathrm{NaF}(\mathrm{s})$, and amorphous $\mathrm{SiO}_{2}$. Solids-bearing $\mathrm{Cd}, \mathrm{Fe}, \mathrm{La}, \mathrm{Ni}, \mathrm{U}, \mathrm{Zr}$, and organic carbon (likely acetate) were treated here as insolvable solids with interstitial solution and supernatant liquid of AZ-102 tank waste. Thus were not considered for possible dissolution or precipitation due to pump jet mixing. These solids have very low solubility limits, as evidenced by very low or below detection levels of aqueous concentrations of species bearing these solids in the interstitial solution. Thus this assumption was judged to be reasonable and conservative

(a) Gray WJ, ME Peterson, RD Scheele, and JM Tingey. 1993. "Characterization of the First Core Sample of Neutralized Current Acid Waste from Double-Shell Tank AZ-102." Unpublished report, Pacific Northwest Laboratory, Richland, Washington.

(b) Morrey EV and JM Tingey. 1995. "Comparison of Simulants to Actual Neutralized Current Acid Waste: Process and Product Testing of Three NCAW Core Samples from Tank 101-AZ and 102-AZ." C95-02.03E, unpublished report, Pacific Northwest Laboratory, Richland, Washington. 
Table 3.1. Chemical Compositions and Their Measured or Estimated Concentrations for Interstitial Solution of AZ-102 Sludge

\begin{tabular}{|c|c|c|c|c|}
\hline Compound & $\begin{array}{c}\text { Measured } \\
\text { Concentration } \\
(\boldsymbol{\mu g} / \mathbf{g})\end{array}$ & $\begin{array}{c}\text { Selected } \\
\text { Aqueous } \\
\text { Species }\end{array}$ & $\begin{array}{c}\text { Measured or } \\
\text { Estimated } \\
\text { Concentration } \\
(\boldsymbol{\mu g} / \mathbf{g})\end{array}$ & Molality \\
\hline $\mathrm{Al}$ & 89 & $\mathrm{Al}(\mathrm{OH})_{4}^{-}$ & 314 & 0.0065 \\
\hline $\mathrm{Cr}$ & 879 & $\mathrm{Cr}(\mathrm{OH})_{4}^{-}$ & 2,029 & 0.0331 \\
\hline $\mathrm{Na}$ & 42,100 & $\mathrm{Na}^{+}$ & 42,100 & 3.59 \\
\hline $\mathrm{TIC}$ & 7,040 & $\mathrm{CO}_{3}^{2-}$ & 35,170 & 1.15 \\
\hline $\mathrm{Si}$ & 484 & $\mathrm{H}_{2} \mathrm{SiO}_{4}^{2-}$ & 1,620 & 0.0338 \\
\hline & & $\mathrm{NO}_{3}^{-}$ & 5,750 & 0.182 \\
\hline & & $\mathrm{NO}_{2}^{-}$ & 2,820 & 0.122 \\
\hline & & $\mathrm{SO}_{4}^{2-}$ & 11,900 & 0.243 \\
\hline & & $\mathrm{F}^{2}$ & 739 & 0.0763 \\
\hline & & $\mathrm{OH}^{-}$ & 2,713 & 0.313 \\
\hline
\end{tabular}

for waste mixing and transport analyses. Table 3.2 shows solids and their measured or estimated concentrations in AZ-102 sludge based on Ryan (1995) and Gray et al. ${ }^{(a)}$

Table 3.2. Solids and Their Measured or Estimated Concentrations in AZ-102 Sludge

\begin{tabular}{|c|c|l|c|c|}
\hline Compound & $\begin{array}{c}\text { Measured } \\
\text { Concentration } \\
(\mu \mathrm{g} / \mathrm{g})\end{array}$ & $\begin{array}{c}\text { Selected } \\
\text { Aqueous } \\
\text { Species }\end{array}$ & $\begin{array}{c}\text { Measured or } \\
\text { Estimated } \\
\text { Concentration } \\
(\boldsymbol{\mu} \mathrm{g} / \mathrm{g})\end{array}$ & Molality \\
\hline $\mathrm{Al}$ & 53,700 & $\mathrm{Al}(\mathrm{OH})_{3}(\mathrm{~s})$ & 155,200 & 3.90 \\
\hline $\mathrm{Na}$ & 59,100 & & & \\
\hline $\mathrm{NO}_{3}{ }^{*}$ & 2,520 & $\mathrm{NaNO}_{3}(\mathrm{~s})$ & 3,454 & 0.0816 \\
\hline $\mathrm{NO}_{2}{ }^{-}$ & 15,400 & $\mathrm{NaNO}_{2}(\mathrm{~s})$ & 23,100 & 0.656 \\
\hline $\mathrm{TIC}^{\mathrm{SO}_{4}{ }^{2 *}}$ & 15,600 & $\mathrm{Na}_{2} \mathrm{CO}_{3} \cdot \mathrm{H}_{2} \mathrm{O}(\mathrm{s})$ & 161,100 & 2.98 \\
\hline $\mathrm{F}$ & 6,540 & $\mathrm{Na}_{2} \mathrm{SO}_{4}(\mathrm{~s})$ & 9,671 & 0.134 \\
\hline $\mathrm{Cr}$ & 460 & $\mathrm{NaF}^{(\mathrm{s})}$ & 1.017 & 0.0475 \\
\hline $\mathrm{Si}$ & 1,920 & $\mathrm{Cr}(\mathrm{OH})_{3}(\mathrm{am})$ & 3,804 & 0.072 \\
\hline $\mathrm{Cd}$ & 4,480 & $\mathrm{SiO}_{2}(\mathrm{am})$ & 9,580 & 0.313 \\
\hline $\mathrm{Fe}^{*}$ & 15,000 & & & \\
\hline $\mathrm{La}^{*}$ & 131,000 & & & \\
\hline $\mathrm{Ni}^{*}$ & 4,500 & & & \\
\hline $\mathrm{U}^{*}$ & 8,860 & & & \\
\hline $\mathrm{Zr}^{*}$ & 12,600 & & & \\
\hline $\mathrm{TOC}^{*}$ & 18,100 & & & \\
\hline$*$ These solids were treated as insolvable solids in this study. & & \\
\hline
\end{tabular}

(a) Gray WJ, ME Peterson, RD Scheele, and JM Tingey. 1993. "Characterization of the First Core Sample of Neutralized Current Acid Waste from Double-Shell Tank AZ-102." Unpublished report, Pacific Northwest Laboratory, Richland, Washington. 


\subsubsection{Step 2.1: Identification of Dissolvable Solids}

We used GMIN to examine whether solid dissolution and precipitation would occur if only one of $\mathrm{Al}(\mathrm{OH})_{3}(\mathrm{~s})$, amorphous $\mathrm{Cr}(\mathrm{OH})_{3}$, thermonatrite $\left(\mathrm{Na}_{2} \mathrm{CO}_{3} \cdot \mathrm{H}_{2} \mathrm{O}(\mathrm{s})\right), \mathrm{NaNO}_{3}(\mathrm{~s}), \mathrm{NaNO}_{2}(\mathrm{~s})$, thenardite $\left(\mathrm{Na}_{2} \mathrm{SO}_{4}(\mathrm{~s})\right), \mathrm{NaF}(\mathrm{s})$, and amorphous $\mathrm{SiO}_{2}$ exists in the interstitial solution. We used the interstitial solution chemical conditions shown in Table 3.1. If these solids did not dissolve much into or precipitate from the interstitial solution, we judged that they were in equilibrium condition in the interstitial solution. The following are chemical simulation results for each of these potentially dissolvable solids.

\section{Gibbsite, $\mathrm{Al}(\mathbf{O H})_{3}(\mathbf{s})$}

We ran the GMIN code with only gibbsite $\left(\mathrm{Al}(\mathrm{OH})_{3}(\mathrm{~s})\right)$ present as a solid in the interstitial solution of the AZ-102 sludge layer to examine whether the solution was saturated with gibbsite. GMIN indicated that $0.069 \mathrm{~m}$ of gibbsite could dissolve in the solution, increasing $\mathrm{Al}(\mathrm{OH})_{4}^{-}$from $0.0065 \mathrm{~m}$ to $0.0755 \mathrm{~m}$ and reducing $\mathrm{OH}^{-}$from 0.313 to $0.249 \mathrm{~m}$. As we will discuss, these values are similar to the measured values of $0.0617 \mathrm{~m}$ of $\mathrm{Al}(\mathrm{OH})_{4}{ }^{-}$and $0.119 \mathrm{~m}$ of $\mathrm{OH}^{-}$in the supernatant liquid (Ryan 1995). The amount of gibbsite change $(0.069 \mathrm{~m})$ was small enough that gibbsite was judged to be in equilibrium condition. Thus we determined that gibbsite was present in the AZ-102 sludge.

\section{$\mathrm{NaNO}_{3}(\mathbf{s})$}

When $\mathrm{NaNO}_{3}(\mathrm{~s})$ was the only solid reacting with the interstitial solution, GMIN predicted that the solution was significantly under-saturated with it. According to the model prediction, $11.81 \mathrm{~m}$ of $\mathrm{NaNO}_{3}(\mathrm{~s})$ must be dissolved to the solution to reach its equilibrium stage. This would increase concentrations of $\mathrm{Na}^{+}$from a measured value of 3.59 to $15.4 \mathrm{~m}$ and $\mathrm{NO}_{3}^{-}$from a measured value of $0.182 \mathrm{~m}$ to $11.99 \mathrm{~m}$. Thus we judged that $\mathrm{NaNO}_{3}(\mathrm{~s})$ was not present in the AZ-102 sludge.

\section{$\mathrm{NaNO}_{2}(\mathbf{s})$}

Next we examined only $\mathrm{NaNO}_{2}(\mathrm{~s})$. Similar to $\mathrm{NaNO}_{3}(\mathrm{~s}), \mathrm{GMIN}$ predicted that $12.97 \mathrm{~m}$ $\mathrm{NaNO}_{2}(\mathrm{~s})$ must dissolve for the solution to reach its solubility limit, indicating the solution is significantly under-saturated with $\mathrm{NaNO}_{2}(\mathrm{~s})$. With $12.97 \mathrm{~m}$ of $\mathrm{NaNO}_{2}(\mathrm{~s})$ dissolving, the resulting $\mathrm{Na}^{+}$and $\mathrm{NO}_{2}{ }^{-}$concentrations in the solution would change from measured values of 3.95 and $0.122 \mathrm{~m}$ to 16.92 and $13.09 \mathrm{~m}$, respectively. So we eliminated $\mathrm{NaNO}_{2}$ (s) as being among the solids in the sludge. Ryan (1995) reported that $15,400 \mu \mathrm{g} / \mathrm{g}^{-} \mathrm{NO}_{2}^{-}$is present among the solids. It is possible that $\mathrm{NO}_{2}^{-}$forms some double salts in the sludge. If this is the case, its solubility is expected to be very low, and the solid-bearing $\mathrm{NO}_{2}{ }^{-}$could be treated as an insoluble solid. Either way, we can eliminate the $\mathrm{NO}_{2}^{-}$-bearing solid from this assessment.

\section{Themonatrite, $\mathrm{Na}_{2} \mathrm{CO}_{3} \cdot \mathrm{H}_{2} \mathrm{O}(\mathrm{s})$}

When themonatrite $\left(\mathrm{Na}_{2} \mathrm{CO}_{3} \cdot \mathrm{H}_{2} \mathrm{O}(\mathrm{s})\right)$ was assigned as the sole solid, $3.25 \mathrm{~m}$ was dissolved for the solution to reach the solubility limit. Correspondingly, $\mathrm{Na}^{+}$, and $\mathrm{CO}_{3}{ }^{2-}$ concentrations of the 
interstitial solution changed from measured values of 3.59 and $1.15 \mathrm{~m}$ to 6.84 and $4.40 \mathrm{~m}$, respectively. The molality of hydroxide also changed from $0.313 \mathrm{~m}$ to $3.56 \mathrm{~m}$. Thus the GMIN results indicate that themonatrite is not among the solids, and we eliminated it from the list of solids present in the sludge. Although it is unlikely, it is possible that at about 25 to $40^{\circ} \mathrm{C}$, $\mathrm{Na}_{2} \mathrm{CO}_{3} \cdot 10 \mathrm{H}_{2} \mathrm{O}(\mathrm{s})$ and $\mathrm{Na}_{2} \mathrm{CO}_{3} \cdot 7 \mathrm{H}_{2} \mathrm{O}(\mathrm{s})$ could be present instead of $\mathrm{Na}_{2} \mathrm{CO}_{3} \cdot \mathrm{H}_{2} \mathrm{O}(\mathrm{s})$. It is also possible that $\mathrm{CO}_{3}$ may be a part of some double or triple salts having very low solubility limits. Because we did not have their thermodynamic data into our GMIN database, we could not check out these possibilities. However, because the waste has been in the tank for about 14 years, liquid, especially the interstitial solution within the sludge layer, is most likely in equilibrium condition with the $\mathrm{CO}_{3}$-bearing solids and not under-saturated with them. If we did not account for these $\mathrm{CO}_{3}$-bearing solids being dissolved, our mixing assessment would be conservative.

\section{Thenardite, $\mathrm{Na}_{2} \mathrm{SO}_{4}(\mathrm{~s})$}

We imposed thenardite $\left(\mathrm{Na}_{2} \mathrm{SO}_{4}(\mathrm{~s})\right)$ as a sodium sulfate solid potentially present in the solids. GMIN predicted that $1.86 \mathrm{~m}$ of thenardite must be dissolved for the solution to reach its solubility limit. This dissolution would increase the concentrations of $\mathrm{Na}^{+}$and $\mathrm{SO}_{4}{ }^{2-}$ from their measured values of 3.59 and $0.243 \mathrm{~m}$ to 5.45 and $2.10 \mathrm{~m}$, respectively. Thus, thenardite may not be among the $\mathrm{AZ}-102$ solids. However, because a significant amount of $\mathrm{SO}_{4}$-bearing solids were dissolved under a laboratory pretreatment process, ${ }^{(a)}$ we performed the AZ-102 waste chemical assessment both with and without thenardite present in the sludge.

\section{$\mathbf{N a F ( s )}$}

When $\mathrm{NaF}(\mathrm{s})$ was added to the solution, only $0.310 \mathrm{~m}$ was dissolved to reach the solubility limit. Thus $\mathrm{NaF}(\mathrm{s})$ is judged to be present in the solids. The resulting $\mathrm{Na}^{+}$and $\mathrm{F}^{-}$concentrations in the interstitial solution are 3.90 and $0.386 \mathrm{~m}$ compared with the measured values of 3.59 and $0.0763 \mathrm{~m}$, respectively.

\section{$\mathrm{Cr}(\mathrm{OH})_{3}(\mathbf{a m})$}

With only $\mathrm{Cr}(\mathrm{OH})_{3}(\mathrm{am})$ present as a solid, GMIN predicted that the interstitial solution is saturated with this solid. The solid precipitated very slightly $(0.033 \mathrm{~m})$. The concentrations of hydroxide and $\mathrm{Cr}(\mathrm{OH})_{4}{ }^{-}$in the solution were slightly changed from the measured value of 0.313 to $0.346 \mathrm{~m}$ and 0.0331 to $0.0661 \mathrm{~m}$, respectively. The modeling suggests that $\mathrm{Cr}(\mathrm{OH})_{3}(\mathrm{am})$ is present among the solids.

\section{$\mathrm{SiO}_{2}(\mathrm{am})$}

GMIN predicted that $0.150 \mathrm{~m}$ of $\mathrm{SiO}_{2}(\mathrm{am})$ was dissolved in the interstitial solution to reach the solubility limit, $\mathrm{H}_{2} \mathrm{SiO}_{4}{ }^{2}$ would increase from an estimated $0.0338 \mathrm{~m}$ to $0.488 \mathrm{~mm}$ and $\mathrm{OH}^{-}$ decrease from 0.313 to $0.013 \mathrm{~m}$. Thus we determined that this solid was present in the sludge.

(a) Gray WJ, ME Peterson, RD Scheele, and JM Tingey. 1993. "Characterization of the First Core Sample of Neutralized Current Acid Waste from Double-Shell Tank AZ-102." Unpublished report, Pacific Northwest Laboratory, Richland, Washington. 
Table 3.3 summarizes how much of the solids are dissolved or precipitated for the interstitial solution to reach the solubility limit for each of the eight solids (Table 3.2) tested with GMIN.

\subsubsection{Step 2.2: Confirmation of Dissolvable Solids}

After selecting five of eight potential dissolvable solids to be solubility-controlling solids, we tested the potential chemical reactions with GMIN by putting all five together with the interstitial solution. This was to make sure that the solids and interstitial solution used in the GMIN code reproduced the measured concentrations of interstitial solution species and solids in AZ-102. The predicted conditions of sludge interstitial solution and solids are presented in Figures 3.1 and 3.2 along with measured data.

Table 3.3. Summary of Solids Dissolution and Precipitation Testing by GMIN

\begin{tabular}{|c|c|c|}
\hline Solids & Molality Dissolved & $\begin{array}{c}\text { Present among AZ-102 } \\
\text { Solids }\end{array}$ \\
\hline Gibbsite $\left(\mathrm{AlOH}_{3}(\mathrm{~s})\right)$ & 0.069 & Yes \\
\hline $\mathrm{NaNO}_{3}(\mathrm{~s})$ & 11.81 & No \\
\hline $\mathrm{NaNO}_{2}(\mathrm{~s})$ & 12.97 & No \\
\hline $\mathrm{NaF}_{(\mathrm{s})}$ & 0.31 & Yes \\
\hline Themonatrite: $\mathrm{Na}_{2} \mathrm{CO}_{3} \cdot \mathrm{H}_{2} \mathrm{O}(\mathrm{s})$ & 3.252 & No \\
\hline Thenardite: $\mathrm{Na}_{2} \mathrm{SO}_{4}(\mathrm{~s})$ & 1.86 & Yes/No \\
\hline $\mathrm{Cr}(\mathrm{OH})_{3}(\mathrm{am})$ & 0.033 (precipitated) & Yes \\
\hline $\mathrm{SiO}(\mathrm{am})$ & 0.150 & Yes \\
\hline
\end{tabular}

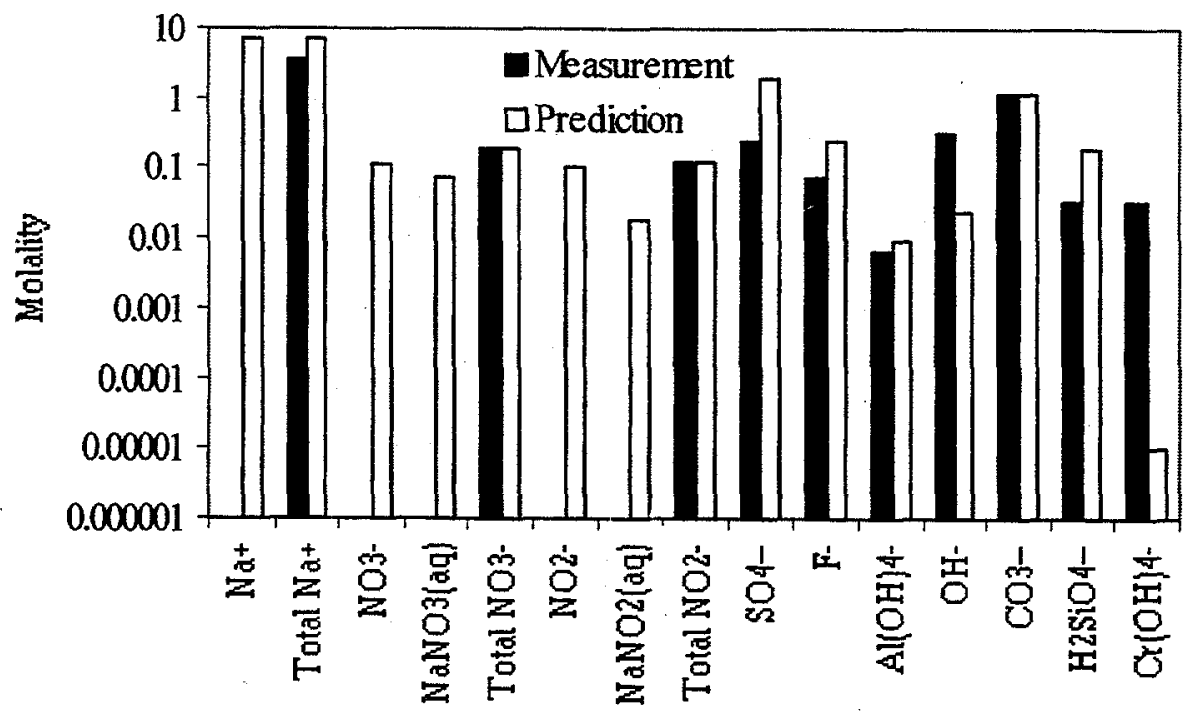

Aqueous Species

Figure 3.1. Predicted Aqueous Species Concentrations of the AZ-102 Interstitial Solution with Measured Data 
These figures show that our AZ-102 waste chemistry predictions are reasonable based on the conditions we imposed (e.g., measured interstitial solution aqueous species concentrations were our starting points without first knowing specific solids present in the sludge). With thenardite present, the predicted $\mathrm{Na}^{+}$concentration was $7.00 \mathrm{~m}$ compared with a measured value of $3.59 \mathrm{~m}$. Without thenardite, the predicted $\mathrm{Na}^{+}$concentration of $3.85 \mathrm{~m}$ is much closer to measured value. For sodium, nitrate, and nitrite, the measurements only included the total amounts.

Through these modeling analyses, we concluded that the solids present in Tank AZ-102 are $\mathrm{Al}(\mathrm{OH})_{3}(\mathrm{~s})$, amorphous $\mathrm{Cr}(\mathrm{OH})_{3}, \mathrm{NaF}(\mathrm{s})$, amorphous $\mathrm{SiO}_{2}$, and possibly thenardite $\left(\mathrm{Na}_{2} \mathrm{SO}_{4}(\mathrm{~s})\right)$. The AZ-102 interstitial solution in the sludge layer consists of $\mathrm{H}_{2} \mathrm{O}$ and aqueous chemical species of $\mathrm{Na}^{+}, \mathrm{Al}(\mathrm{OH})_{4}{ }^{-}, \mathrm{Cr}(\mathrm{OH})_{4}^{-}, \mathrm{CO}_{3}{ }^{2-}, \mathrm{H}_{2} \mathrm{SiO}_{4}{ }^{2-}, \mathrm{NO}_{3}^{-}, \mathrm{NO}_{2}^{-}, \mathrm{SO}_{4}{ }^{2-}, \mathrm{F}^{-} \mathrm{OH}^{-}, \mathrm{NaNO}_{3}(\mathrm{aq})$, and $\mathrm{NaNO}_{2}$ (aq). We then mixed the sludge having these chemical characteristics with the AZ-102 supernatant liquid to determine whether any chemical and associated physical property changes would occur.

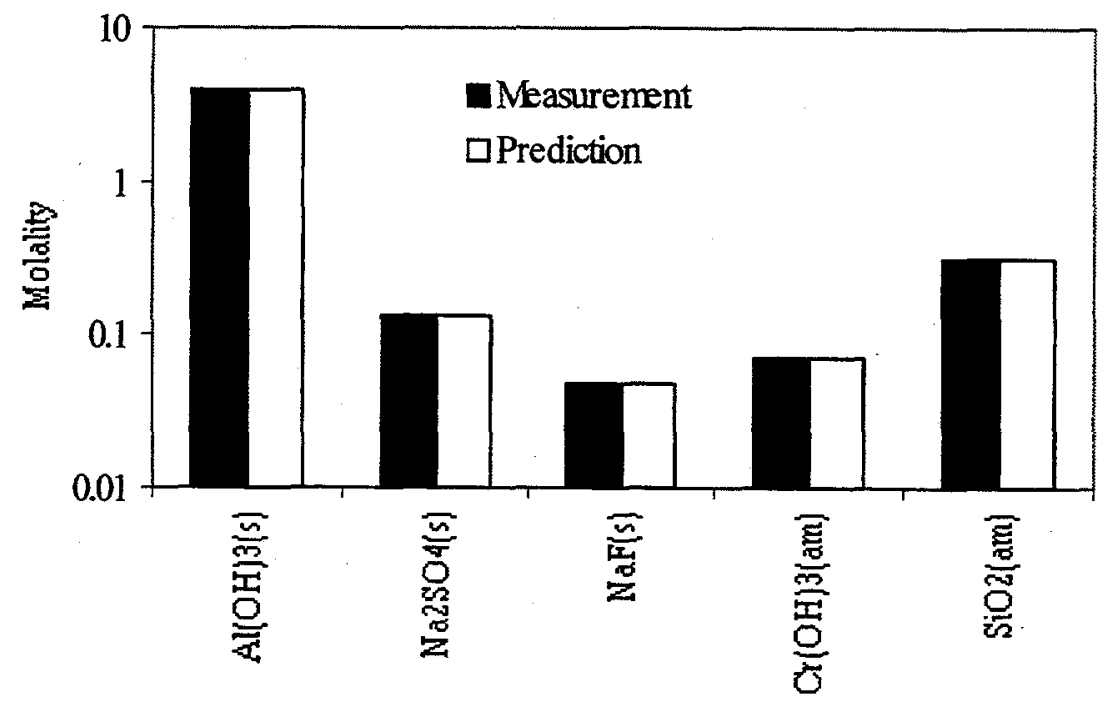

Solids

Figure 3.2. Predicted AZ-102 Solid Concentrations with Measured Data

\subsection{Step 3: Mixture of AZ-102 Sludge and Supernatant Liquid}

Tank AZ-102 contains nine times as much supernatant liquid as AZ-102 sludge by volume (Ryan 1995). The supernatant liquid contains $84.1 \mathrm{wt} \%$ water. Its temperature averages about $131^{\circ} \mathrm{F}\left(55^{\circ} \mathrm{C}\right)$. Table 3.4 shows its measured or estimated aqueous species concentrations (Ryan $1995)$ (a) $^{\text {(a) }}$

(a) Gray WJ, ME Peterson, RD Scheele, and JM Tingey. 1993. "Characterization of the First Core Sample of Neutralized Current Acid Waste from Double-Shell Tank AZ-102." Unpublished report, Pacific Northwest Laboratory, Richland, Washington. 
This AZ-102 supernatant liquid was assumed fully mixed with the sludge, both the solids and interstitial solution. We assigned the predicted sludge chemistry shown in Figures 3.1 and 3.2 to ensure that the solids and interstitial solution within the sludge layer are in equilibrium condition prior to mixing with the supernatant liquid. We then applied the GMIN code to the fully mixed AZ-102 waste to determine potential chemical reactions. As before, we used a waste temperature of $131^{\circ} \mathrm{F}\left(55^{\circ} \mathrm{C}\right)$. We conducted this chemical assessment both with and without thenardite $\left(\mathrm{Na}_{2} \mathrm{SO}_{4}(\mathrm{~s})\right)$ present in the original $\mathrm{AZ}-102$ sludge.

Predicted aqueous chemical concentrations of the resulting supernatant liquid for the case with thenardite are presented in Figure 3.3. This figure also shows the measured chemical concentrations of the original supernatant liquid prior to mixing and the weighted measured tank arithmatic average concentration (without chemical reactions) to illustrate the effects of chemical reactions between the sludge and supernatant liquid. The figure indicates that aqueous chemical concentrations are very similar among these three cases. Predicted solid concentrations for this case are presented in Figure 3.4. For comparison, this figure also includes expected solids concentrations resulting from physical mixing alone without chemical reactions (weighted measured tank arithmatic average). The measurements for sodium, nitrate, and nitrite only included the total amount.

As shown in Figure 3.4, all thenardite $\left(\mathrm{Na}_{2} \mathrm{SO}_{4}(\mathrm{~s})\right), \mathrm{NaF}(\mathrm{s})$, and $\mathrm{SiO}_{2}(\mathrm{am})$ dissolved. A small amount of gibbsite $\left[\mathrm{Al}(\mathrm{OH})_{3}(\mathrm{~s})\right]$ and $\mathrm{Cr}(\mathrm{OH})_{3}(\mathrm{am})$ precipitated to increase their amount by 0.031 and $0.018 \mathrm{~m}$, respectively. Consequently, there are small increases on total $\mathrm{Na}^{+}, \mathrm{SO}_{4}{ }^{2-}, \mathrm{F}$, and $\mathrm{SiO}_{4}{ }^{2-}$ concentrations and small reductions in $\mathrm{Al}(\mathrm{OH})_{4}{ }^{-}, \mathrm{Cr}(\mathrm{OH})_{4}{ }^{-}$and $\mathrm{OH}^{-}$, as shown in Figure 3.3. However, these aqueous chemical changes are very minor.

Table 3.4. Chemical Compositions and Measured or Estimated Concentrations of the AZ-102 Supernatant Liquid

\begin{tabular}{|c|c|c|c|c|}
\hline Compound & $\begin{array}{c}\text { Measured } \\
\text { Concentration } \\
(\boldsymbol{\mu g} / \mathrm{g})\end{array}$ & $\begin{array}{c}\text { Selected } \\
\text { Aqueous } \\
\text { Species }\end{array}$ & $\begin{array}{c}\text { Measured or } \\
\text { Estimated } \\
\text { Concentration } \\
(\boldsymbol{\mu g} / \mathbf{g})\end{array}$ & Molality \\
\hline $\mathrm{Al}$ & 1,400 & $\mathrm{Al}(\mathrm{OH})_{4}{ }^{-}$ & 4,930 & 0.0617 \\
\hline $\mathrm{Cr}$ & 879 & $\mathrm{Cr}(\mathrm{OH})_{4}^{-}$ & 2,029 & 0.0201 \\
\hline $\mathrm{Na}$ & 48,360 & $\mathrm{Na}^{+}$ & 54,220 & 2.804 \\
\hline $\mathrm{TIC}$ & 5,310 & $\mathrm{CO}_{3}{ }^{2-}$ & 26,540 & 0.526 \\
\hline $\mathrm{Si}$ & 484 & $\mathrm{H}_{2} \mathrm{SiO}_{4}{ }^{2-}$ & 1,620 & 0.0205 \\
\hline & & $\mathrm{NO}_{3}^{-}$ & 21,640 & 0.415 \\
\hline & & $\mathrm{NO}_{2}^{-}$ & 25,090 & 0.649 \\
\hline & & $\mathrm{SO}_{4}{ }^{2-}$ & 15,730 & 0.195 \\
\hline & & $\mathrm{F}^{-}$ & 913 & 0.0572 \\
\hline & & $\mathrm{OH}^{-}$ & 1,709 & 0.119 \\
\hline
\end{tabular}




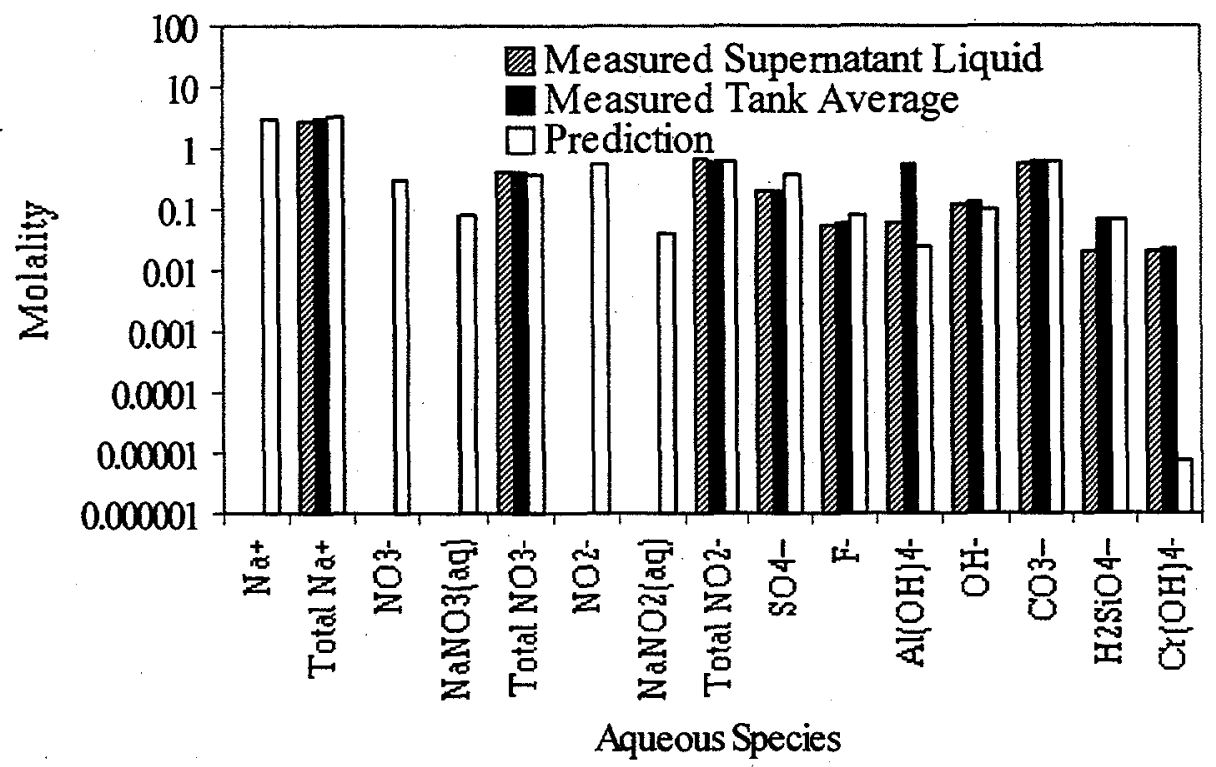

Figure 3.3. Predicted Aqueous Species Concentrations Resulting from Mixing the Tank AZ-102 Sludge and Supernatant Liquid, and Measured Values of the Original Supernatant Liquid Prior to Mixing

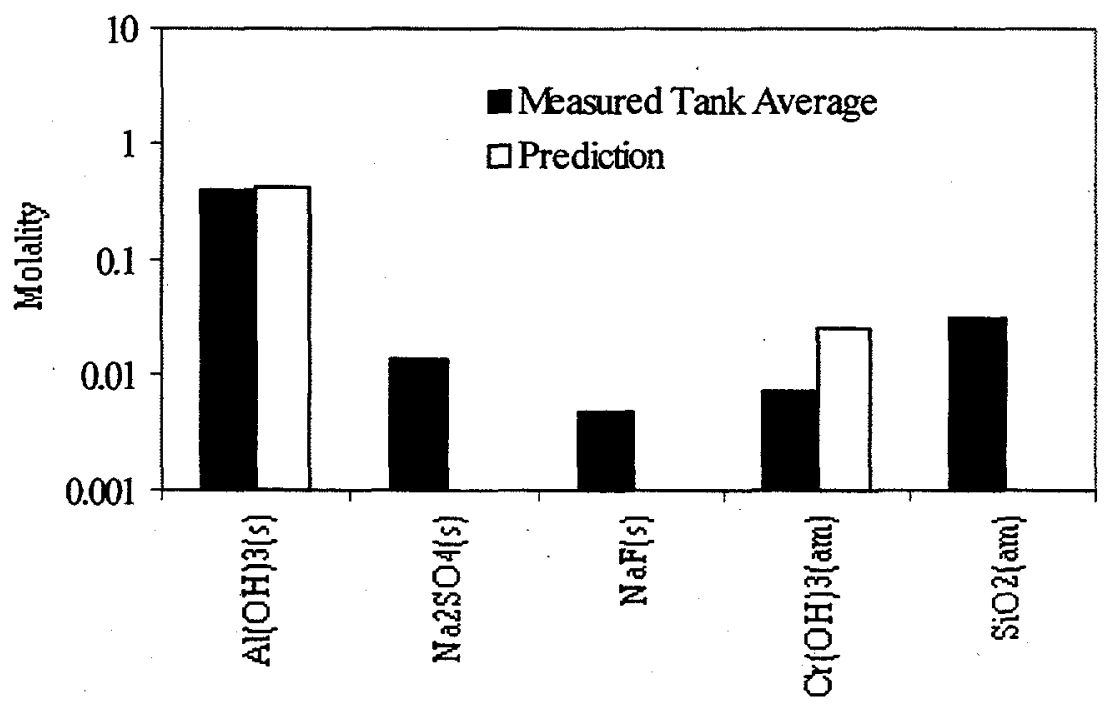

Solids

Figure 3.4. Predicted Solids Concentrations Resulting from Mixing Tank AZ-102 Sludge and Supernatant Liquid and Expected Solid Concentrations Without Chemical Reactions 


\subsection{Step 4: Determination of Changes on Waste Properties and Solid Amount due to Chemical Reactions}

The dissolution of thenardite $\left(\mathrm{Na}_{2} \mathrm{SO}_{4}(\mathrm{~s})\right), \mathrm{NaF}(\mathrm{s})$, and $\mathrm{SiO}_{2}(\mathrm{am})$ attributes to a reduction of solids weight by $5,180,550,510 \mathrm{~kg}$, respectively, for a total solid weight loss of $6,240 \mathrm{~kg}$. On the other hand, precipitation of gibbsite $\left(\mathrm{Al}(\mathrm{OH})_{3}(\mathrm{~s})\right)$ and $\mathrm{Cr}(\mathrm{OH})_{3}(\mathrm{am})$ contributes a solid weight gain of 6,540 and $510 \mathrm{~kg}$, totaling $7,050 \mathrm{~kg}$. Thus mixing the AZ-102 sludge and supernatant liquid would result in the solids gaining $810 \mathrm{~kg}$. Because the total AZ-102 sludge weighs approximately $536,400 \mathrm{~kg}$ (Ryan 1995), the solid weight gain of $810 \mathrm{~kg}$ corresponds to $0.15 \%$ of the original sludge weight.

When we did not include thenardite among the $\mathrm{AZ}-102$ solids, all $\mathrm{NaF}(\mathrm{s})$, and $\mathrm{SiO}_{2}(\mathrm{am})$ were dissolved, and a small amount of gibbsite $\left[\mathrm{Al}(\mathrm{OH})_{3}(\mathrm{~s})\right]$ and $\mathrm{Cr}(\mathrm{OH})_{3}(\mathrm{am})$ precipitated, increasing its amount by 0.031 and $0.018 \mathrm{~m}$, respectively. This corresponded to solid weight losses of 550 and $510 \mathrm{~kg}$ for $\mathrm{NaF}(\mathrm{s})$ and $\mathrm{SiO}_{2}(\mathrm{am})$ and weight gains of 6,540 and $510 \mathrm{~kg}$. The net result is the solid weight gain of $5,990 \mathrm{~kg}$, corresponding to $1.1 \mathrm{wt} \%$ gain by the total AZ-102 sludge.

The chemical assessment discussed in this section indicates that mixing the sludge and supernatant liquid of Tank AZ-102 would not change the waste properties and solids amount in any discernable manner due to chemical reactions resulting from the pump jet mixing. Thus, we did not include the effects of chemistry on pump jet mixing when we assessed the effectiveness of the two 300 -hp mixer pumps to mix the sludge and supernatant liquid. 


\subsection{Pump Jet Waste Mixing Evaluation}

\subsection{Pump Jet Mixing in Current AZ-102 Tank Conditions}

\subsubsection{Sludge Mobilization}

We evaluated how much AZ-102 waste would be mixed by the 300-hp mixer pumps in simulations with the TEMPEST computer code (Onishi and Trent 1999). Because the chemical assessment discussed in Section 3 indicated that the pump jet mixing would change the AZ-102 waste properties and total solids volume very little, we used the values reported in the AZ-102 Tank Characterization Report (Ryan 1995) and 1993 PNNL measurements. ${ }^{\text {(a) }}$ Based on these reports, we assigned the supernatant liquid density and viscosity to be $1,100 \mathrm{~kg} / \mathrm{m}^{3}$ and $1 \mathrm{cP}$, respectively, in the model. The solids density and sludge yield strength were assigned to be $2,360 \mathrm{~kg} / \mathrm{m}^{3}$ and $1,540 \mathrm{~Pa}$, respectively. With the assigned solid volume concentration of $31 \%$ in the sludge layer, the bulk sludge density corresponded to the measured value of $1,490 \mathrm{~kg} / \mathrm{m}^{3}$.

The viscosity of the slurry changes spatially and temporally during mixing operations as a result of the mixing of supernatant liquid and solids. Based on viscosity measurements reported by Gray et al., (a) we programmed the slurry viscosity in the AZ-102 model to vary with the solids volume concentration during the simulation as

$$
\mu=\mu_{L}\left\{\frac{\mu_{s}}{\mu_{L}}\right\}^{\frac{c_{v}}{c_{v \max }}}
$$

where

$$
\begin{aligned}
& \mathrm{C}_{\mathrm{v}}=\text { solid volume fraction of the slurry } \\
& \mathrm{C}_{\mathrm{V} \max }=\text { maximum solid volume fraction }(0.33 \text { in this study) } \\
& \mu \quad=\text { viscosity of slurry at solid concentration of } \mathrm{C}_{\mathrm{V}} \\
& \mu_{\mathrm{L}} \quad=\text { viscosity of supernatant liquid }(1.0 \mathrm{cP} \text { in this study) } \\
& \mu_{\mathrm{S}} \quad=\text { viscosity of sludge layer }\left(426 \mathrm{cP} \text { when the sludge moves at strain rate of } 5 \mathrm{~s}^{-1}\right) .
\end{aligned}
$$

As shown in Figure 2.1, the AZ-102 solid size distribution varied from 1 to $11 \mu \mathrm{m}$, averaging $3.4 \mu \mathrm{m}$. Corresponding settling velocities are small, $7.4 \times 10^{-7}, 8.6 \times 10^{-6}$, and $9.0 \times 10^{-5} \mathrm{~m} / \mathrm{s}$, respectively. As previous pump jet mixing studies indicate (Onishi et al. 1996b; Onishi and Recknagle 1997, 1998; Whyatt et al. 1996), these settling velocities are much smaller than an expected slurry velocity induced by pump jets in the tank, and resulting distributions of 1- to 11$\mu \mathrm{m}$ solid particles are expected to be very similar to each other. Thus we assigned the diameters of all the solids to be $3.4 \mu \mathrm{m}$ for the AZ-102 pump jet mixing modeling. Because the actual solids settling velocities will decrease with solid concentrations expected to occur in the tank, we

(a) Gray WJ, ME Peterson, RD Scheele, and JM Tingey. 1993. "Characterization of the First Core Sample of Neutralized Current Acid Waste from Double-Shell Tank AZ-102." Unpublished report, Pacific Northwest Laboratory, Richland, Washington. 
assigned the hindering settling velocity changing with the solid concentration during the simulation as

$$
\mathrm{V}_{\mathrm{s}}=\mathrm{V}_{\mathrm{so}}\left(\mathbb{1}-\frac{\mathrm{C}_{\mathrm{V}}}{\mathrm{C}_{\mathrm{V}_{\max }}}\right)^{\mathrm{a}}
$$

where

a $=$ constant (4.7 in this study based on the Stokes Law)

$\mathrm{V}_{\mathrm{s}}=$ hindered setting velocity at solid volume fraction of $\mathrm{C}_{\mathrm{v}}$

$\mathrm{V}_{\mathrm{so}}=$ unhindered settling velocity (settling velocity in a clear liquid containing no solids).

As stated above, the AZ-102 model contains twenty 30-inch (76-cm)-diameter airlift circulators and 33-inch (84-cm)-diameter steam heating coils. These airlift circulators and heating coils are suspended approximately 30 in. $(0.76 \mathrm{~m})$ above the tank bottom. Because they act as potential obstacles to the jets in mixing the waste, we included them in the model.

Each of the pumps has a 17 -inch $(43-\mathrm{cm})$-diameter withdrawal inlet and two 6-inch $(0.15-\mathrm{m})$ diameter nozzles to inject $60-\mathrm{f} / \mathrm{sec}(18.3 \mathrm{~m} / \mathrm{s})$ jets. Because the pumps are on opposite sides of the tank, $22 \mathrm{ft}(6.7 \mathrm{~m})$ from the center, and they were assumed to rotate at $0.2 \mathrm{rpm}$ in a synchronized mode, we only needed to simulate one half (the right side) of AZ-102 based on symmetry.

We ran the three-dimensional AZ-102 model with the TEMPEST computer code to examine the effectiveness of the pumps to mix the waste. TEMPEST simulated movements of AZ-102 supernatant liquid and 3.4- $\mu \mathrm{m}$ solids for two simulation hours. Figure 4.1 shows the initial velocity and solids volume concentration distributions on a vertical plane containing the pump center and the nearest tank wall from the off-centered pump. We assigned this position the 3 $o^{\prime}$ clock position and $0^{\circ}$, from which other vertical planes were measured. This figure shows the initial 35-inch (0.89-m)-thick sludge (nonconvective) layer at the tank bottom and 310-inch (7.87-m)-thick supernatant liquid (convective) layer, which together make up 345 inches (8.76 $\mathrm{m})$ of the waste in Tank AZ-102. It also shows the positions of one of the rotating pumps, its withdrawal inlet, and a nozzle injecting a $60-\mathrm{ft} / \mathrm{sec}(18.3-\mathrm{m} / \mathrm{s})$ jet into the sludge layer. It shows one of the air lift circulators near the pump on this plane. The tank boundary is indicated by the solid line, and the presence of the velocity vector indicates that its location is within the tank. The solids concentration within the sludge layer is $31 \mathrm{vol} \%$, as discussed previously. The initial solids concentration in the supernatant liquid layer was assigned a small value $(0.001 \mathrm{vol} \%)$ rather than 0 to handle the settling velocity of the solids for all solids concentrations.

The top of Figure 4.1 shows the time ( 0 simulation second in this plot). The right side of the figure describes which vertical plane it is showing (in this case the r-z plane, which is Vertical Plane 2 ( $I=2$ ) at the 3 o'clock position), and an area of the plot coverage on this vertical plane (in this case, $\mathrm{J}=1$ to 44 , indicating the entire horizontal direction from the pump center to $13.3 \mathrm{~m}$ beyond the tank wall, and $K=1$ to 23 , indicating the vertical direction from the 


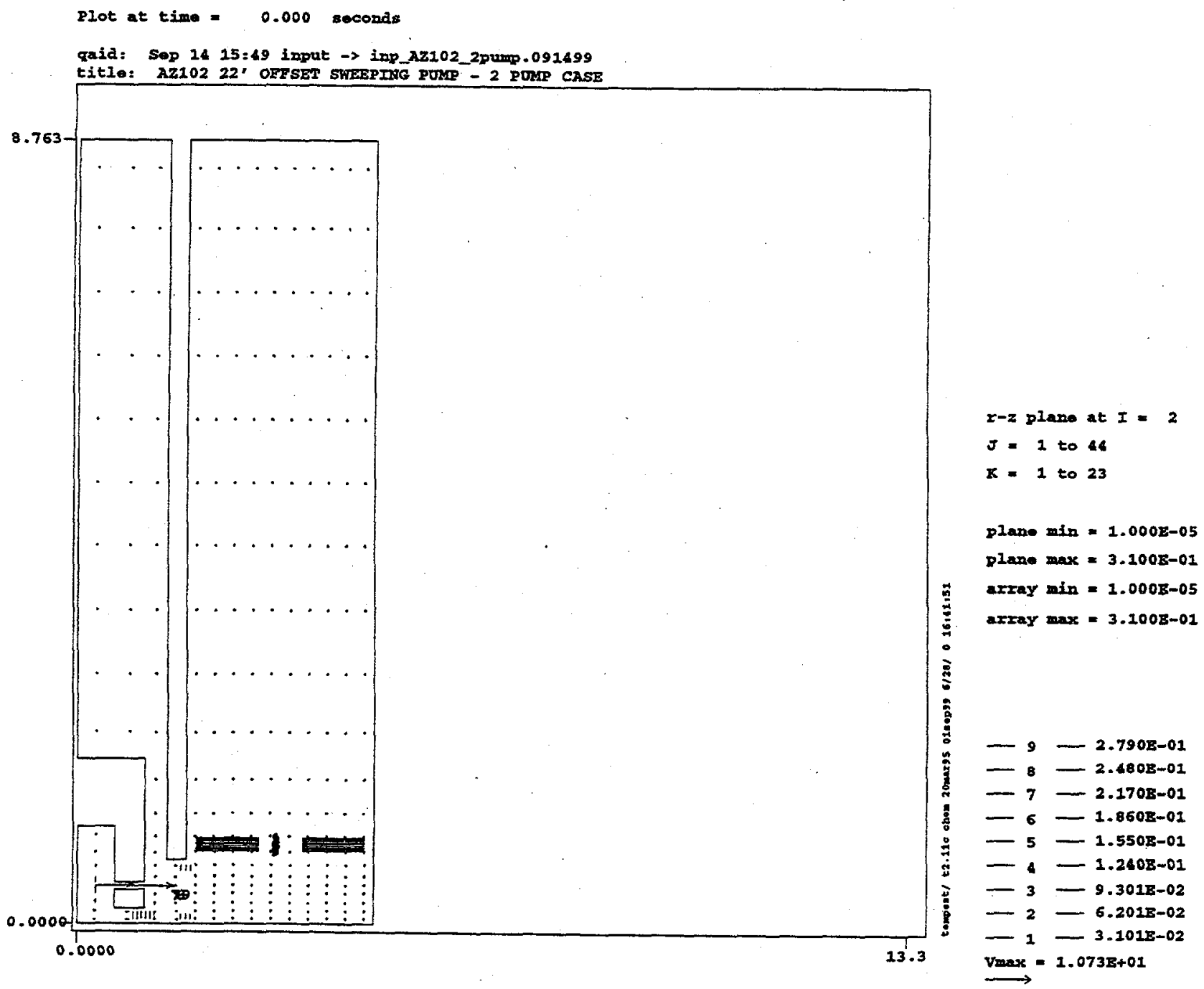

Figure 4.1. Initial Conditions of Sludge and Supernatant Liquid on Vertical Plane 2 (in $30^{\prime}$ clock position assigned as $0^{\circ}$ )

tank bottom to the waste surface at $8.76 \mathrm{~m}$ ). The bottom right side of the figure also shows solids concentrations (expressed in volume fractions of one being $100 \mathrm{vol} \%$ ) represented by Lines 1 through 9. Plane min and max indicate the minimum and maximum values [solid volume fractions of $1.0 \times 10^{-5}$ (or $0.001 \mathrm{vol} \%$ ) and 0.31 (or $31 \mathrm{vol} \%$ ), respectively, in this case] within the plotted plane, while array min and max indicate the minimum and maximum values [solid volume fractions of $1.0 \times 10-5$ (or $0.001 \mathrm{vol} \%$ ) and 0.31 (or $31 \mathrm{vol} \%$ ), respectively] encountered within the entire tank simulation area. At the bottom right, the maximum velocity on this vertical plane is shown (in this case $10.73 \mathrm{~m} / \mathrm{s}$ with its corresponding scale length). All velocity magnitude in this plot is scaled to this magnitude. Note that the jet velocity at the nozzle exit was assigned as $60 \mathrm{ft} / \mathrm{sec}(18.3 \mathrm{~m} / \mathrm{s})$. The maximum velocity of $10.73 \mathrm{~m} / \mathrm{s}$ in this figure is the velocity within the nozzle, not at the nozzle exit, and increases from 0 at the beginning to the final $16.37 \mathrm{~m} / \mathrm{s}$ within a few seconds. 
The AZ-102 modeling indicated it would take approximately one to two hours for two pumps to reach the final waste mixing condition. The predicted vertical distributions of velocity and solid concentrations are shown in Figures 4.2 through 4.9 at 2 hours and 43 simulation seconds.

The AZ-102 model has 42 grid resolution in the azimuthal coordinate direction and thus has 40 computational vertical planes (from Vertical Planes $2(I=2)$ to 41 ( $I=41)$. [Vertical Planes 1 $(I=1)$ and $42(I=42)$ are not computational planes but are used for internal computational

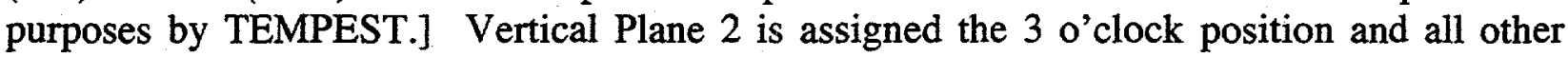
vertical plane positions are measured by counter-clockwise degrees from this point in $9^{\circ}$ increments. Thus, for example, Vertical Plane $12(\mathrm{I}=12)$ is located $90^{\circ}$ counter-clockwise from Vertical Plane 2.

At 2 hours and 42 simulation seconds, one of the two jets was oriented along the longest distance from the pump center to the tank wall [Vertical Plane 15 ( $I=15)$, which is $117^{\circ}$ counterclockwise from Vertical Plane 2], while the accompanying second jet of the same rotating pump was oriented at $207^{\circ}$ counter-clockwise from Vertical Plane 2.

Figure 4.2 shows the predicted velocity and solid concentration on Vertical Plane 2, depicting the original sludge eroded away except the bottom seven inches $(0.18 \mathrm{~m})$. The airlift circulator did not deter sludge erosion. The suspended solids were uniformly distributed with a concentration of $1.57 \mathrm{vol} \%$ ( 0.0157 volume fraction). This is also true on Vertical Plane $7\left(45^{\circ}\right.$ counter-clockwise from Vertical Plane 2), as shown in Figure 4.3. However, on Vertical Plane $10\left(72^{\circ}\right.$ from Vertical Plane 2), shown in Figure 4.4, the jets did not erode the sludge just in front of the tank wall.

Although airlift circulators located near the pump are not interfering with the jet mixing the waste (see Figure 4.2), the comparison of Figure 4.5 (Vertical Plane 13, $99^{\circ}$ from Vertical Plane 2) and Figure 4.6 (Vertical Plane $14,108^{\circ}$ from Vertical Plane 2) indicates that an airlift circulator on Vertical Plane 13 limits sludge mobilization by the rotating jets.

The jets must travel the longest distance ( $44 \mathrm{ft}$ or $13 \mathrm{~m}$ ) to reach the tank wall along Vertical Plane 15 ( $117^{\circ}$ from Vertical Plane 2). As shown in Figure 4.7, an airlift circulator present on this vertical plane was still buried in the sludge, even though the rotating, $60-\mathrm{ft} / \mathrm{sec}(18.3 \mathrm{~m} / \mathrm{s})$ jet has been shooting along this direction as well. The jet mobilized the sludge farthest along this direction, removing the sludge up to $23 \mathrm{ft}(7.0 \mathrm{~m})$ from the pump. However, the sludge within 7 inches $(0.18 \mathrm{~m})$ of the tank bottom was not mobilized, as shown in these figures (Figures 4.2 through 4.9). The suspended solids are very uniformly distributed (99\% uniformity), and concentrations are around $1.57 \pm 0.002 \mathrm{vol} \%$ for all these planes except for in the sludge that is not mobilized. 


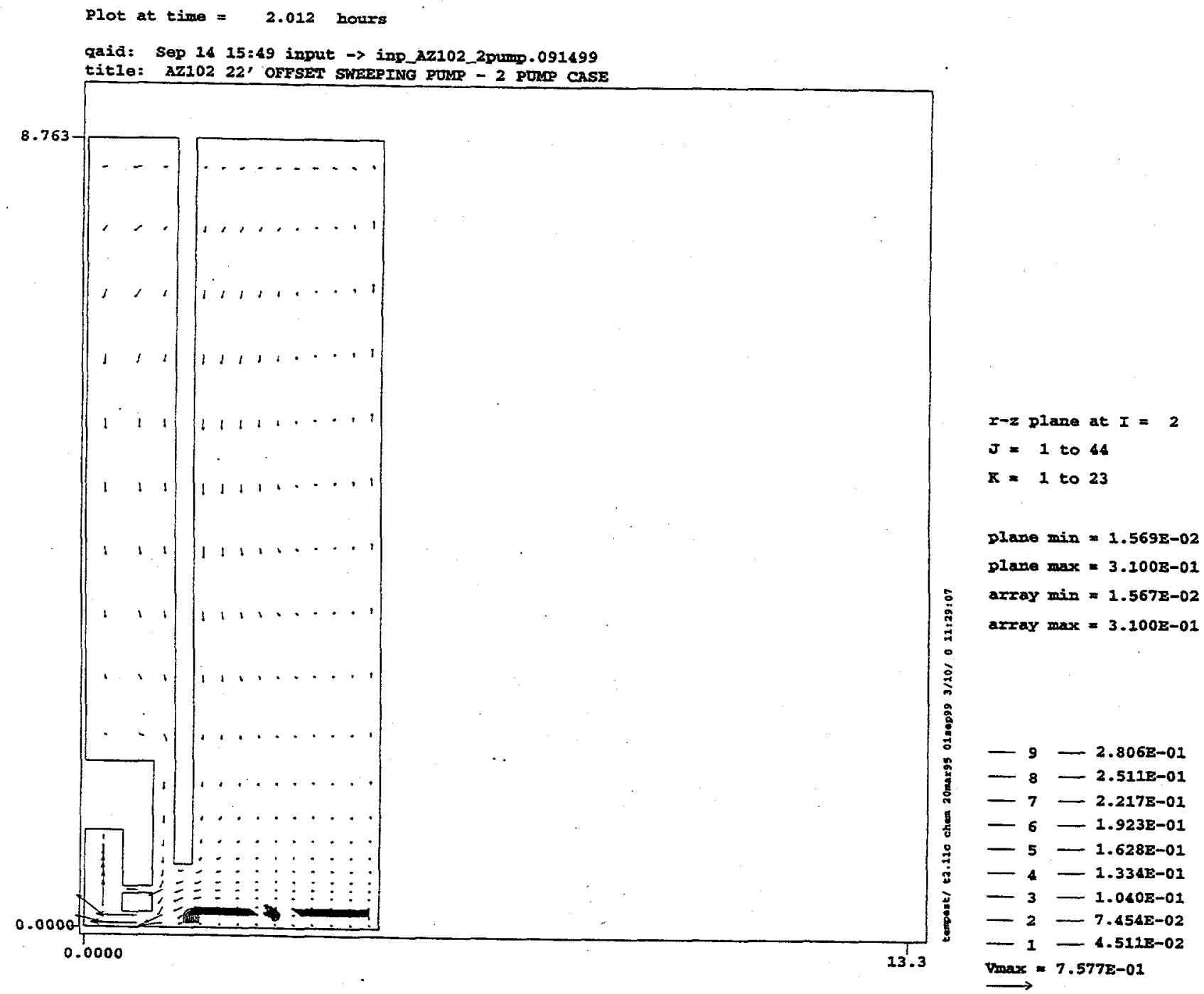

Figure 4.2. Predicted Distributions of Velocity $(\mathrm{m} / \mathrm{s})$ and Solid Concentration (volume fraction) on Vertical Plane 2 at Two Simulation Hours

Figure 4.8 depicts the flow and solid concentration along Vertical plane $17\left(135^{\circ}\right.$ from Vertical Plane 2). The airlift circulator present on Vertical Plane 17 is slightly closer to the pump than is the one present on Vertical Plane 13 (see Figure 4.5), and in this case the jet moves below the airlift circulator to further erode the sludge beyond it. Figure 4.9 shows the predicted velocity and solid distributions on Vertical Plane $21\left(171^{\circ}\right.$ from Vertical Plane 2, or $9^{\circ}$ short of $180^{\circ}$ from Vertical Plane 2). (Note that on Vertical Plane 22, the plane orientation is at 9 o'clock, containing both the pump center and AZ-102 tank center.) On Vertical Plane 21, the rotating jet mobilized the sludge almost to the tank wall, except that within 7 inches $(0.18 \mathrm{~m})$ of the tank bottom. Again, the suspended solids concentrations are all around $1.57 \mathrm{vol} \%$. 


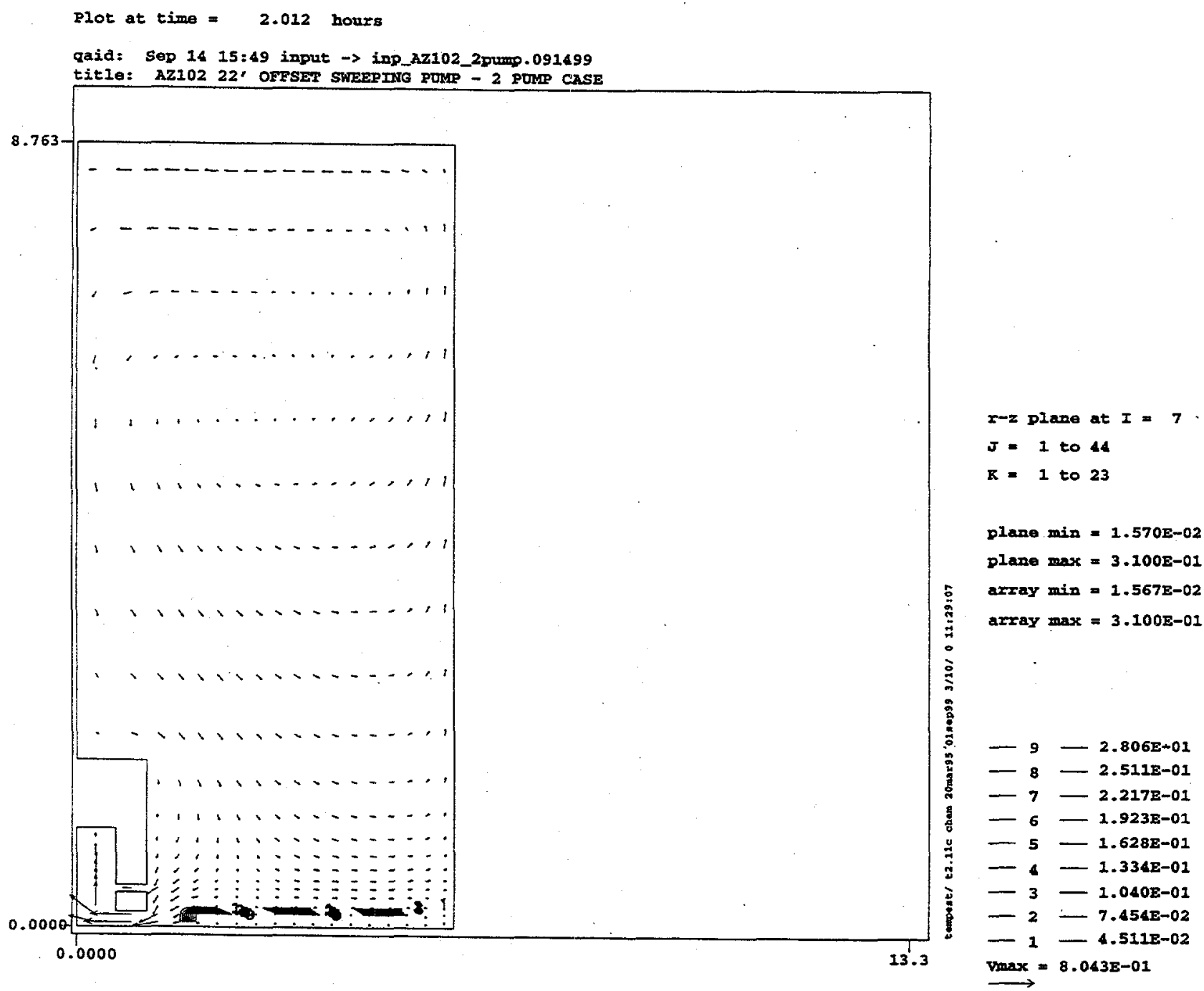

Figure 4.3. Predicted Distributions of Velocity $(\mathrm{m} / \mathrm{s})$ and Solid Concentration (volume fraction) on Vertical Plane 7 ( $45^{\circ}$ counter-clockwise from Vertical Plane 2$)$ at Two Simulation Hours

If the rotating jets had mobilized all the sludge and uniformly distributed the solids within the entire tank, the resulting solids concentration would be 3.1 vol\%. Note that the solids constitute $31 \mathrm{vol} \%$ of the original sludge, which in turn corresponds to $10 \mathrm{vol} \%$ of the waste. The suspended solids concentration predicted by the AZ-102 model is $1.57 \mathrm{vol} \%$, which is $50 \%$ of 3.1 vol\%. Thus, the rotating jet pumps mobilized $50 \%$ of the sludge. 


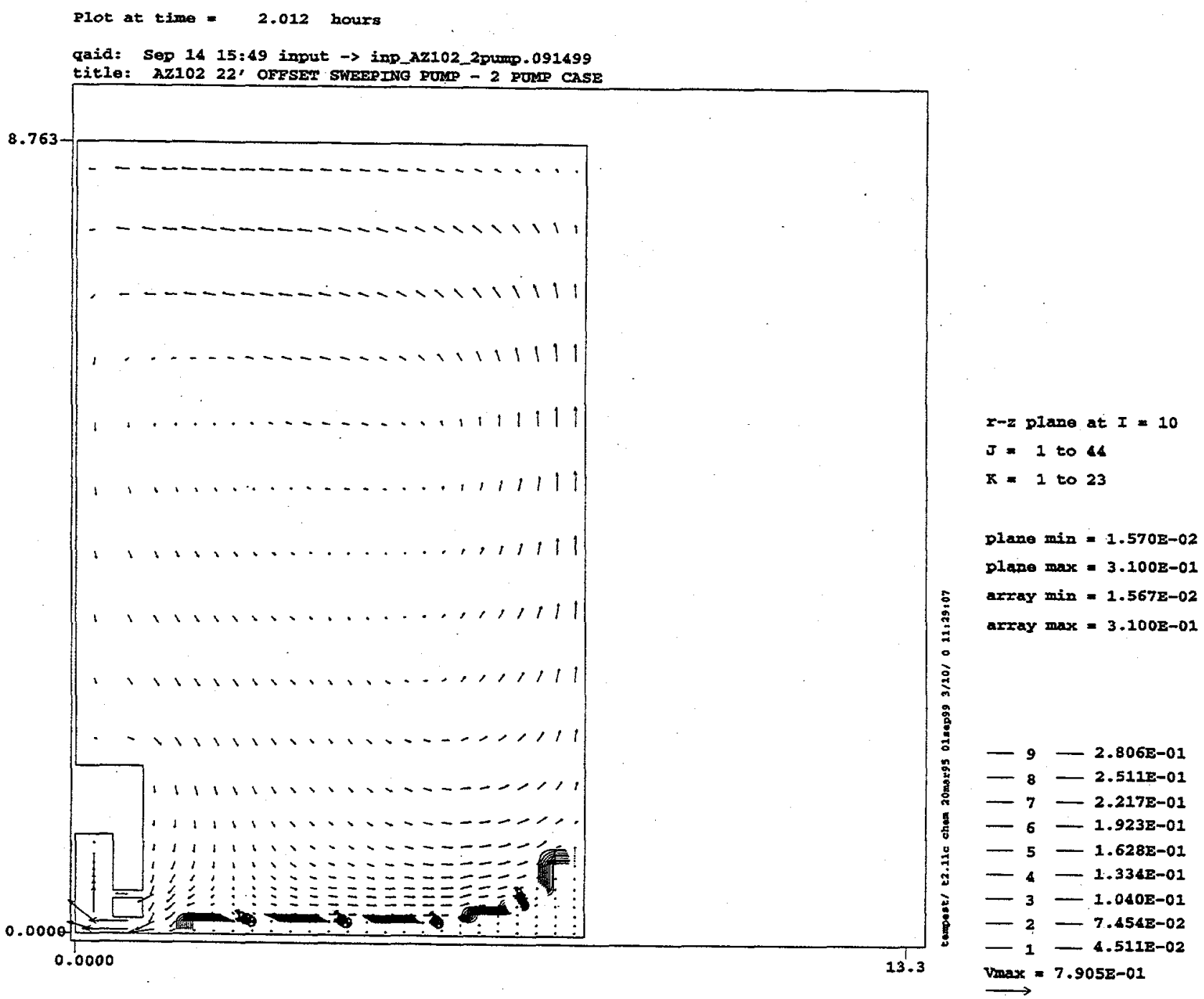

Figure 4.4. Predicted Distributions of Velocity $(\mathrm{m} / \mathrm{s})$ and Solid Concentration (volume fraction) on Vertical Plane 10 ( $72^{\circ}$ counter-clockwise from Vertical Plane 2) at Two Simulation Hours

These results indicate that

- the rotating jets mobilized the sludge located up to $23 \mathrm{ft}(7.0 \mathrm{~m})$ from the pump

- the jets did not erode the sludge within the seven inches $(0.18 \mathrm{~m})$ immediately above the tank bottom

- the resulting suspended solids concentration would be uniformly distributed at $1.6 \mathrm{vol} \%$ within the entire tank (except in the region of non-eroded sludge)

- the two 300 -hp pumps will mobilize $50 \%$ of the original sludge 


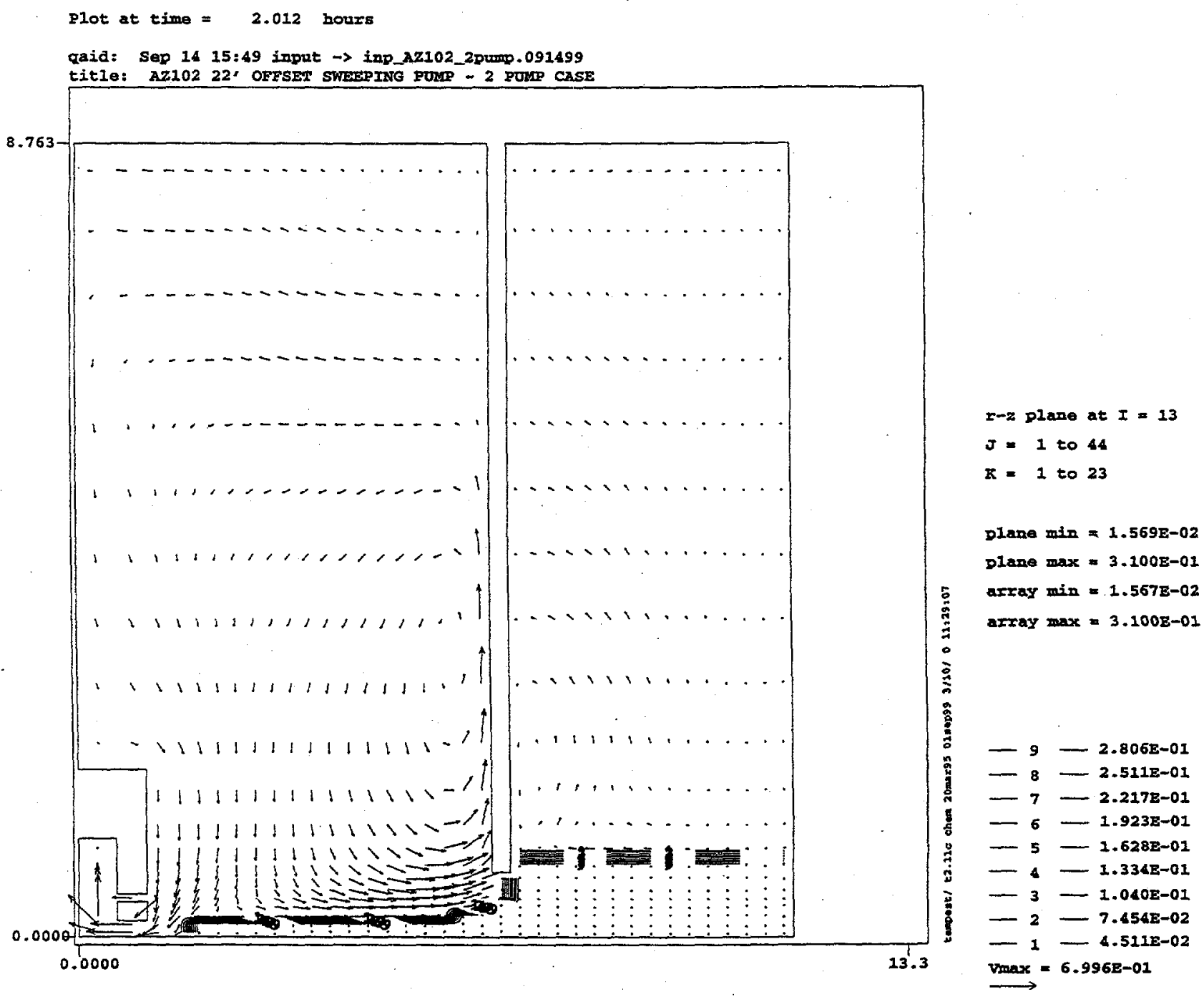

Figure 4.5. Predicted Distributions of Velocity $(\mathrm{m} / \mathrm{s})$ and Solid Concentration (volume fraction) on Vertical Plane $13\left(99^{\circ}\right.$ counter-clockwise from Vertical Plane 2) at Two Simulation Hours

- It would take approximately one to two hours to reach the final condition

- The 22 airlift circulators and steam heating coils have some impacts, but they are relatively small not significant in overall sludge erosion. 


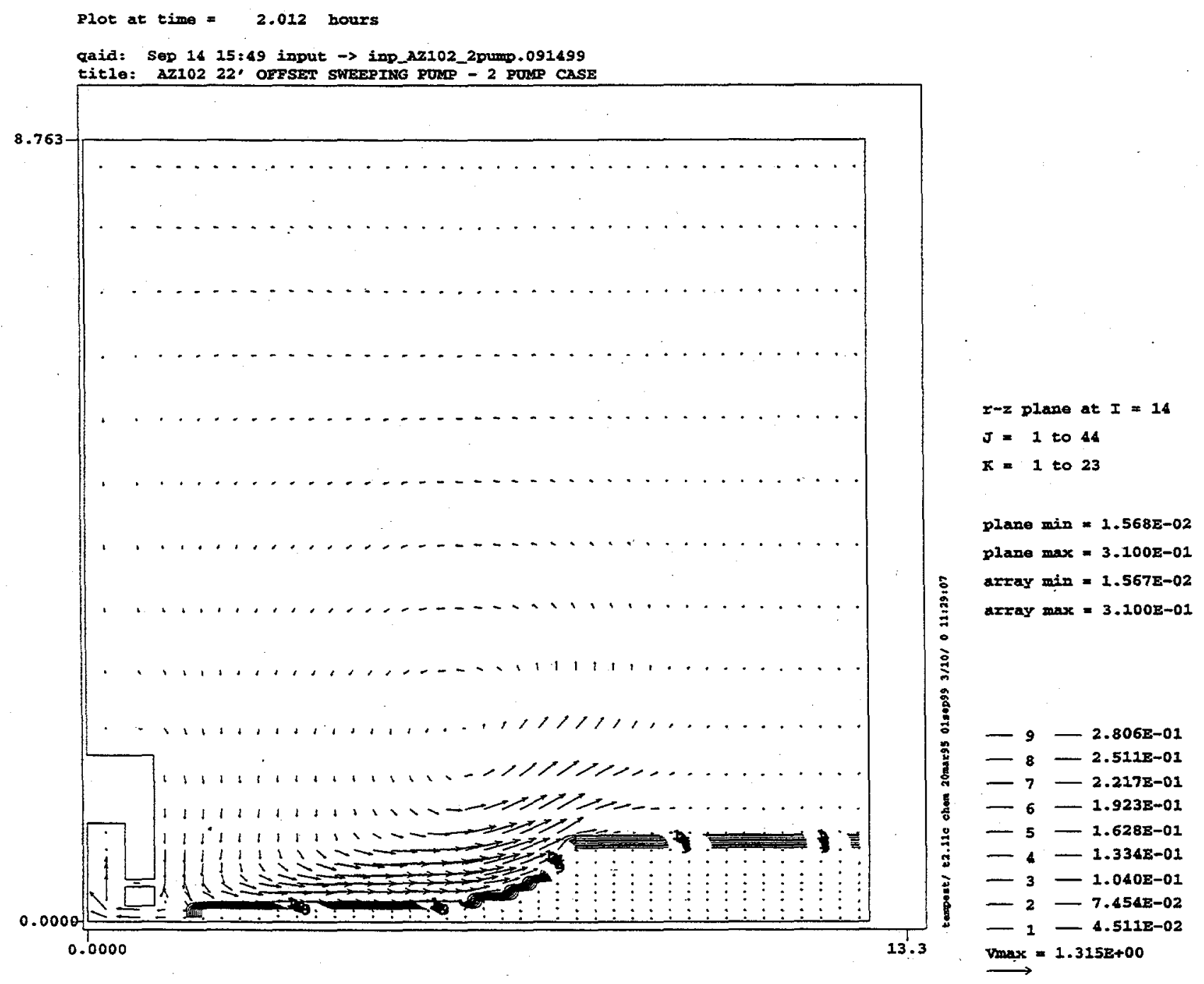

Figure 4.6. Predicted Distributions of Velocity $(\mathrm{m} / \mathrm{s})$ and Solid Concentration (volume fraction) on Vertical Plane 14 (108 counter-clockwise from Vertical Plane 2) at Two Simulation Hours 


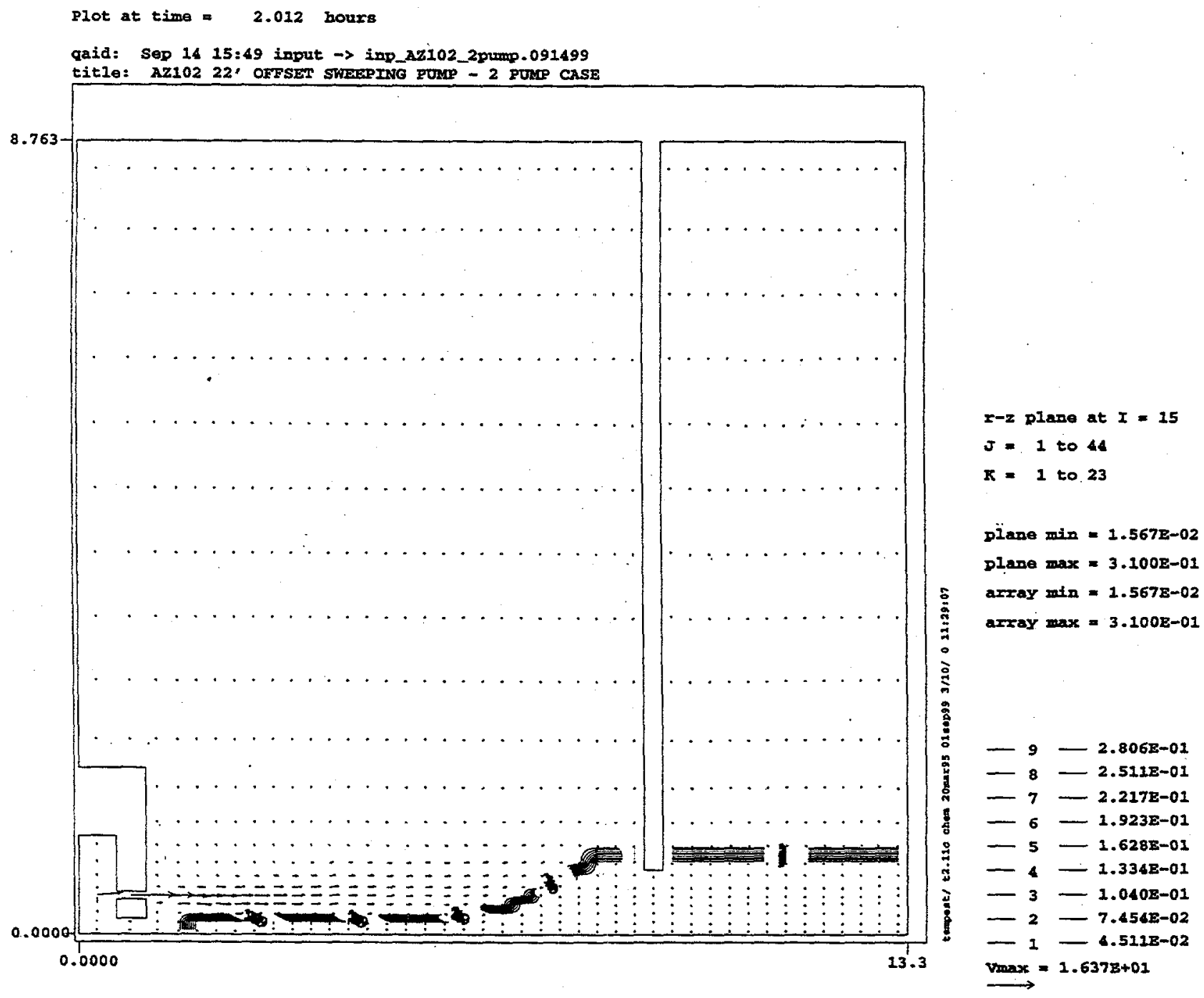

Figure 4.7. Predicted Distributions of Velocity $(\mathrm{m} / \mathrm{s})$ and Solid Concentration (volume fraction) on Vertical Plane 15 (117 counter-clockwise from Vertical Plane 2) at Two Simulation Hours 


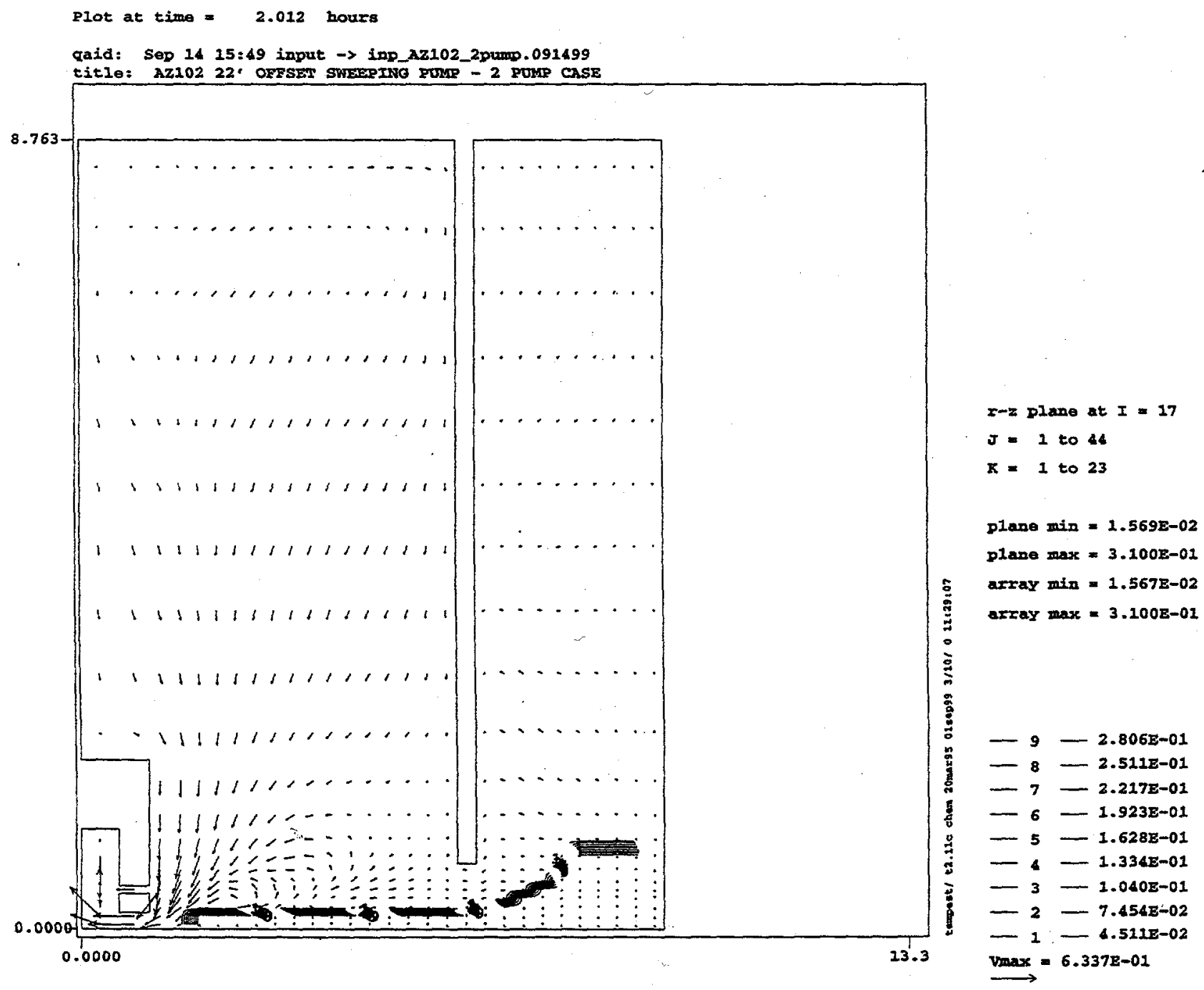

Figure 4.8. Predicted Distributions of Velocity $(\mathrm{m} / \mathrm{s})$ and Solid Concentration (volume fraction) on Vertical Plane 17 (135 counter-clockwise from Vertical Plane 2) at Two Simulation Hours 


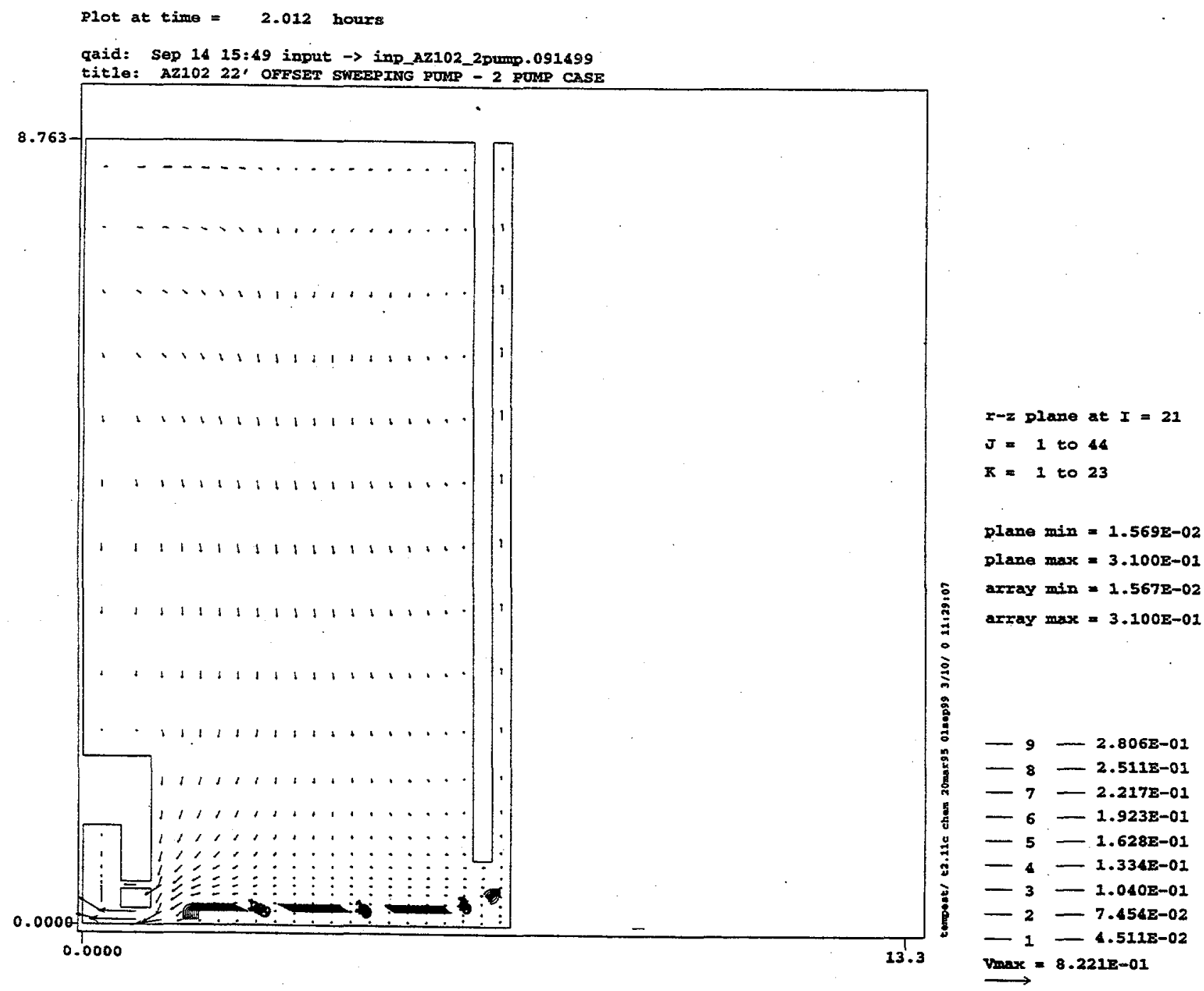

Figure 4.9. Predicted Distributions of Velocity $(\mathrm{m} / \mathrm{s})$ and Solid Concentration (volume fraction) on Vertical Plane 21 ( $171^{\circ}$ counter-clockwise from Vertical Plane 2) at Two Simulation Hours

\subsubsection{Jet Velocity Distribution}

The AZ-102 modeling predicted that two 300 -hp pumps could mobilize the sludge up to $23 \mathrm{ft}$ $(7.0 \mathrm{~m})$ away from the pump. In this section, we examine how the jet velocity changes with distance as it moves forward. As the jet penetrates into the sludge/slurry layer, it entrains the surrounding sludge and slurry (mixture of the sludge and supernatant liquid), resulting in the jet's spreading laterally and vertically and its velocity decreasing. 
There have been many experimental studies to determine how jet velocity changes with longitudinal and lateral distances for a homogeneous jet penetrating into a still fluid in infinite space (e.g., water jet injected into still water, and air jet injected into still air). These studies indicate that the velocity along the jet centerline may decrease linearly with the downstream distance, as expressed by the following nondimensional form (Wiegel 1966):

where

$$
\begin{aligned}
& V^{*}=1 \quad \text { for } \quad X^{*} \leq 6.2 \\
& \mathrm{~V}^{*}=\frac{6.2}{\mathrm{X}^{*}} \quad \text { for } \quad \mathrm{X}^{*} \geq 6.2
\end{aligned}
$$

$$
\mathrm{V}^{*}=\frac{\mathrm{V}_{\mathrm{cl}}}{\mathrm{V}_{\mathrm{o}}} \quad \text { and } \quad \mathrm{X}^{*}=\frac{\mathrm{x}}{\mathrm{D}_{\mathrm{o}}}
$$

$\mathrm{D}_{\mathrm{o}} \quad=$ nozzle diameter

$\mathrm{V}_{\mathrm{cl}} \quad=$ jet centerline velocity

$\mathrm{V}_{\mathrm{o}} \quad=$ jet exit velocity at a nozzle

$\mathrm{x}=$ downstream distance along the jet centerline

The lateral velocity distribution may be expressed by the following normal (or Gaussian) distribution (Wiegel 1966):

where

$$
\mathrm{V}=\mathrm{V}_{\mathrm{cl}} \mathrm{e}^{-77\left(\frac{\mathrm{r}}{\mathrm{x}}\right)^{2}}=\mathrm{V}_{\mathrm{cl}} \mathrm{e}^{-77\left(\frac{\mathrm{R}^{*}}{\left.\mathrm{x}^{*}\right)^{2}}\right.}
$$

$$
\mathrm{R}^{*}=\frac{\mathrm{r}}{\mathrm{D}_{\mathrm{o}}}
$$

and $r=$ the lateral distance from the jet centerline.

The TEMPEST code reproduced the velocity distribution of the homogeneous jet well (Trent and Michener 1993), as shown in Figure 4.10, which compares the predicted jet centerline velocities with the velocity distribution expressed by Equation 4.3. However, these homogeneous jet conditions are quite different from the Tank AZ-102 pump jet condition. For example, unlike the homogeneous jet case, in AZ-102

- the jet rotates at $2 \mathrm{rpm}$

- the jet density and viscosity may be different from those of surrounding sludge/slurry and supernatant liquids, at least until the waste is fully mixed

- the sludge is non-Newtonian and has yield strength 


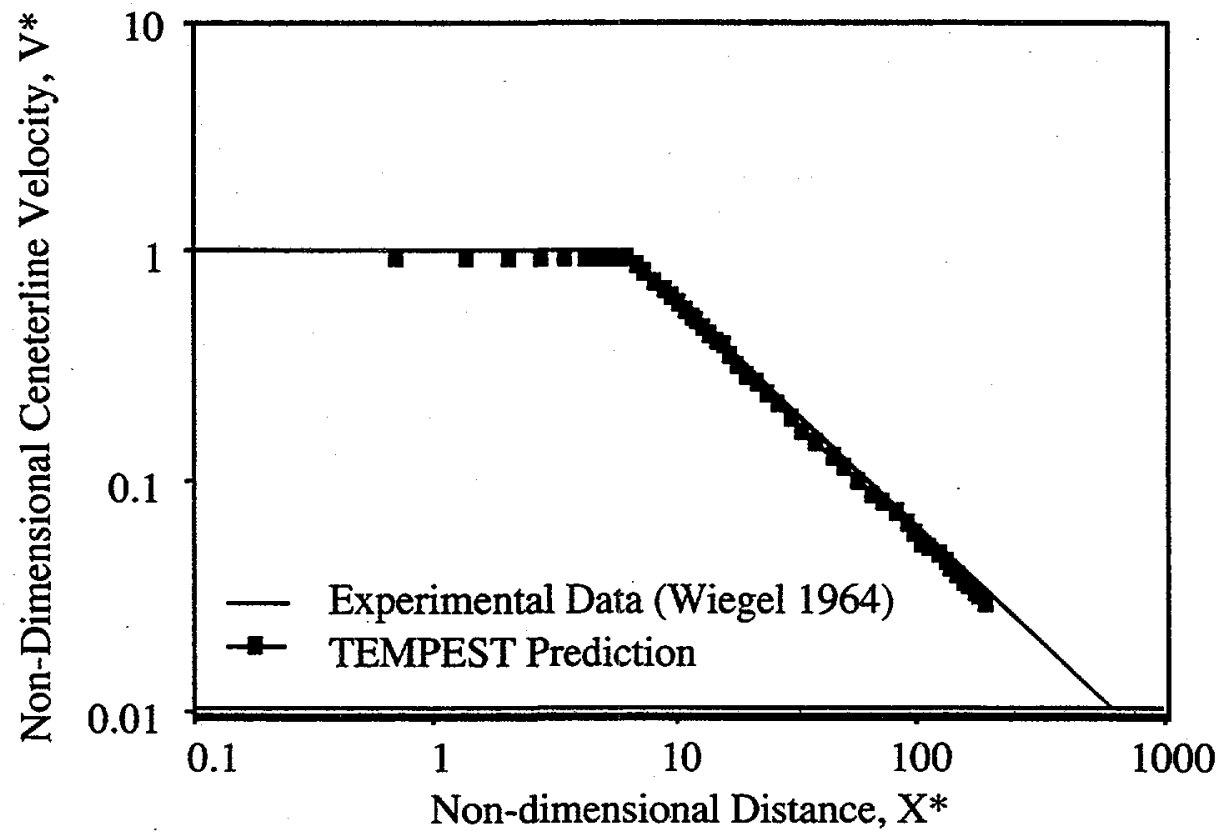

Figure 4.10. Jet Centerline Velocity and TEMPEST Prediction Compared with Measured Values for Three-Dimensional Homogeneous Jet

- the jet penetration was stopped by the non-erodible portion of the sludge

- the jet density and viscosity may vary temporally and spatially

- the jet is placed near the tank bottom and thus its spread toward the tank bottom and the non-erodible sludge is restricted

- the jets may be affected by the presence of the airlift circulators, heating coils, and the tank wall.

We examined how jet velocity changes with distance for the AZ-102 pump jet. Because the jet penetrated farthest on Vertical Plane 15 (see Figure 4.7), we used the predicted velocity on this plane at 2 hours and 42 simulation seconds for this analysis. At that time, the jets are rotating counter-clockwise, and one of them is oriented on this vertical plane. As stated previously, the distance between the pump center and the tank wall is the farthest ( $44 \mathrm{ft}$ or $13 \mathrm{~m}$ ) on Vertical Plane 15, and the jet penetrated up to $23 \mathrm{ft}(7.0 \mathrm{~m})$.

Figure 4.11 shows the predicted nondimensional centerline jet velocity, $\mathrm{V}^{*}$, with nondimensional centerline distance, $\mathrm{X}^{*}$, for the AZ-102 pump jet, together with values based on Equation 4.3. Figure 4.12 shows the dimensional values (the centerline jet velocity expressed in $\mathrm{m} / \mathrm{s}$ versus the centerline distance from the nozzle exit expressed in $\mathrm{m}$ ) for the same results. As expected, there are some similarities and differences between these two cases. Basic similarity is that the centerline jet velocity reduces its value at the rate approximately proportional to the distance from the jet exit. These figures also show that the AZ-102 jet velocity is smaller than the homogeneous jet velocity at the equal distance. Many of these differences are attributed to the seven differences of the AZ-102 case from the homogeneous case stated above. Figure 4.12 also shows that, when the penetration of the jet into the sludge was stopped at $23 \mathrm{ft}(7.0 \mathrm{~m})$, the 


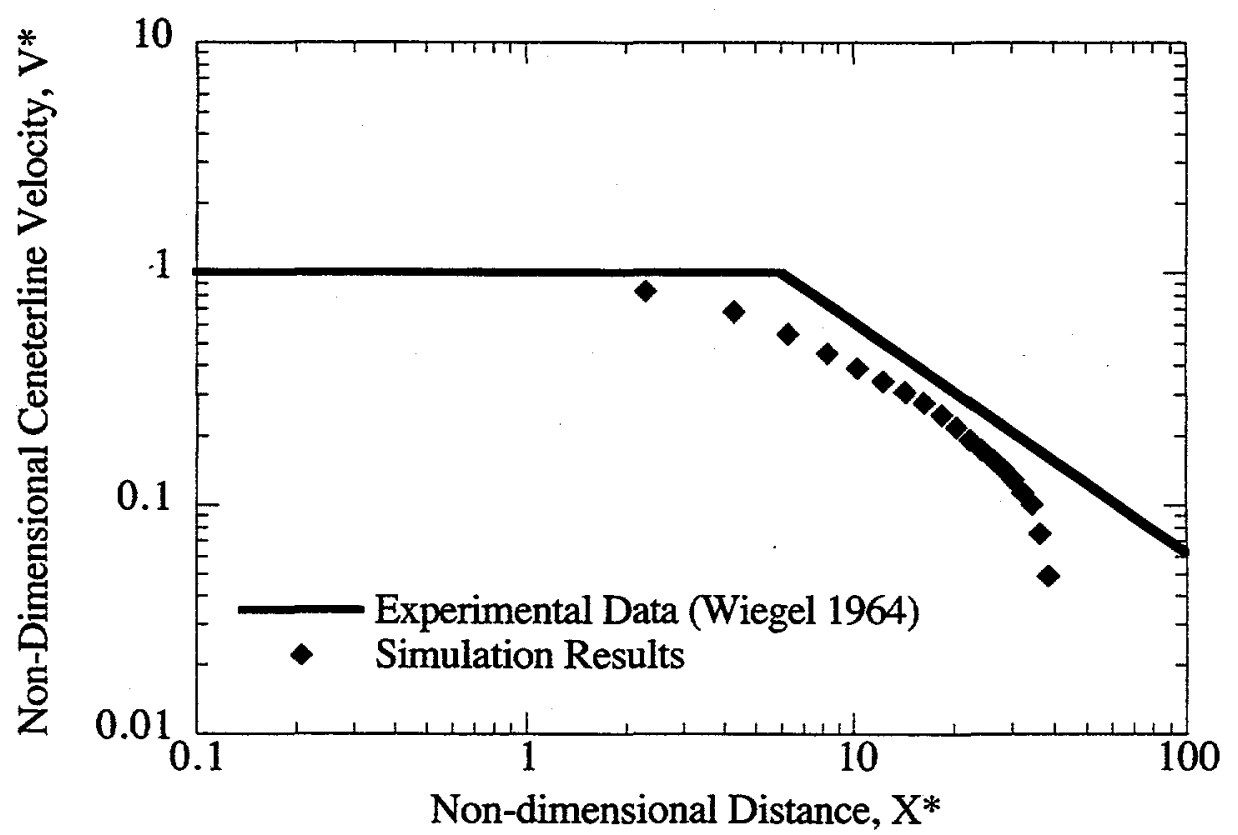

Figure 4.11. Predicted Nondimensional Jet Centerline Velocity of the AZ-102 Pump Jet, with the Homogeneous Jet Velocity Distribution

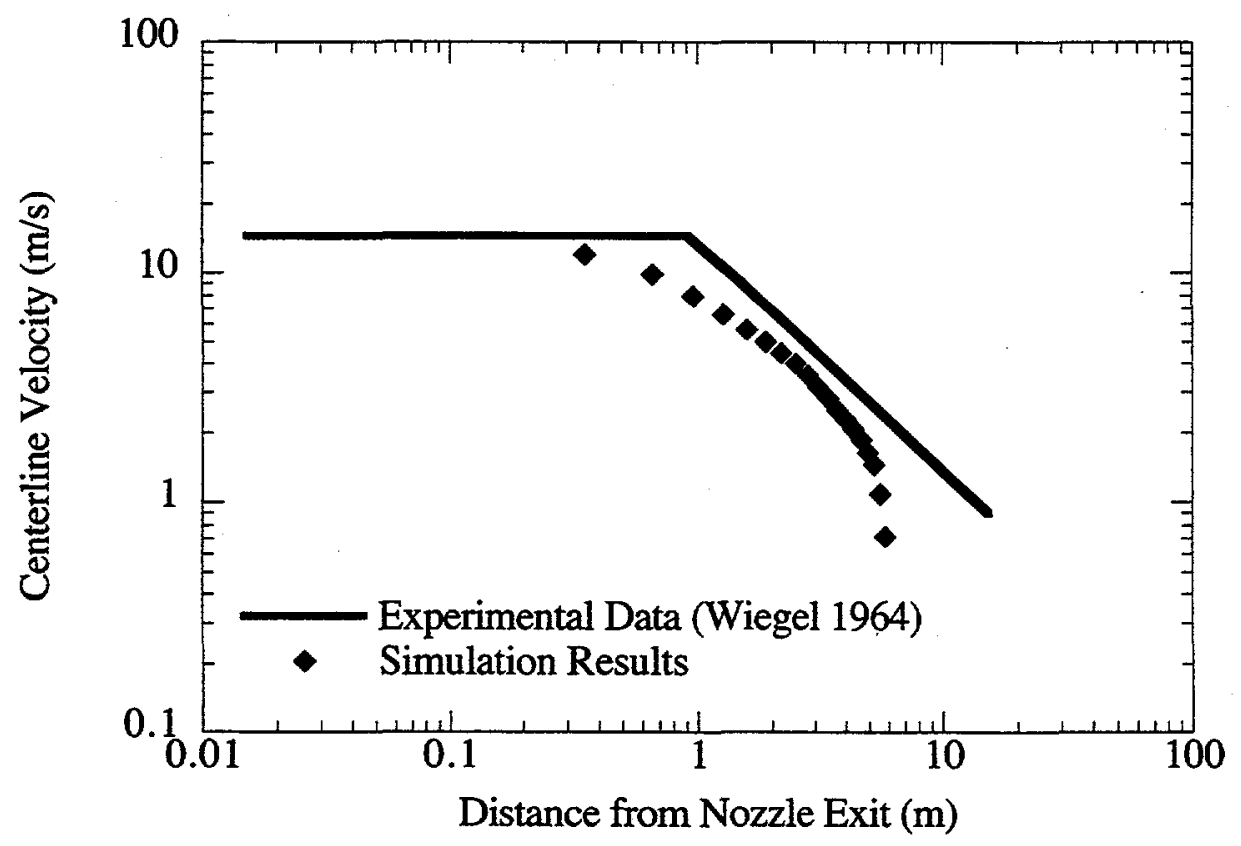

Figure 4.12. Predicted Jet Centerline Velocity $(\mathrm{m} / \mathrm{s})$ with Centerline Distance $(\mathrm{m})$ of the AZ-102 Pump Jet with Homogeneous Jet Velocity Distribution 
jet velocity was approximately $2.6 \sim 3.3 \mathrm{ft} / \mathrm{sec}(0.8 \sim 1.0 \mathrm{~m} / \mathrm{s})$, indicating that this magnitude of the jet velocity is needed to erode sludge that has a $1,540 \mathrm{~Pa}$ yield strength.

We selected jet velocities at $5 \mathrm{ft}(1.6 \mathrm{~m}), 10 \mathrm{ft}(3.1 \mathrm{~m})$, and $15 \mathrm{ft}(4.6 \mathrm{~m})$ from the pump nozzle exit to examine the lateral distributions of the longitudinal jet velocity. These distances correspond to $8.9 \mathrm{ft}(2.7 \mathrm{~m}), 13.8 \mathrm{ft}(4.2 \mathrm{~m})$, and $18.7 \mathrm{ft}(5.7 \mathrm{~m})$ from the pump center. As stated above, the jet was oriented along Vertical Plane 15 at 2 hours and 42 simulation seconds. The jet, rotating at $2 \mathrm{rpm}$, was on Vertical Planes 13 and 14 only 6 and 3 simulation seconds ago. For Vertical Planes 13 and 14, we used the velocity components parallel to the longitudinal velocity on Vertical Plane 15. Using these velocity values, the nondimensional lateral distributions of longitudinal jet velocity on the right half of the jet is presented in Figure 4.13. The corresponding dimensional values (longitudinal velocity expressed in $\mathrm{m} / \mathrm{s}$ versus lateral distance from the centerline expressed in $\mathrm{m}$ ) are presented in Figure 4.14. These figures also show the experimental velocity distributions of the homogeneous jet (Equation 4.4). The thick solid lines are AZ-102 jet values; the thin solid lines show the measured homogeneous velocity values.

Comparing these two cases indicates that the longitudinal velocity of the AZ-102 jet away from the jet centerline was much greater than those of the homogeneous jet, especially $13.8 \mathrm{ft}$ $(4.2 \mathrm{~m})$ and $18.7 \mathrm{ft}(6.7 \mathrm{~m})$ from the pump exit, reflecting the seven differences of AZ-102 from the homogeneous case. This point is also confirmed by the fact that the AZ-102 centerline jet velocity was less than the homogeneous jet velocity. The AZ-102 jet should spread more.

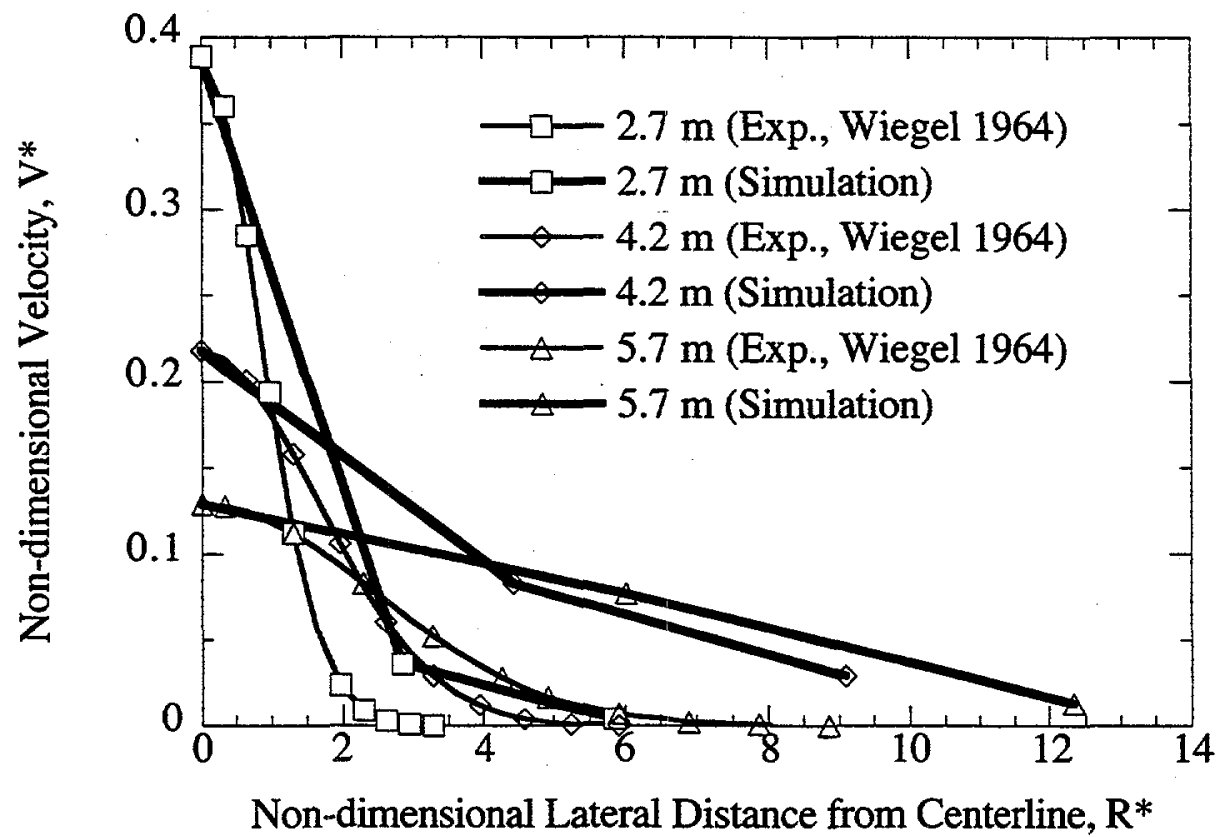

Figure 4.13. Predicted Lateral Distribution of Nondimensional Longitudinal Velocity for the AZ-102 Pump Jet with the Homogeneous Jet Velocity Distribution 


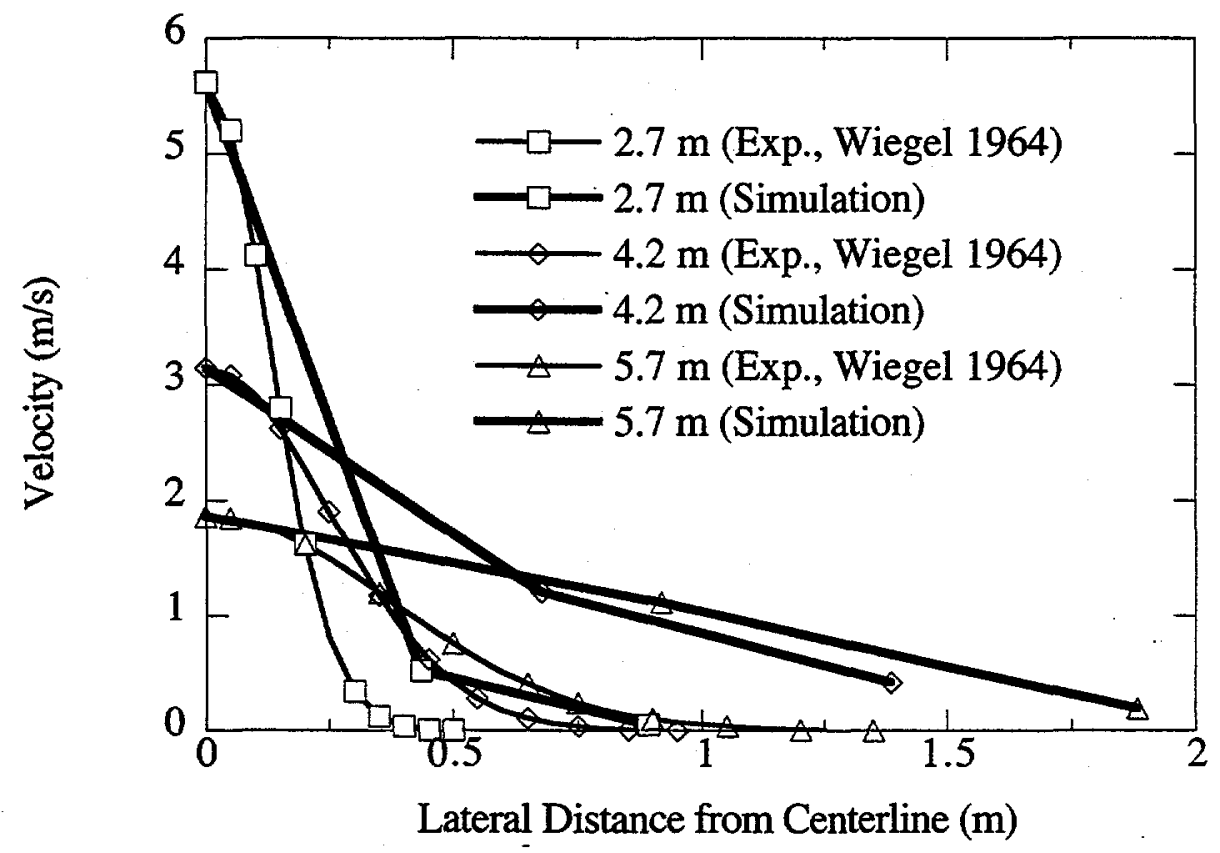

Figure 4.14. Predicted Lateral Distribution of Longitudinal Velocity with Lateral Distance for AZ-102 Pump Jet with Homogeneous Jet Velocity Distribution

At $8.9 \mathrm{ft}(2.7 \mathrm{~m})$, the velocity difference between the AZ-102 jet and the homogeneous jet is relatively small, indicating that the jet rotated away only three seconds ago mostly dies out. Its velocity there was reduced from a peak $18.7 \mathrm{ft} / \mathrm{sec}(5.7 \mathrm{~m} / \mathrm{s})$ to $2.0 \mathrm{ft} / \mathrm{sec}(0.6 \mathrm{~m} / \mathrm{s})$ in three seconds. The jet rotated away six seconds ago dies out totally near the pump. However, $8.9 \mathrm{ft}$ $(2.7 \mathrm{~m}), 13.8 \mathrm{ft}(4.2 \mathrm{~m})$, and $18.7 \mathrm{ft}(5.7 \mathrm{~m})$ from the pump, the jet velocities at lateral distances of $1.3 \mathrm{ft}(0.4 \mathrm{~m}), 2.6 \mathrm{ft}(0.8 \mathrm{~m})$, and $3 \mathrm{ft}(1.0 \mathrm{~m})$ are still enough to erode the sludge there because the velocity of the jet rotating away from these locations is still greater than $3 \mathrm{ft} / \mathrm{sec}(1 \mathrm{~m} / \mathrm{s})$.

The edge of the AZ-102 jet was roughly $2 \mathrm{ft}(0.6 \mathrm{~m}), 6 \mathrm{ft}(1.8 \mathrm{~m})$, and more than $7 \mathrm{ft}(2 \mathrm{~m})$ at $8.9 \mathrm{ft}(2.7 \mathrm{~m}), 13.8 \mathrm{ft}(4.2 \mathrm{~m})$, and $18.7 \mathrm{ft}(5.7 \mathrm{~m})$, respectively, from the pump, according to Figures 4.13 and 4.14 . These values are much larger than the homogeneous jet's $1.3 \mathrm{ft}(0.4 \mathrm{~m}), 2$ $\mathrm{ft}(0.7 \mathrm{~m})$, and $3 \mathrm{ft}(0.9 \mathrm{~m})$ widths.

\subsection{Alternative Pump Jet Mixing Approaches}

The AZ-102 pump jet mixing evaluation reported in Section 4.1 indicated that two 300-hp pumps would mobilize half of the AZ-102 sludge because the sludge has a strong yield strength of $1,540 \mathrm{~Pa}$. We examined alternative approaches that may mobilize most of the sludge using the same two pumps.

Solids dissolution experiments showed that a pretreatment process being considered for the AZ-102 waste could dissolve about half of the solids and, by doing so, reduce the original sludge 
yield strength significantly. ${ }^{(a, b)}$ The waste will undergo the pretreatment process prior to the treatment (solidification) required for its eventual disposal.

The specific pretreatment procedure (sludge washing) tested for the AZ-102 waste involved the following six steps:

- Add ferric nitrate to the AZ-102 sludge

- Add water to this AZ-102 sludge at 3:1 (water to sludge) volume ratio

- Mix them and decant

- Add water to the remaining sludge at 3:1 (water to sludge) volume ratio

- Mix them and decant

- Add sodium hydroxide (to obtain a concentration of $0.04 \mathrm{M}$ ) and sodium nitrate (to obtain a concentration of $0.04 \mathrm{M}$ ) to the remaining sludge.

The resulting mixture had the remaining sludge (washed sludge) and standing supernatant liquid at 2:1 volume ratio. This mixture had only half of the original solids amount and half of the radionuclides originally present in the AZ-102 sludge. On average, this mixture had a yield strength of $0.53 \mathrm{~Pa}$ and a viscosity of $105 \mathrm{cP}^{(\mathrm{a}, \mathrm{b})}$ This liquid was mostly water, so its density and viscosity are expected to be around $1,000 \mathrm{~kg} / \mathrm{m}^{3}$ and $1 \mathrm{cP}$, respectively. Note that the original AZ-102 sludge has a yield strength of $1,540 \mathrm{~Pa}$.

The pretreatment study indicates that the diluent (a mixture of water, ferric nitrate, sodium nitrite, and sodium hydroxide) could reduce the sludge yield strength by dissolving half the original AZ-102 solids. Equation 4.1 expresses the change in slurry viscosity with solids concentration. The alternative approach assessment in this study was thus conducted by assuming that this diluent would dissolve half of the AZ-102 sludge and would reduce the yield strength and viscosity of the washed AZ-102 sludge. The validity of this assumption could be tested in the laboratory. The current study did not address chemical reaction processes of solids dissolution by the diluent, but it used the solids dissolution effects on sludge rheology to assess the effectiveness of the two 300-hp pumps to mix the significantly weakened sludge in Tank AZ-102.

We did not have measured values of the yield strength and viscosity of the washed AZ-102 sludge without a standing supernatant liquid on it. We used the following sets of rheology measurements ${ }^{(a, b)}$ to select appropriate values of yield strength and viscosity for the washed sludge:

- The mixture of the AZ-102 sludge and the pretreatment diluent has a yield strength of $0.53 \mathrm{~Pa}$ and viscosity of $105 \mathrm{cP}$

(a) Gray WJ, ME Peterson, RD Scheele, and JM Tingey. 1993. "Characterization of the First Core Sample of Neutralized Current Acid Waste from Double-Shell Tank AZ-102." Unpublished report, Pacific Northwest Laboratory, Richland, Washington.

(b) Morrey EV and JM Tingey. 1995. "Comparison of Simulants to Actual Neutralized Current Acid Waste: Process and Product Testing of Three NCAW Core Samples from Tank 101-AZ and 102-AZ." C95-02.03E, unpublished report, Pacific Northwest Laboratory, Richland, Washington. 
- A slurry mixture consisting of $40 \mathrm{vol} \%$ original AZ-102 sludge and $60 \mathrm{vol} \%$ original AZ-102 supernatant liquid has a yield strength of $2.07 \mathrm{~Pa}$; its viscosity measures $426 \mathrm{cP}$

- A slurry mixture consisting of $10 \mathrm{vol} \%$ original AZ-102 sludge and $90 \mathrm{vol} \%$ original AZ-102 supernatant liquid does not have yield strength; its viscosity is about $7 \mathrm{cP}$.

Based on this information and consultation with PNNL staff who conducted these measurements, we selected a yield strength of $1.2 \mathrm{~Pa}$ and a viscosity of $270 \mathrm{cP}$ for the washed sludge.

It is interesting to note that the washed sludge has an average solids diameter of $4.2 \mu \mathrm{m}$, while the original AZ-102 sludge has a average particle size of $3.4 \mu \mathrm{m}$. Thus, even though half of the original AZ-102 solids were dissolved by this pretreatment (washing) process, overall solid sizes did not change much. Using $4.3 \mu \mathrm{m}$ for the average solids size, we evaluated the following two alternative approaches to enhance mixing with the two 300 -hp pumps.

\subsubsection{Approach 1: Three-Step Approach}

Step 1: Pump out the original AZ-102 supernatant liquid only

Step 2: Add the diluent (the mixture of water, ferric nitrate, sodium nitrite, and sodium hydroxide) to AZ-102 Tank at 6:1 diluent to sludge volume ratio

Step 3: Mix the diluent-washed, weakened, and reduced amount of AZ-102 sludge with the diluent using two 300 -hp mixer pumps.

To evaluate this approach, we examined the following three cases (Cases 1 through 3). All three cases assumed that the sludge yield strength was reduced to $1.2 \mathrm{~Pa}$ as a result of solids dissolution. Initial conditions were the following:

Case 1: Half the original solids were assumed dissolved before pump mixing, but the sludge thickness of $35 \mathrm{in} .(0.89 \mathrm{~m})$ was not reduced. Instead, the solid volume fraction within the sludge was reduced to $15.5 \mathrm{vol} \%$, half the original $31 \mathrm{vol} \%$.

Case 2: Half the original solids were assumed dissolved before pump mixing, and their sludge thickness was reduced to $17.5 \mathrm{in}$. $(0.45 \mathrm{~m})$, half the original sludge thickness of 35 in. $(0.89 \mathrm{~m})$. The washed solids volume fraction is $31 \mathrm{vol} \%$ in the reduced sludge layer.

Case 3: Yield strength was reduced to $1.2 \mathrm{~Pa}$, but the original solids amount was not reduced. Thus the washed solid layer thickness is still $35 \mathrm{in} .(0.89 \mathrm{~m})$, and its volume fraction in the sludge layer is $31 \mathrm{vol} \%$. This is the most conservative of the three cases. 


\subsubsection{Approach 2: Four-Step Approach}

Step 1: Mix the original AZ-102 sludge and supernatant liquid using two 300-hp pumps.

Step 2: Pump the resulting AZ-102 slurry from the tank

Step 3: Add the diluent (mixture of water, ferric nitrate, sodium nitrite, and sodium hydroxide) to $\mathrm{AZ}-102$ at 6:1 diluent to remaining sludge volume ratio

Step 4: Mix the remaining diluent-washed, weakened, and reduced amount of AZ-102 sludge and the diluent using two 300 -hp mixer pumps.

Alternative Approach 2 was evaluated as Case 4. This case has the following initial conditions:

Case 4: The yield strength was reduced to $1.2 \mathrm{~Pa}$ as a result of solids dissolution. The remaining sludge thickness was further reduced by half to be 8.8 inches $(0.22 \mathrm{~m})$, $25 \%$ of the original sludge thickness of 34.5 inches $(0.89 \mathrm{~m})$. The solids volume fraction was kept at 31 vol\%.

For all four cases, we assumed that all the solids were settled on the tank bottom at the beginning of the simulation.

\subsubsection{Alternative Approach Evaluation Results}

We ran the TEMPEST code to simulate these four cases for two simulation hours to determine how much sludge would be mobilized and how well it would be mixed by the two 300-hp mixer pumps with its yield strength significantly reduced by sludge washing. The simulations indicated that the final mixing conditions were achieved in less than two simulation hours for all four cases. The results shown here, at 2 hours and 42 simulation seconds, show one of the rotating jets orienting itself to the farthest tank wall within the half-tank simulated region.

\section{Case 1}

The pump jet mixing simulation results for Case 1 show that all the solids were eroded by the rotating jets and were fully mixed within the tank by two simulation hours. This is clearly shown in Figures 4.15 through 4.17, presenting predicted distributions of the velocity and solid concentrations at Vertical Plane $14\left(108^{\circ}\right.$ from Vertical Plane 2$), 15\left(117^{\circ}\right.$ from Vertical Plane 2 ), and $17\left(135^{\circ}\right.$ from Vertical Plane 2$)$, respectively. As noted previously, the jets must travel the longest distance $(44 \mathrm{ft}$ or $13 \mathrm{~m})$ to reach the tank wall along Vertical Plane $15\left(117^{\circ}\right.$ from Vertical Plane 2). As shown in Figures 4.16 and 4.17, the airlift circulators and heating coils did not deter the rotating jets from mobilizing the weakened sludge.

Comparing these figures with their corresponding figures for the original sludge (having 1,540 Pa yield strength) (Figures 4.6 through 4.8), the benefits of reducing the yield strength of the sludge by washing it with the diluent are obvious. Solids concentrations for Case 1 are very uniform throughout the tank, varying only from 2.18 to 2.19 vol\% (or 99\% uniformity). 


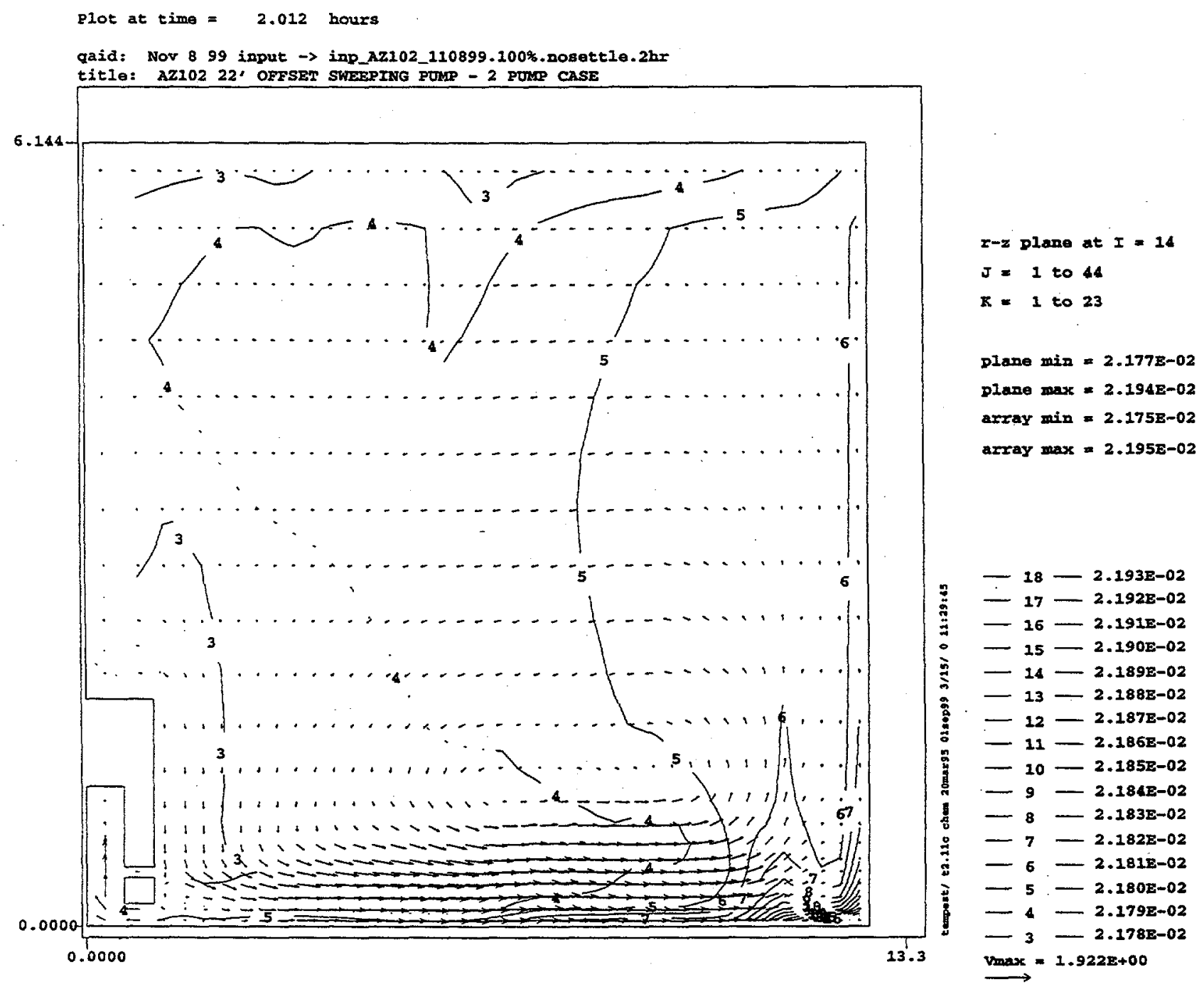

Figure 4.15. Predicted Distributions of Velocity $(\mathrm{m} / \mathrm{s}$ ) and Solid Concentration (volume fraction) on Vertical Plane $14\left(108^{\circ}\right.$ counter-clockwise from Vertical Plane 2) at Two Simulation Hours for Case 1 


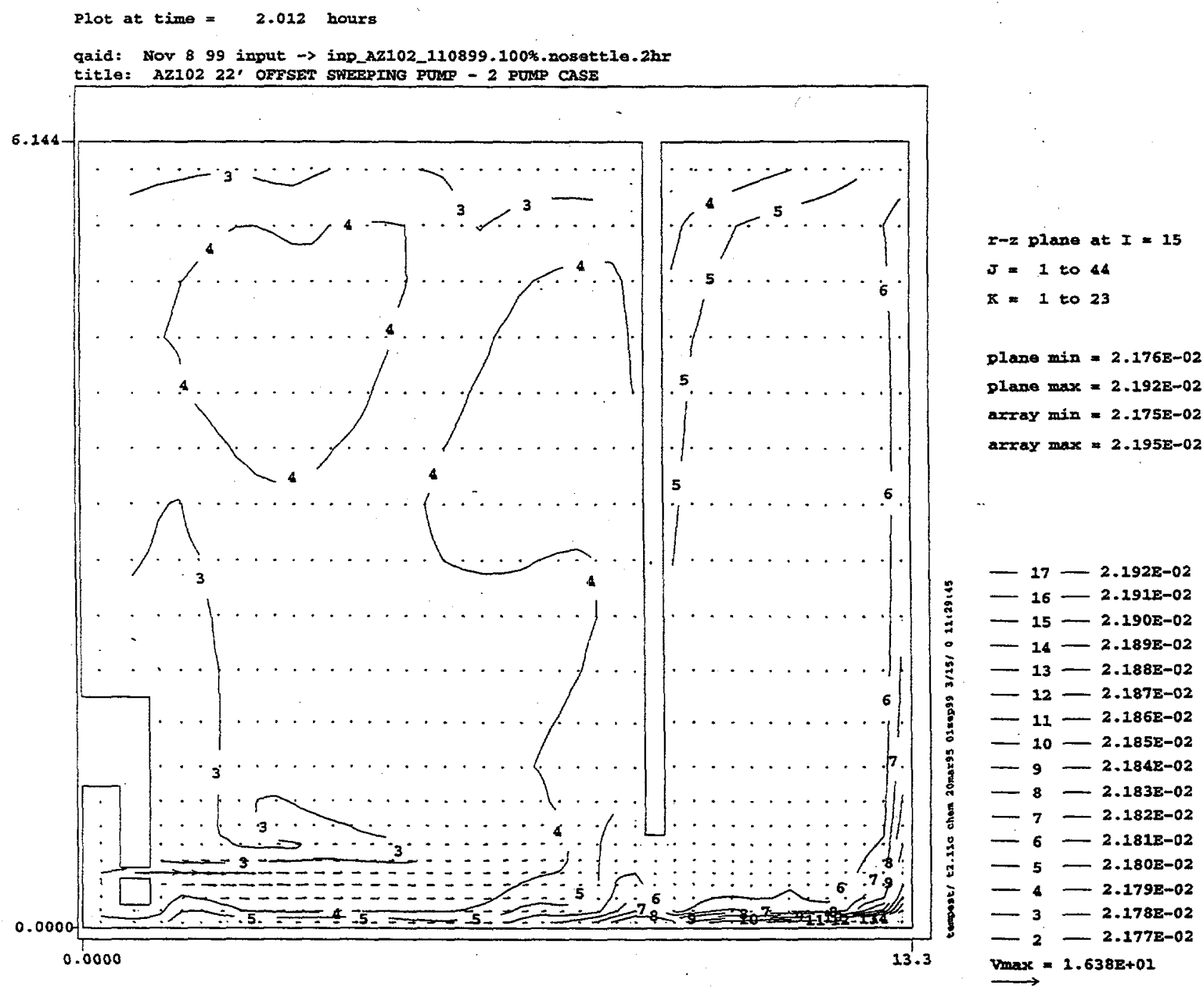

Figure 4.16. Predicted Distributions of Velocity $(\mathrm{m} / \mathrm{s})$ and Solid Concentration (volume fraction) on Vertical Plane 15 (117 counter-clockwise from Vertical Plane 2) at Two Simulation Hours for Case 1 


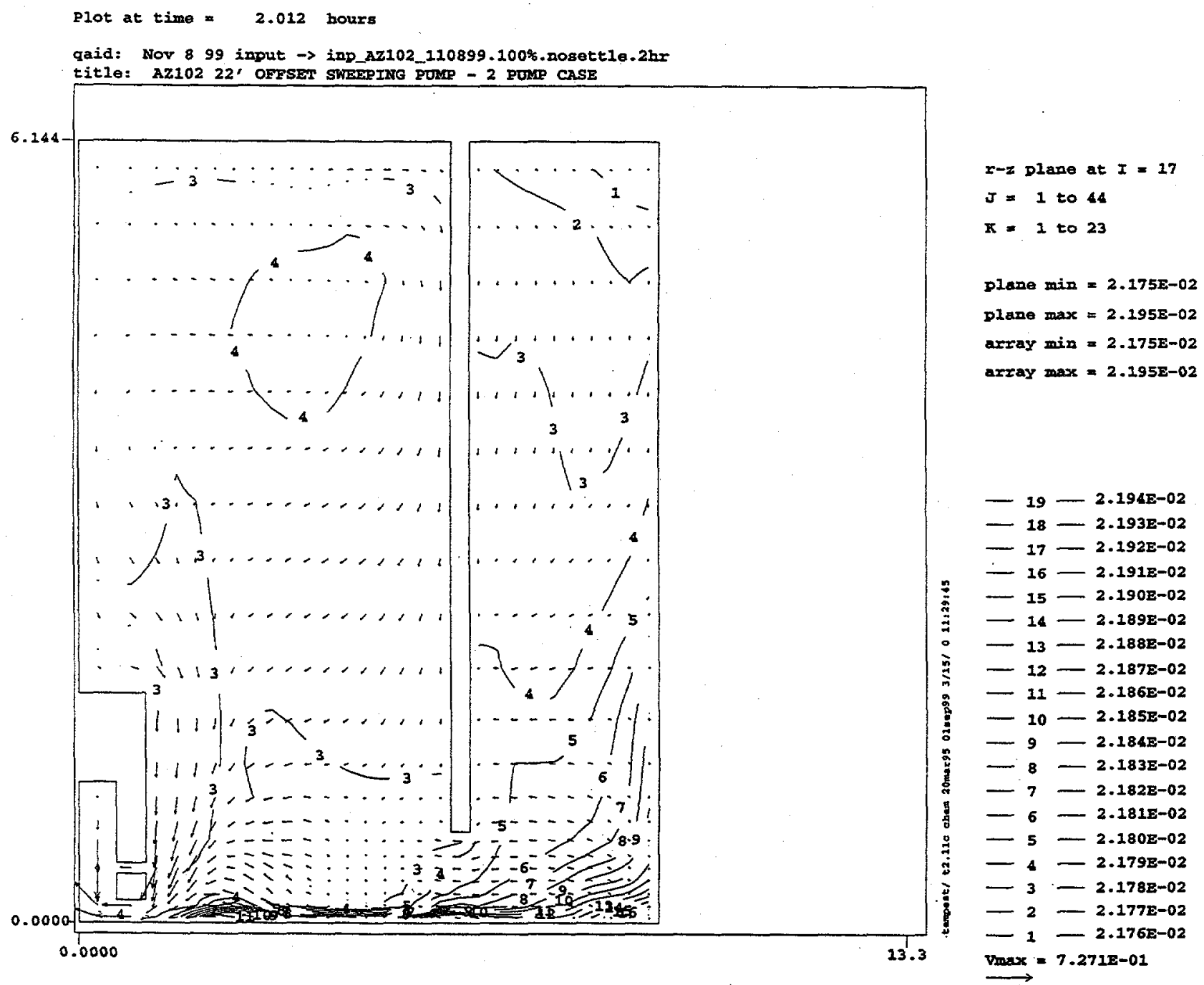

Figure 4.17. Predicted Distributions of Velocity $(\mathrm{m} / \mathrm{s})$ and Solid Concentration (volume fraction) on Vertical Plane $17\left(135^{\circ}\right.$ counter-clockwise from Vertical Plane 2) at Two Simulation Hours for Case 1

\section{Case 2}

The modeling for case 2 also indicated that all the solids were eroded from the tank bottom by the 300-hp pumps and the resulting suspended solids were homogeneously mixed throughout the tank. Figures 4.18 through 4.20 show predicted distributions of the velocity and solids concentrations at Vertical Planes 14, 15, and 17, respectively, indicating that the suspended solids concentrations are from 2.54 to $2.56 \mathrm{vol} \%$. 


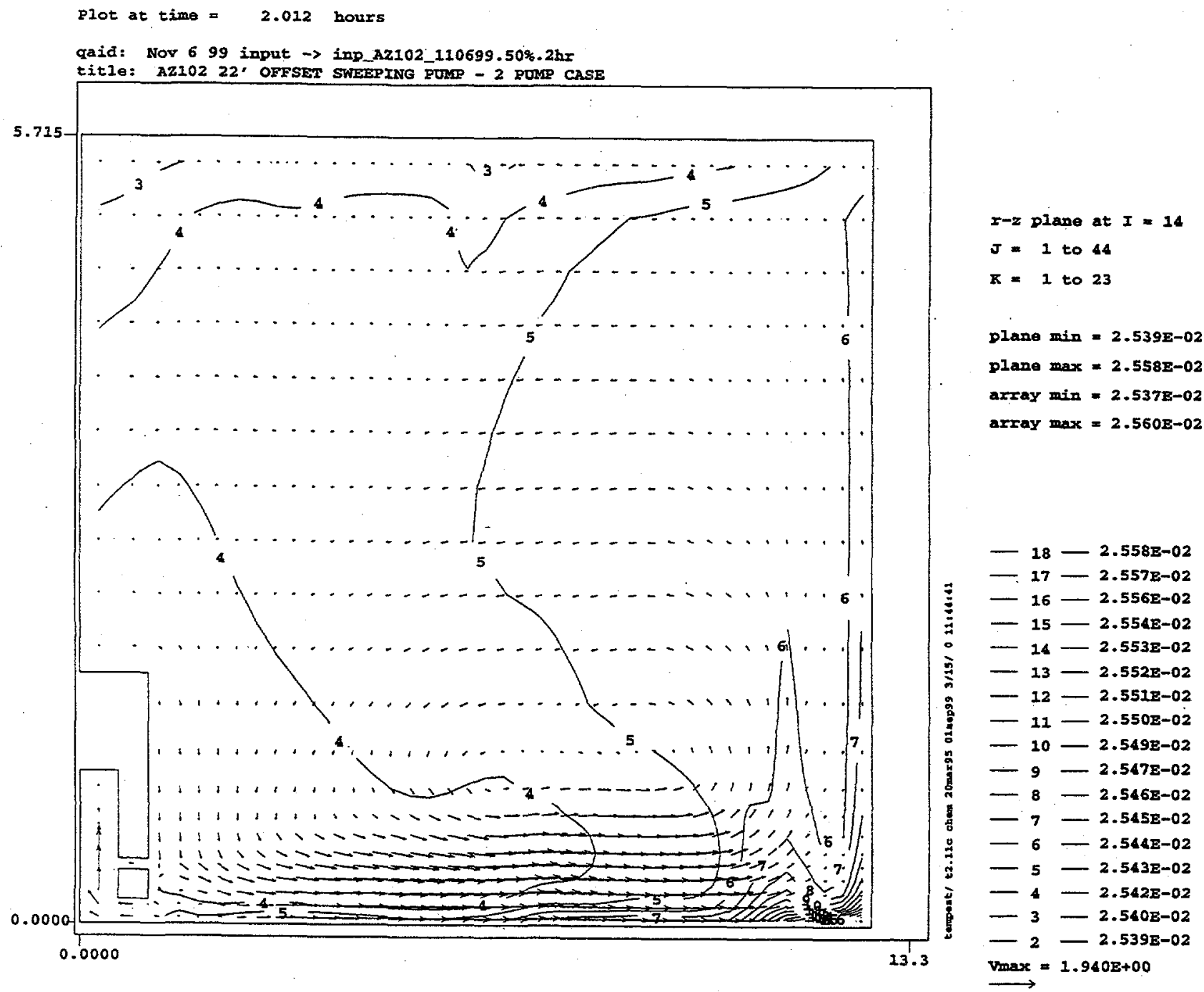

Figure 4.18. Predicted Distributions of Velocity $(\mathrm{m} / \mathrm{s})$ and Solid Concentration (volume fraction) on Vertical Plane 14 ( $108^{\circ}$ counter-clockwise from Vertical Plane 2) at Two Simulation Hours for Case 2 


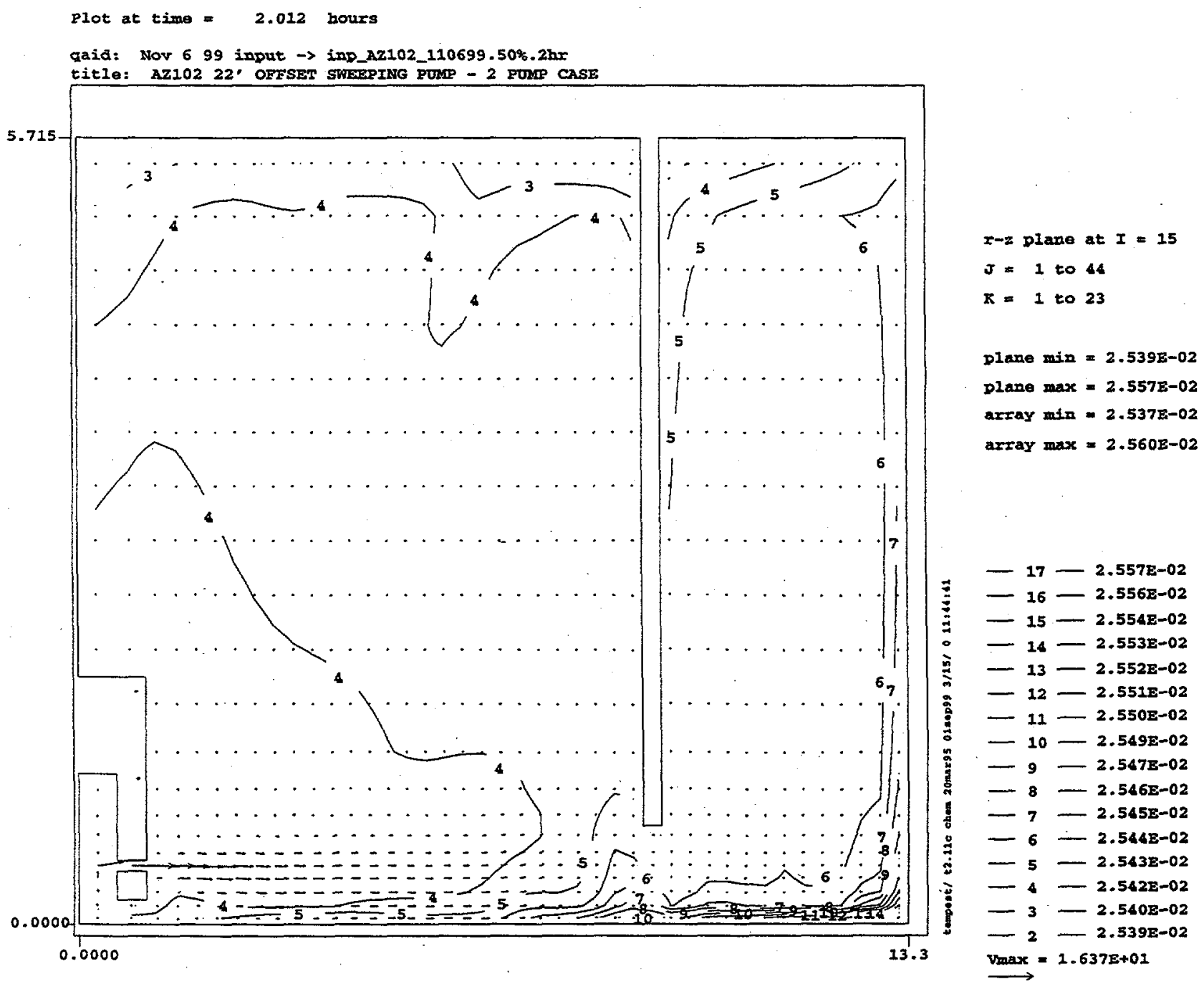

Figure 4.19. Predicted Distributions of Velocity $(\mathrm{m} / \mathrm{s})$ and Solid Concentration (volume fraction) on Vertical Plane 15 ( $117^{\circ}$ counter-clockwise from Vertical Plane 2) at Two Simulation Hours for Case 2 


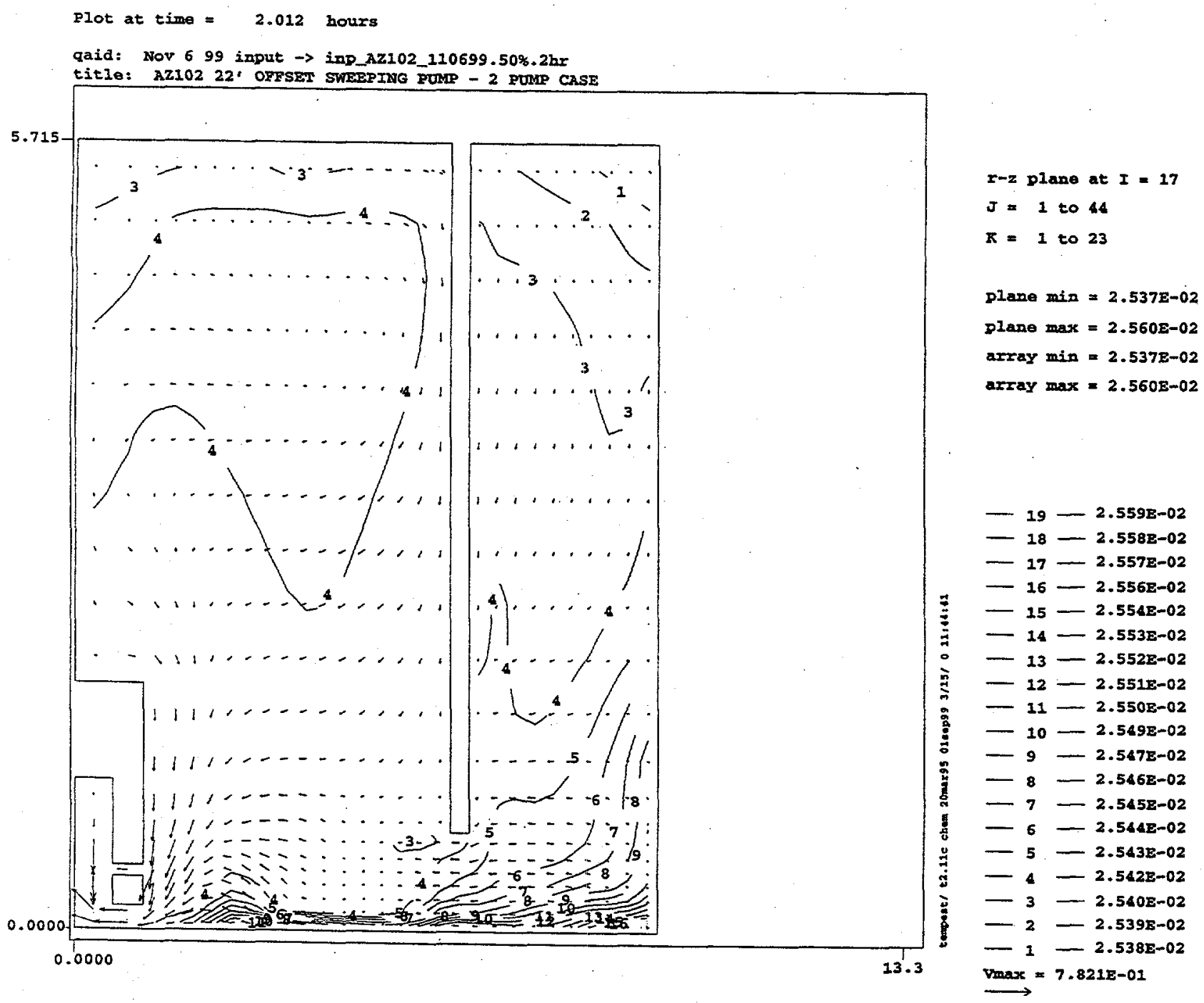

Figure 4.20. Predicted Distributions of Velocity $(\mathrm{m} / \mathrm{s}$ ) and Solid Concentration (volume fraction) on Vertical Plane $17\left(135^{\circ}\right.$ counter-clockwise from Vertical Plane 2) at Two Simulation Hours for Case 2

\section{Case 3}

Even for the most conservative Case 3 , the modeling indicated that all the sludge was eroded from the tank bottom and was fully mixed throughout the tank. This is shown in Figures 4.21 through 4.23 for predicted velocities and solid distributions on Vertical Planes 14, 15, and 17. In this case, the suspended solid concentration varies from 4.35 to 4.38 vol\%. The solids concentrations are twice as high as in Cases 1 and 2 because Case 3 did not reduce the total amount of $\mathrm{AZ}-102$ solids due to solids dissolution. 


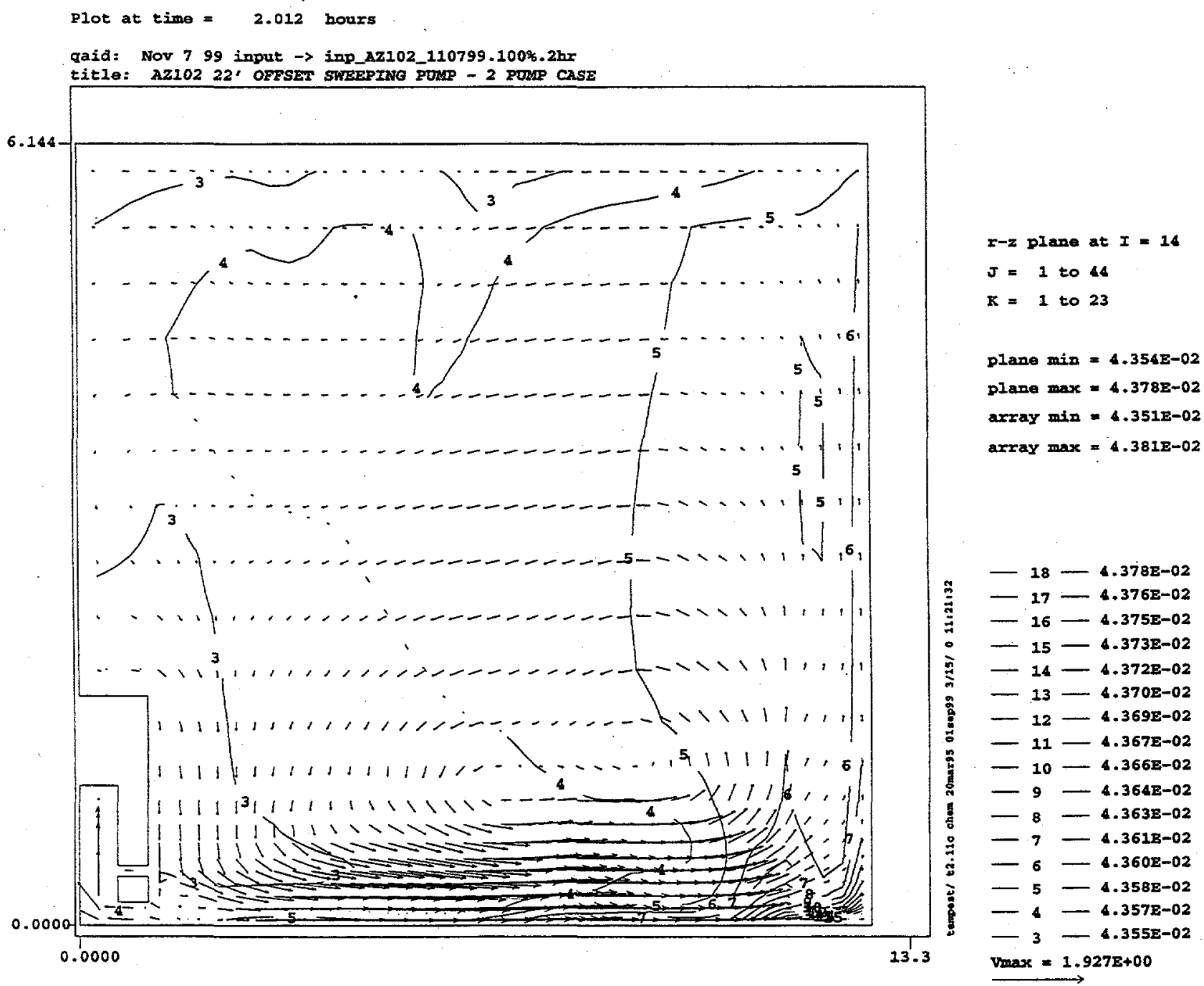

Figure 4.21. Predicted Distributions of Velocity $(\mathrm{m} / \mathrm{s}$ ) and Solid Concentration (volume fraction) on Vertical Plane 14 (108 ${ }^{\circ}$ counter-clockwise from Vertical Plane 2) at Two Simulation Hours for Case 3 


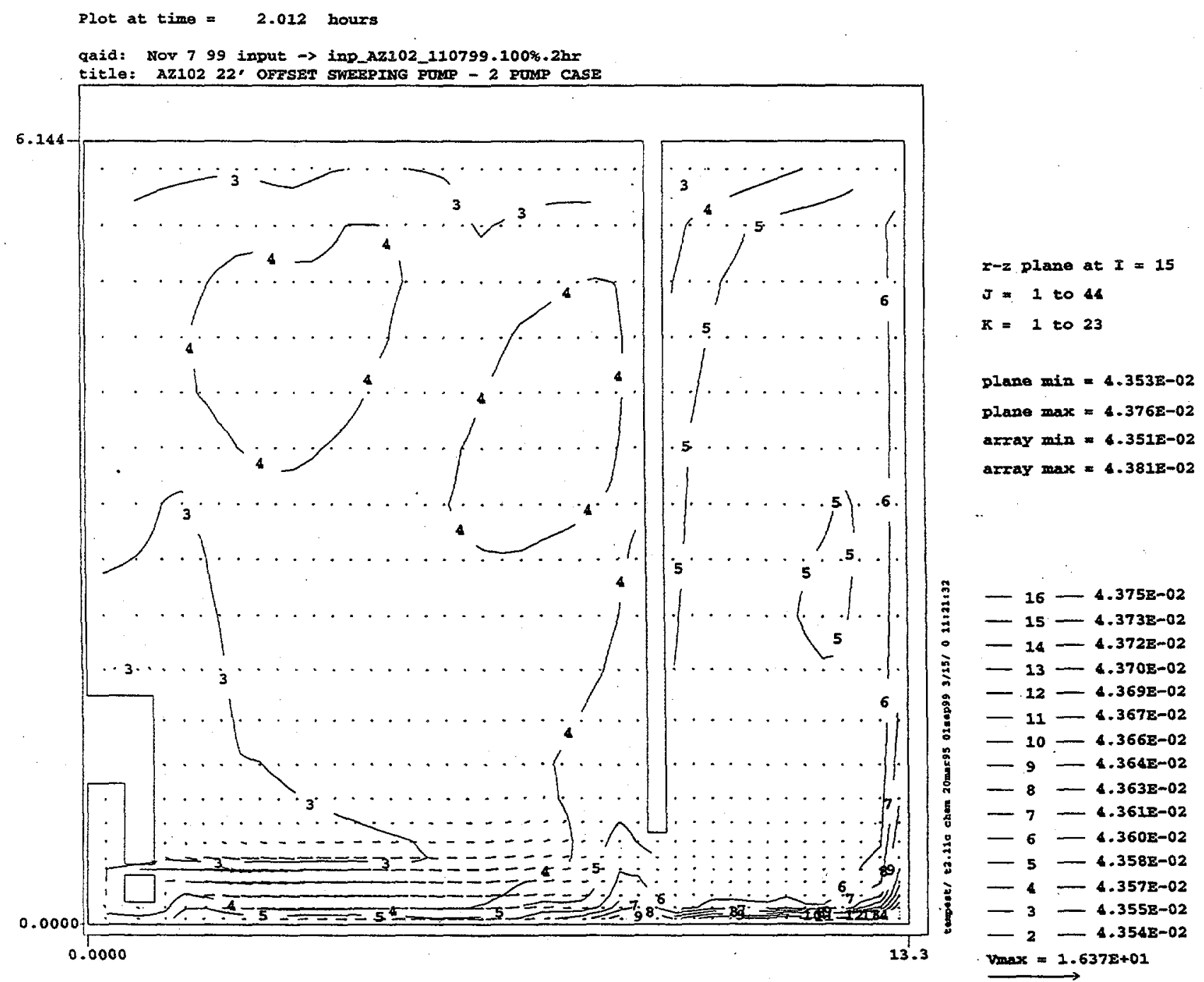

Figure 4.22. Predicted Distributions of Velocity $(\mathrm{m} / \mathrm{s})$ and Solid Concentration (volume fraction) on Vertical Plane 15 ( $117^{\circ}$ counter-clockwise from Vertical Plane 2) at Two Simulation Hours for Case 3 


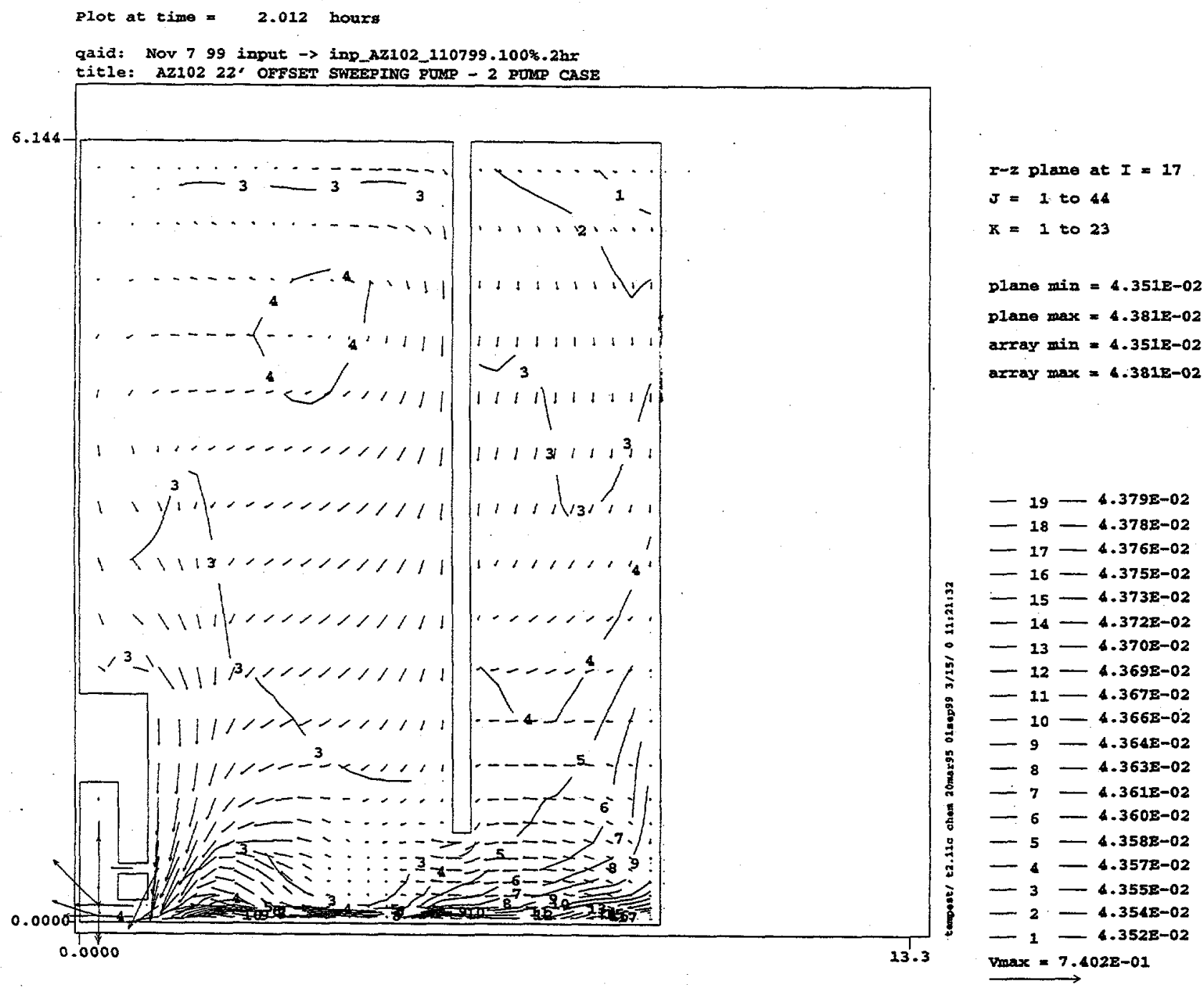

Figure 4.23. Predicted Distributions of Velocity $(\mathrm{m} / \mathrm{s})$ and Solid Concentration (volume fraction) on Vertical Plane $17\left(135^{\circ}\right.$ counter-clockwise from Vertical Plane 2) at Two Simulation Hours for Case 3

\section{Case 4}

This case addresses Approach 2 (Four-Step Approach). Similar to the Approach 1 cases, the simulation for Case 4 indicated that all the sludge would be eroded from the tank bottom by the rotating jets and would be fully mixed within the tank. Predicted distributions of velocity and solids concentrations on Vertical Planes 14, 15, and 17 are presented in Figures 4.24 through 4.26 , showing no sludge layer left on the tank bottom and the suspended solid concentrations varying from 2.22 to 2.25 vol\% ( $99 \%$ uniformity). The suspended concentrations for Case 4 are basically the same as those of Case 2, because Case 4 has half of both solids amounts and the total amount of the mixture of sludge and diluent of Case 2 . 


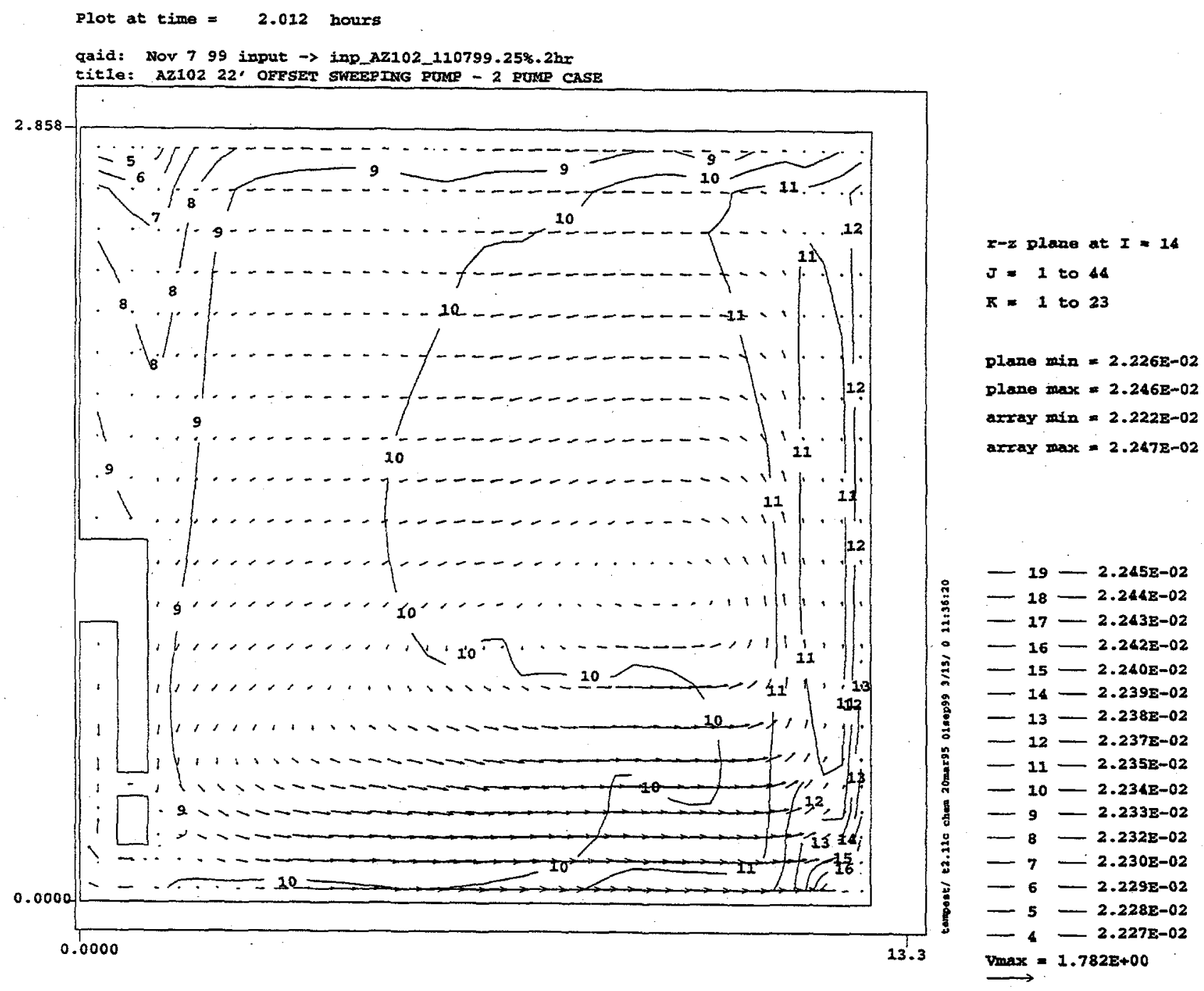

Figure 4.24. Predicted Distributions of Velocity $(\mathrm{m} / \mathrm{s})$ and Solid Concentration (volume fraction) on Vertical Plane 14 ( $108^{\circ}$ counter-clockwise from Vertical Plane 2) at Two Simulation Hours for Case 4

For all these cases, model evaluations indicated that two 300-hp mixer pumps would completely mobilize and uniformly mix the sludge within two hours if the diluent were added to AZ-102, as considered under both the alternative approaches. 


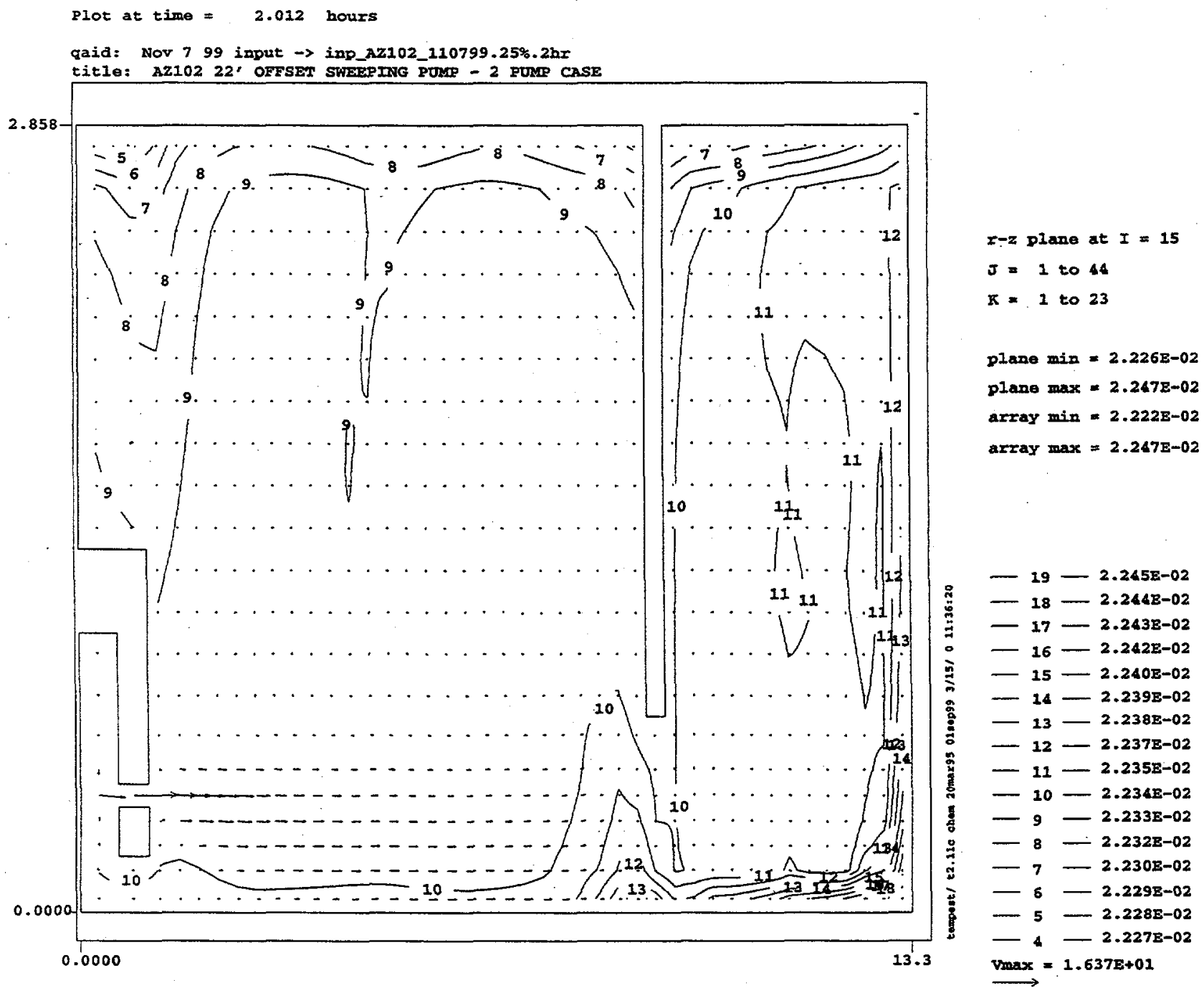

Figure 4.25. Predicted Distributions of Velocity $(\mathrm{m} / \mathrm{s})$ and Solid Concentration (volume fraction) on Vertical Plane 15 ( $117^{\circ}$ counter-clockwise from Vertical Plane 2) at Two Simulation Hours for Case 4 


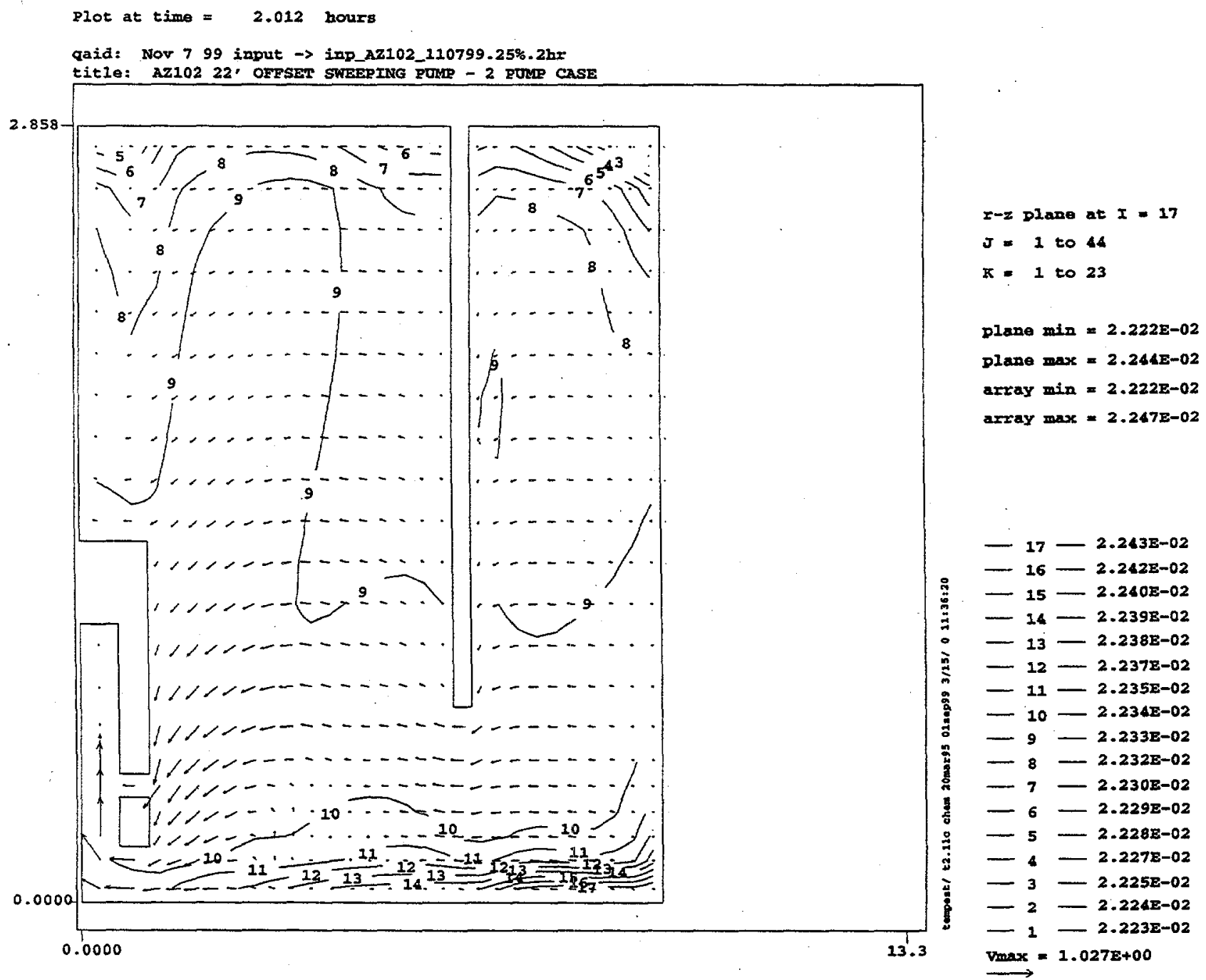

Figure 4.26. Predicted Distributions of Velocity $(\mathrm{m} / \mathrm{s})$ and Solids Concentration (volume fraction) on Vertical Plane $17\left(135^{\circ}\right.$ counter-clockwise from Vertical Plane 2) at Two Simulation Hours for Case 4 


\subsection{AZ-102 Waste Pipeline Transfer}

The AZ-102 modeling discussed in Section 4 indicated that two 300-hp mixer pumps would mobilize $50 \%$ of the sludge and produce uniform distribution of the suspended solids with $1.6 \mathrm{mg} / \mathrm{L}$ concentration. The AZ-102 slurry (a mixture of the AZ-102 supernatant liquid and mobilized sludge) would be transferred to the planned waste treatment (vitrification) plant and/or to the AP Tank Farm in the Hanford 200 East Area through 3-inch $(7.6-\mathrm{cm})$ pipelines. We evaluated whether a transfer pump could move this AZ-102 slurry to the treatment plant and the AP Tank Farm.

We used three empirical methods of Wasp (1963, 1977), Oroskar-Turian (1980), and ZandiGovatos (1967) to determine the critical pipeline velocity above which all solids present in the AZ-102 slurry will be kept in suspension during the pipeline transfer. Thus, the pipeline slurry flow moving above this critical velocity would avoid potential pipeline plugging. Among these three methods, the Wasp and Oroskar-Turian methods are expected to be more accurate, due partially to their better handling of the viscosities of supernatant liquid and sludge viscosity. We used the Wasp method to determine the associated pressure drops in evaluating the adequacy of the transfer pump capacity.

As discussed in Section 3, the AZ-102 slurry is not expected to have chemical reactions that would have a significant adverse effect on waste properties or solids volume. We did not include the effects of temperature change on chemical reaction and slurry properties during the pipeline transfer. We used the parameters listed in Table 5.1 for this pipeline assessment.

The Wasp, Oroskar-Turian, and Zandi-Govatos methods estimated that the critical velocity for the AZ-102 slurry pipeline transfer would be $1.2 \mathrm{ft} / \mathrm{sec}(0.37 \mathrm{~m} / \mathrm{s}), 1.5 \mathrm{ft} / \mathrm{sec}(0.46 \mathrm{~m} / \mathrm{s})$, and $0.1 \mathrm{ft} / \mathrm{sec}(0.03 \mathrm{~m} / \mathrm{s})$, respectively. At $1.2 \mathrm{ft} / \mathrm{sec}(0.37 \mathrm{~m} / \mathrm{s})$, the Wasp method determined the pipeline transfer conditions shown in Table 5.2.

Table 5.1. Pipeline Transfer Assessment Parameters

\begin{tabular}{|l|l|}
\hline \multicolumn{1}{|c|}{ Parameters } & \multicolumn{1}{c|}{ Values } \\
\hline Solids Concentration & $1.6 \mathrm{vol} \%$ \\
\hline Solids diameter & values shown in Figure 2.1 \\
\hline Associated Volume Fraction & $\begin{array}{l}\text { values proportional to } \\
\text { those shown in Figure } 2.1\end{array}$ \\
\hline Solids Density & $2,360 \mathrm{~kg} / \mathrm{m}^{3}$ \\
\hline Liquid Density & $1,100 \mathrm{~kg} / \mathrm{m}^{3}$ \\
\hline Liquid Viscosity & $1.0 \mathrm{cP}$ \\
\hline Pipe Diameter & 3.068 inches \\
\hline Pipeline Roughness & $50 \mu \mathrm{m}$ \\
\hline $\begin{array}{l}\text { Equivalent Pipeline Length } \\
\text { from AZ to AP Farm }\end{array}$ & $3,474 \mathrm{ft}$ \\
\hline $\begin{array}{l}\text { Equivalent Pipeline Length } \\
\text { from AZ Farm to the Treatment Plant }\end{array}$ & $6,473 \mathrm{ft}$ \\
\hline
\end{tabular}


Table 5.2. AZ-102 Slurry Transfer Conditions at Critical Velocity of $1.2 \mathrm{ft} / \mathrm{sec}(0.37 \mathrm{~m} / \mathrm{s})$

\begin{tabular}{|l|l|}
\hline \multicolumn{1}{|c|}{ Conditions } & \multicolumn{1}{c|}{ Calculated Values } \\
\hline Critical Velocity & $1.2 \mathrm{ft} / \mathrm{sec}(0.37 \mathrm{~m} / \mathrm{s})$ \\
\hline Reynolds Number & 30,200 \\
\hline Pressure Drop from AZ to AP Farm & $7.3 \mathrm{ft}(2.2 \mathrm{~m})$ water \\
\hline $\begin{array}{l}\text { Pressure Drop from AZ Farm to } \\
\text { Treatment Plant }\end{array}$ & $14 \mathrm{ft}(4.2 \mathrm{~m})$ water \\
\hline Slurry Viscosity & $1.0 \mathrm{cP}$ \\
\hline Slurry Density & $1,120 \mathrm{~kg} / \mathrm{m}^{3}$ \\
\hline $\begin{array}{l}\text { Suspended Solids Concentration } \\
\text { Uniformity }\end{array}$ & $99.6 \%$ \\
\hline Friction Factor & 0.0063 \\
\hline
\end{tabular}

As shown in Table 5.2, the expected Reynolds number is 30,200, indicating that the pipeline flow would be in a turbulent region. The pressure drops from the AZ Farm to the AP Farm and to the treatment plant are expected to be $7.3 \mathrm{ft}(2.2 \mathrm{~m})$ and $14 \mathrm{ft}(4.2 \mathrm{~m})$ of water, respectively. Because the transfer pump has $450 \mathrm{ft}(137 \mathrm{~m})$ of water head, these pressure drops correspond to only $1.6 \%$ and $3 \%$ of the available pump head. Thus, this analysis indicates that the transfer pump has an enough capacity to transfer the AZ-102 slurry through the 3-inch $(7.6-\mathrm{cm})$ pipelines without plugging the pipeline.

Because the waste is expected to be transferred at $6-\mathrm{ft} / \mathrm{sec}(1.8 \mathrm{~m} / \mathrm{s})$ pipeline velocity, we evaluated the pressure drop at $6 \mathrm{ft} / \mathrm{sec}(1.8 \mathrm{~m} / \mathrm{s})$ with the Wasp method. The results are shown in Table 5.3. In this case, the pressure drops from the AZ Farm to the AP Farm and to the treatment plant are expected to be $153 \mathrm{ft}(47 \mathrm{~m})$ and $285 \mathrm{ft}(87 \mathrm{~m})$, corresponding to $34 \%$ and $63 \%$ of the available $450-\mathrm{ft}(137-\mathrm{m})$ pump head, respectively. Thus the transfer pump has the enough capacity to transfer the AZ-102 slurry at $6 \mathrm{ft} / \mathrm{sec}(1.8 \mathrm{~m} / \mathrm{s})$ to AP Farm and the treatment plant. Calculated pressure drops at various pipeline velocities for the AZ-102 slurry with 1.6 vol\% solids are shown in Figure 5.1.

Table 5.3. AZ-102 Slurry Transfer Conditions at Pipeline Velocity of $6 \mathrm{ft} / \mathrm{sec}(1.8 \mathrm{~m} / \mathrm{s})$

\begin{tabular}{|l|l|}
\hline \multicolumn{1}{|c|}{ Conditions } & \multicolumn{1}{c|}{ Calculated Values } \\
\hline Solids Concentration & $1.6 \mathrm{vol} \%$ \\
\hline Pipeline Velocity & $6 \mathrm{ft} / \mathrm{sec}(1.8 \mathrm{~m} / \mathrm{s})$ \\
\hline Reynolds Number & 154,000 \\
\hline Suspended Solids Concentration Uniformity & $99.9 \%$ \\
\hline Pressure Drop from AZ to AP Farm & $153 \mathrm{ft}(47 \mathrm{~m})$ \\
\hline $\begin{array}{l}\text { Pressure Drop from AZ Farm to the } \\
\text { Treatment Plant }\end{array}$ & $285 \mathrm{ft}(87 \mathrm{~m})$ \\
\hline
\end{tabular}




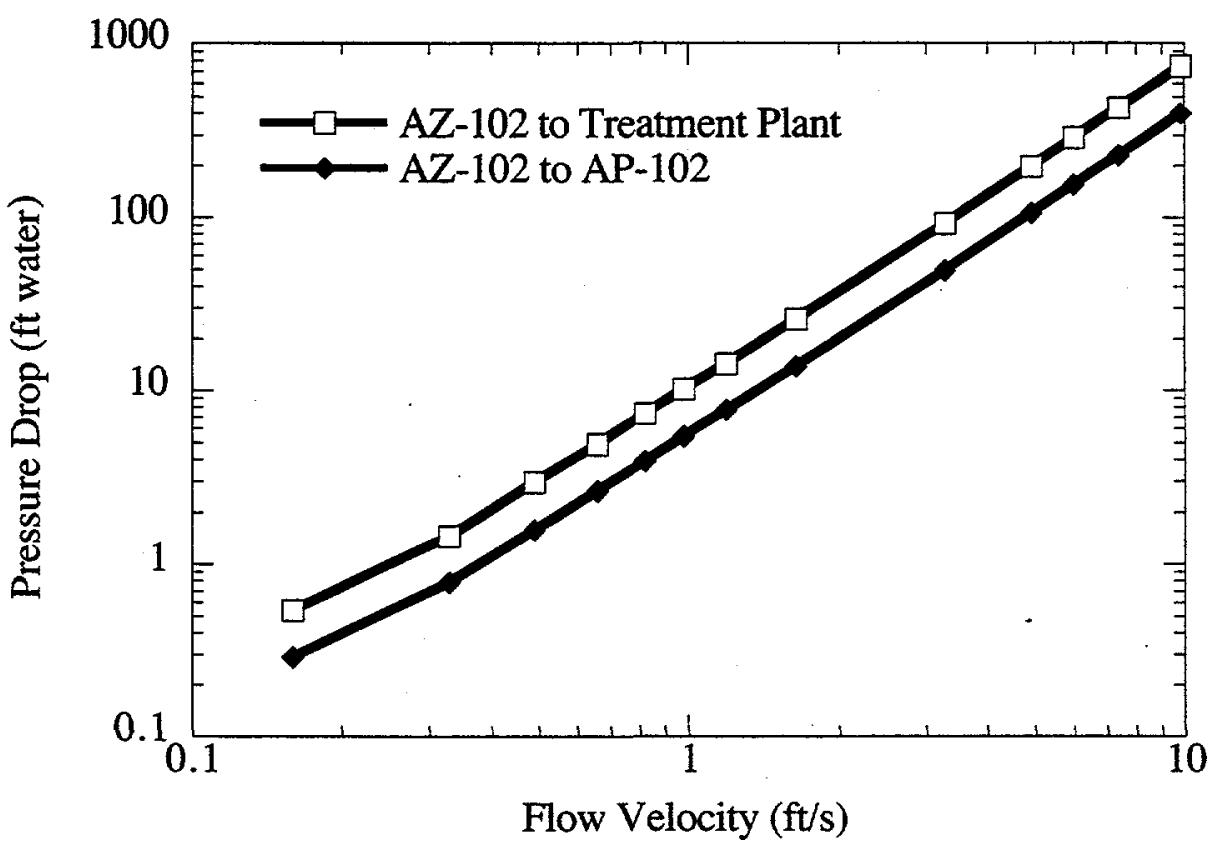

Figure 5.1. Calculated Pipeline Pressure Drop Versus Pipeline Velocity for the AZ-102 Slurry with 1.6 vol\% Solids

We also determined at what solids concentration the pressure drop from the AZ-102 to the treatment plant would be equal to the available $450-\mathrm{ft}(137-\mathrm{m})$ pressure head when the slurry velocity is $6 \mathrm{ft} / \mathrm{sec}(1.8 \mathrm{~m} / \mathrm{s})$. The calculated pressure drop versus solid concentration is shown in Figure 5.2. As shown in this figure, the pressure drop from the AZ Farm to the treatment plant would be $450 \mathrm{ft}(137 \mathrm{~m})$ when the solid concentration becomes $36 \mathrm{vol} \%$. At this solids concentration, the pressure drop to the AP Tank Farm would be $240 \mathrm{ft}(74 \mathrm{~m})$. However, even if all of the solids in Tank AZ-102 were mobilized by the mixer pumps, the average suspended solids concentration would be $3.1 \mathrm{vol} \%$, which is less than $10 \%$ of the $36 \mathrm{vol} \%$. The critical velocity for the slurry with 36 -vol\% solids was estimated to be $2.1 \mathrm{ft} / \mathrm{sec}(0.64 \mathrm{~m} / \mathrm{s})$, which is less than the operating velocity of $6 \mathrm{ft} / \mathrm{sec}(1.8 \mathrm{~m} / \mathrm{s})$.

These assessments indicate that the critical velocity for the AZ-102 slurry is $1.5 \mathrm{ft} / \mathrm{sec}$ $(0.40 \mathrm{~m} / \mathrm{s})$ or less, which is much smaller than the $6-\mathrm{ft} / \mathrm{sec}(1.8-\mathrm{m} / \mathrm{s})$ design pipeline velocity. At 6-ft/sec, an expected pressure drop from Tank AZ-102 to either the treatment plant or the AP Tank Farm is less than the available $450-\mathrm{ft}(137-\mathrm{m})$ pressure head. Even if the entire amount of AZ-102 solids are mobilized and transferred through the 3-inch $(7.6-\mathrm{cm})$ pipeline, the pressure drop would be much less than the available head of the transfer pump. Thus, the mobilized AZ-102 slurry under expected conditions would be transferred to the treatment plant or the AP Tank Farm without depositing solids within the pipelines. 


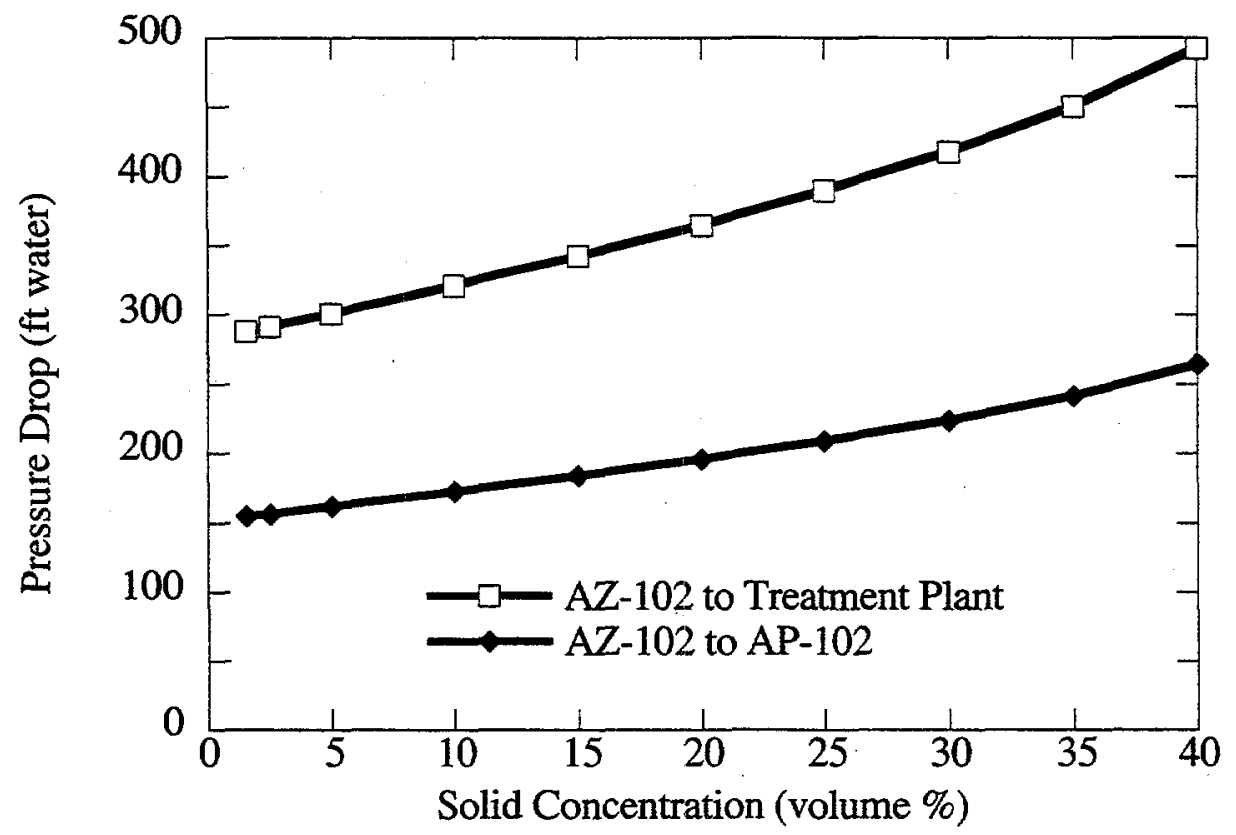

Figure 5.2. Calculated Pipeline Pressure Drop Versus Solids Concentration for the AZ-102 Slurry at $6 \mathrm{ft} / \mathrm{sec}(1.8 \mathrm{~m} / \mathrm{s})$ 


\subsection{Summary and Conclusions}

We examined how well two 300 -hp mixer pumps would mix the solid and liquid radioactive wastes stored in Hanford Tank AZ-102 and confirmed the adequacy of a 3-inch $(7.6-\mathrm{cm})$ pipeline system to transfer the resulting mixed waste slurry to the AP Tank Farm and the planned waste treatment (vitrification) plant within the 200 East Area of the Hanford Site.

Our waste chemical modeling assessment using the GMIN chemical code indicates that the sludge, consisting of the solids and interstitial solutions, and the supernatant liquid are basically in an equilibrium condition, so the pump jet mixing of the sludge and supernatant liquid of AZ-102 waste would not change the waste properties and the solids amount in any discernable manner due to chemical reactions. Some of the chemical assessment results are stated below:

- Most of the solids present in the sludge are non-dissolvable with AZ-102 interstitial solution and supernatant liquid.

- Expected dissolvable solids with these solutions are $\mathrm{Al}(\mathrm{OH})_{3}(\mathrm{~s}), \mathrm{NaF}(\mathrm{s})$, $\mathrm{Cr}(\mathrm{OH})_{2}(\mathrm{am}), \mathrm{SiO}_{2}(\mathrm{am})$, and possibly thenardite $\left(\mathrm{Na}_{2} \mathrm{SO}_{4}(\mathrm{~s})\right)$.

- Mixing of the supernatant liquid and sludge would dissolve $\mathrm{NaF}(\mathrm{s}), \mathrm{SiO}_{2}(\mathrm{am})$, and $\mathrm{Na}_{2} \mathrm{SO}_{4}(\mathrm{~s})$, while small amounts of $\mathrm{Cr}(\mathrm{OH})_{2}(\mathrm{am})$ and $\mathrm{Al}(\mathrm{OH})_{3}(\mathrm{~s})$ would precipitate.

- Resulting changes on solid amounts due to precipitation and dissolution are insignificant to the total amount of the AZ-102 waste (1.5\% or less).

We then evaluated how much AZ-102 waste the two 300-hp mixer pumps would mix by simulating pump jet mixing with the TEMPEST computer code. Because the chemical assessment indicated that the pump jet mixing would not change the AZ-102 waste properties and total solids volume very much, we did not simulate the potential chemical reactions during the pump jet mixing modeling. The mixing assessment indicates that the two 300 -hp mixer pumps would mobilize half of the sludge, which has a yield strength of $1,540 \mathrm{~Pa}$. Some of the main results are described below.

- The two 300 -hp pumps will mobilize $50 \%$ of the original sludge

- The rotating pump jets would mobilize the sludge up to $23 \mathrm{ft}(7.0 \mathrm{~m})$ from the pump

- Jets would not erode the sludge within 7 in. $(0.18 \mathrm{~m})$ of the tank bottom

- The resulting suspended solids concentration would be 1.6 vol\% and uniformly distributed in the entire tank (except the region of noneroded sludge)

- It will take one to two hours to reach the final fully mixed condition

- Twenty-two airlift circulators and steam heating coils have some relatively small impacts, but they are not significant in the overall sludge erosion

- The centerline jet velocity reduces its value at a rate approximately proportional to the distance from the jet exit. However, the AZ-102 jet velocity is smaller than that of the classical homogeneous jet experiment at equal distance because the nonhomogeneous, rotating, non-Newtonian, AZ-102 jets are located near the tank bottom and are confined by the sludge bank and tank wall. 
Because pump jet mixing would mobilize only half of the AZ-102 sludge, we explored a possible way to improve the effectiveness of the pumps to mobilize the AZ-102 waste. The previous AZ-102 pre-treatment experimental study indicates that the diluent (a mixture of water, ferric nitrate, sodium nitrite, and sodium hydroxide) could significantly reduce the sludge yield strength by dissolving half the original AZ-102 solids. Thus, we developed the concept of two alternative approaches and assessed them by assuming that this diluent would dissolve half of the AZ-102 solids and reduce the yield strength from 1,540 $\mathrm{Pa}$ to $1.2 \mathrm{~Pa}$. The validity of this assumption could be tested in laboratory studies. The alternative approaches considered here are

\section{Approach 1: Three-step approach}

Step 1: Pump out the original AZ-102 supernatant liquid only

Step 2: Add the diluent (the mixture of water, ferric nitrate, sodium nitrite, and sodium hydroxide) to Tank AZ-102 at a 6:1 (diluent to sludge) volume ratio

Step 3: Mix the diluent-washed, weakened, and reduced amount of AZ-102 sludge with the diluent using two 300-hp mixer pumps.

\section{Approach 2: Four-step approach}

Step 1: Mix the original AZ-102 sludge and supernatant liquid using two 300-hp pumps

Step 2: Pump the resulting AZ-102 slurry from the tank

Step 3: Add the diluent (mixture of water, ferric nitrate, sodium nitrite, and sodium hydroxide) to AZ-102 tank at 6:1 (diluent to remaining sludge) volume ratio

Step 4: Mix the remaining diluent-washed, weakened, and reduced amount of AZ-102 sludge and the diluent by two 300 -hp mixer pumps.

We applied the TEMPEST code to four cases representing these two alternative approaches. These pump jet mixing simulations indicated that for both alternative approaches, two $300-\mathrm{hp}$ mixer pumps would totally mobilize and uniformly mix the sludge within two hours if this diluent were added to Tank AZ-102.

We used the three empirical methods of Wasp, Oroskar-Turian, and Zandi-Govatos to determine whether a transfer pump could move the AZ-102 slurry (a mixture of the AZ-102 supernatant liquid and mobilized sludge) to the AP Tank Farm and to the planned waste treatment (vitrification) plant through three-inch $(7.6-\mathrm{cm})$ pipelines. Because the AZ-102 slurry is basically in equilibrium condition, we did not include the effects of chemical reactions in the pipeline assessment.

The assessments indicate that the critical velocity for the AZ-102 slurry is $1.5 \mathrm{ft} / \mathrm{sec}$ $(0.46 \mathrm{~m} / \mathrm{s})$ or less, which is much less than the expected $6-\mathrm{ft} / \mathrm{sec}(1.8-\mathrm{m} / \mathrm{s})$ operating pipeline velocity. At the $1.2-\mathrm{ft} / \mathrm{sec}(0.37 \mathrm{~m} / \mathrm{s})$ critical velocity (with corresponding Reynolds number of 30,200 ) predicted by the Wasp method, the associated pressure drops from the AZ Farm to the AP Farm and the treatment plant are expected to be $7.3 \mathrm{ft}(2.2 \mathrm{~m})$ and $14 \mathrm{ft}(4.2 \mathrm{~m})$ of water, 
respectively. Because the transfer pump has $450 \mathrm{ft}(137 \mathrm{~m})$ of water head, these pressure drops correspond to only $1.6 \%$ and $3 \%$ of the available pump head.

At a 6-ft/sec $(1.8 \mathrm{~m} / \mathrm{s})$ operating velocity, the expected pressure drop from Tank AZ-102 to the AP Tank Farm or the treatment plant is $153 \mathrm{ft}(47 \mathrm{~m})$ and $285 \mathrm{ft}(87 \mathrm{~m})$, respectively, corresponding to $34 \%$ and $63 \%$ of the available $450-\mathrm{ft}$ (137-m) pump head.

We determined that the pressure drop from the AZ Tank Farm to the treatment plant would be $450 \mathrm{ft}(137 \mathrm{~m})$ at $6 \mathrm{ft} / \mathrm{sec}(1.8 \mathrm{~m} / \mathrm{s})$ velocity if the solids concentration becomes $36 \mathrm{vol} \%$. At this solids concentration, the pressure drop to the AP Tank Farm would be $240 \mathrm{ft}(74 \mathrm{~m})$. However, even if the entire amount of solids in Tank AZ-102 were mobilized by the mixer pumps, the average suspended solid concentrations would be $3.1 \mathrm{vol} \%$, which is less than $10 \%$ of the $36 \mathrm{vol} \%$. Thus, even if the entire volume of solids in Tank AZ-106 were mobilized and transferred through the 3-in. $(7.6-\mathrm{cm})$ pipelines, the pressure drop would be much less than the available head of the transfer pump. The estimated critical velocity for the slurry with 36-vol\% solids is $2.1 \mathrm{ft} / \mathrm{sec}(0.64 \mathrm{~m} / \mathrm{s})$, which is less than the operating velocity of $6 \mathrm{ft} / \mathrm{sec}(1.8 \mathrm{~m} / \mathrm{s})$. Thus, the pipeline transfer pump has the enough capacity to transfer the AZ-102 slurry under expected conditions to AP Tank Farm and the treatment plant without depositing solids within the pipelines. 


\subsection{References}

Felmy AR. 1995. "GMIN: A Computerized Chemical Equilibrium Program Using a Constrained Minimization of the Gibbs Free Energy." Chemical Equilibrium and Reaction Models. SSSA Special Publication 42, pp. 37-407.

Mahoney LA and DS Trent. 1995. "Correlation Models for Waste Tank Sludge and Slurries." PNL-10695, Pacific Northwest National Laboratory, Richland, Washington.

Onishi Y and KP Recknagle. 1997. "Tank AZ-101 Criticality Assessment Resulting from Pump Jet Mixing: Sludge Mixing Simulations." PNNL-11486, Pacific Northwest National Laboratory, Richland, Washington.

Onishi Y and KP Recknagle. 1998. Performance Evaluation of Rotating Pump Jet Mixing of Radioactive Wastes in Hanford Tanks 241-AP-102 and -104. PNNL-11920, Pacific Northwest National Laboratory, Richland, Washington.

Onishi Y and DS Trent. March 1999. "Mobilization Modeling of Erosion-Resisting Radioactive Tank Waste." Proceedings of the Rheology in the Mineral Industry II, Kahuku, pp. 45-56. United Engineering Foundation, New York.

Onishi Y, HC Reid, DS Trent, and JD Hudson. 1996a. "Tank Waste Modeling with Coupled Chemistry and Hydrothermal Dynamics." Proceedings of 1996 National Heat Transfer Conference, Vol. 9, pp. 262-269. The American Nuclear Society, Houston.

Onishi Y, R Shekarriz, KP Recknagle, PA Smith, J Liu, YL Chen, DR Rector, and JD Hudson. 1996b. "Tank SY-102 Waste Retrieval Assessment: Rheological Measurements and Pump Jet Mixing Simulation." PNNL-11352, Pacific Northwest National Laboratory, Richland, Washington.

Oroskar AR and RM Turian. 1980. "The critical velocity in pipeline flow of slurries." AIChE J., 26, pp. 550-558.

Rodi W. 1984. "Turbulence Models and Their Application in Hydraulics-a State of the Art Review." Institut fur Hydromechanik, University of Karlsruhe, Germany.

Ryan GW. 1995. Tank Characterization Report for Double Shell Tank 241-AZ-102. WHC-SDWM-ER-411 Rev. 0, Westinghouse Hanford Company, Richland, Washington.

Schreiber RD. 1995. Tank Characterization Report for Double Shell Tank 241-AZ-102. WHCSD-WM-ER-411 Rev. 0-A, Westinghouse Hanford Company, Richland, Washington.

Trent DS and TE Michener. 1993. Numerical Simulation of Jet Mixing Concepts in Tank 241SY-101. PNL-8559, Pacific Northwest Laboratory, Richland, Washington. 
Trent DS and LL Eyler. 1994. "TEMPEST: A Computer Program for Three-Dimensional Time Dependent Computational Fluid Dynamics." PNL-8857 Vol. 1, Version T, Mod 2, Pacific Northwest National Laboratory, Richland, Washington.

Wasp EJ. 1963. "Cross Country Coal Pipe Line Hydraulics." Pipeline News, p. 20.

Wasp EJ, JP Kenny, and RL Gandhi. 1977. "Solid-Liquid Slurry Pipeline Transportation." Trans. Tech. Publ.

Whyatt GA, RJ Serne, SV Mattigold, Y Onishi, MR Powell, JH Westik Jr, LM Liljegren, GR Golcar, KP Recknagle, PM Doctor, VG Zhirnov, and J Dixon. 1996. Potential for Criticality in Hanford Tanks Resulting from Retrieval of Tank Waste. PNNL-11304, Pacific Northwest National Laboratory, Richland, Washington.

Wiegel RL. 1964. Oceanographical Engineering. Prentice-Hall, Inc., New Jersey, pp. 424-427.

Zandi I and G Govatos. 1967. "Heterogeneous Flow of Solids in Pipelines." J. Hydr. Div., ASCE, 93:HY3, Proc. Paper 5244, pp. 145-159. 


\section{Distribution}

No. of

Copies

Offsite

2 DOE Office of Scientific and

Technical Information

W. L. Boyt

U.S. Army Corps of Engineers

Waterways Experimental Station Hydraulics Laboratory

Vicksburg, MS 39180

C. T. Crowe

Washington State University

Department of Mechanical Engineering Pullman, WA 99164

G. H. Jirka

Cornell University

Department of Environmental Engineering

Ithaca, NY 14853

M. Katona

Department of Civil and Environmental Engineering

Washington State University

Pullman, WA 99164

K. Kim

Columbia University

H. Krumb School of Mines

809 Seely W. Mudd

New York, NY 10027

R. B. Krone

University of California At Davis

Department of Civil and Environmental Engineering

Davis, CA 95616-5294

E. E. Michaelides

Tulane University

School of Engineering

New Orleans, LA 70118

P. R. Reed

U.S. Nuclear Regulatory Commission Office of Nuclear Regulatory Research MS-T-9B3

Washington, D.C. 20555
No. of

Copies

G. L. Schnoor

University of Iowa

Center for Global and Regional

Environmental Research

Iowa City, IA 52242

K. W. Yeh

U. S. Environmental Protection Agency International Office

401 M St. SW

Washington, D.C. 20460

\section{Onsite}

5 DOE Richland Operations Office

E. J. Cruz (2)

H6-60

J. J. Davis (3)

S6-62

8 CH2M Hill Hanford Group
J. G. Kristofzski
H6-63
D. A. Reynolds
R2-11
R. W. Root
R2-50
J. E. Van Beek (5)
R3-47

1 Fluor Daniel Hanford Company

D. L. Herting

T6-07

4 NUMATEC Hanford Company

P. J. Certa

R3-73

C. A. Rieck (3)

R3-47

44 Pacific Northwest National Laboratory

S. Q. Bennett

R. A. Brouns

K7-90

J. L. Buelt

H6-61

T. H. Dunning

K9-09

A. R. Felmy

K1-96

P. A. Gauglitz

K8-96

R. E. Gephart

K6-28

W. L. Kuhn

K9-76

Y. Onishi (20)

$\mathrm{K} 7-15$

K. P. Recknagle (5)

K7-15

J. R. Rustad

K7-15

B. E. Wells (5)

K8-96

Information Release (5)

K7-15

K1-06

Distr.1 